\title{
Comprehensive Information Retrieval and Model Input Sequence (CIRMIS)
}

\author{
User's Manual
}

April 1977

Prepared for the Energy Research and Development Administration under Contract EY-76-C-06-1830 
NOTICE

This report was prepared as an account of work sponsored by the United States Government. Neither the United States nor the Energy Research and Deveiopment Administration, nor any of their employees, nor any of their contractors, subcontractors, or their employees, makes any warranty, express or implied, or assumes any legal liability or responsibility for the accuracy, completeness or usefulness of any information, apparatus, product or process disclosed, or represents that its use would not infringe privately owned rights.

\author{
PACIFIC NORTHWEST LABORATORY \\ operated by \\ BATTELLE \\ for the \\ ENERGY RESEARCH AND DEVELOPMENT ADMINISTRATION \\ Under Contract EY-76-C-06-7830
}

\author{
Printed in the United States of America \\ Available from \\ National Technical Information Service \\ U.S. Department of Commerce \\ 5285 Port Royal Road \\ Springfield, Virginia 22151 \\ Price: Printed Copy $5 \_$_ : Microfiche $\$ 3.00$
}

$\begin{array}{cc}\text { •Pages } & \text { NTIS } \\ \text { Selling Price } \\ 001-025 & \$ 4.50 \\ 026-050 & \$ 5.00 \\ 051-075 & \$ 5.50 \\ 076-100 & \$ 6.00 \\ 101-125 & \$ 6.50 \\ 126-150 & \$ 7.00 \\ 151-175 & \$ 7.75 \\ 176-200 & 58.50 \\ 201-225 & \$ 8.75 \\ 226-250 & \$ 9.00 \\ 251-275 & \$ 10.00 \\ 276-300 & \$ 10.25 \\ & \end{array}$


COMPREHENSIVE INFORMATION RETRIEVAL AND MODEL INPUT SEQUENCE (CIRMIS)

USER'S MANUAL

by

D. R. Friedrichs

April 1977

Battelle

Pacific Northwest Laboratories Richland, Washington 99352 
. 


\section{CONTENTS}

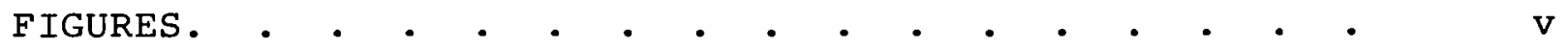

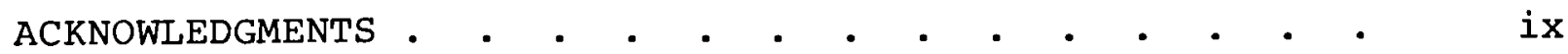

INTRODUCTION • • • • • • • • • • • • • • • • • •

1.0 WELL-BASED DATA RETRIEVAL SYSTEM. • • • • • • I-1

INITIAL STARTUP PROCEDURES. . . . . . . . . $1-1$

Monitor Operation . . . . . . . . . . $1-2$

DATA TYPES • • • • • • • • • • • • • • • • •

HYDSCP - Well Hydrograph. . . . . . . . 1-6

CTMSCP - Contamination History. . . . . . 1-6

WDCSCP - Well Structure Documentation . . . 1-8

OUTPUT DEVICES. • • • • • • • • • • • • •

2.0 SPECIAL APPLICATIONS AND MANIPULATIONS. • . . . 2-1

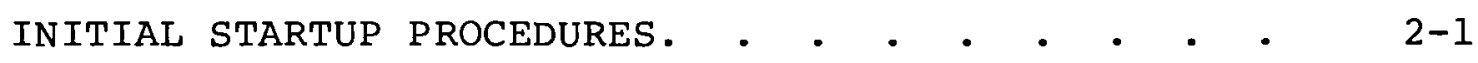

NORMAL CIRMIS OPERATION. • • • • • • • • .

BYPASSING CIRMIS OPERATION. • • • . • • • • •

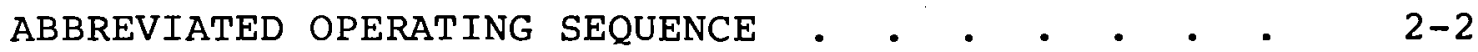

DETAILED OPERATING SEQUENCE • . . • . • • • . 2-7

Special Applications Selection Routine . . . 2-7

1. Selecting a Special Function . . . 2-7

2. General Project Specifications. . . 2-7

3. Program Control Options . . . . 2-8

Special Function Options. . . . . . . . 2-8

Special Function Input Specifications . . . 2-8 
OPERATING THE SPECIAL FUNCTION PROGRAMS • • • • 2-10

Category I - Surface File Manipulation . . 2-10

SURFACE GENERATOR Program. . . . . . 2-10

MATRIX EDITOR Program • • • • • • • 2-15

SURFACE CONTOURING Program . . . . . 2-19

Category II - Calculation Programs . . . . 2-20

TRAVEL TIME Program . . . . . . . 2-22

PATHLINE Program. . . . . . . . . 2-24

Category III - Utility Programs . . . . . 2-24

MAP GENERATOR Program • • • • • • • $2-25$

BYPASS CIRMIS CONTROL Program • • • . 2-28

UPDATE Program . • . . . . . . . . $2-31$

3.0 MODEL INPUT SEQUENCING • • • • • • • • • • • •

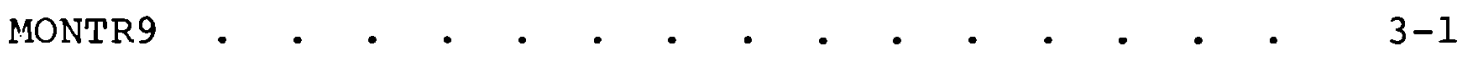

CIRMIS STARTUP PROCEDURES . • • • • • • • • . $3-2$

ABBREVIATED OPERATING SEQUENCE • • • • • • • •

DETAILED OPERATING SEQUENCE • • • • • • • • • 3-4

Model Input Sequencing Routine. . . . . . 3-4

Model Specification Page - Program Control

Options • • • • • • • • • • • • • $3-5$

Model Specification Page - Model Input

Specifications . . . . . . . . . . . 3-5

OPERATING THE PREDICTIVE MODELS . • • • • • • 3-6

FLOWTUBE Program • • • • • • • • • • $3-6$

FLOWTUBE Program Options. • • • • • • 3-8

Detailed Operating Sequence-FLOWTUBE. • • • 3-9 


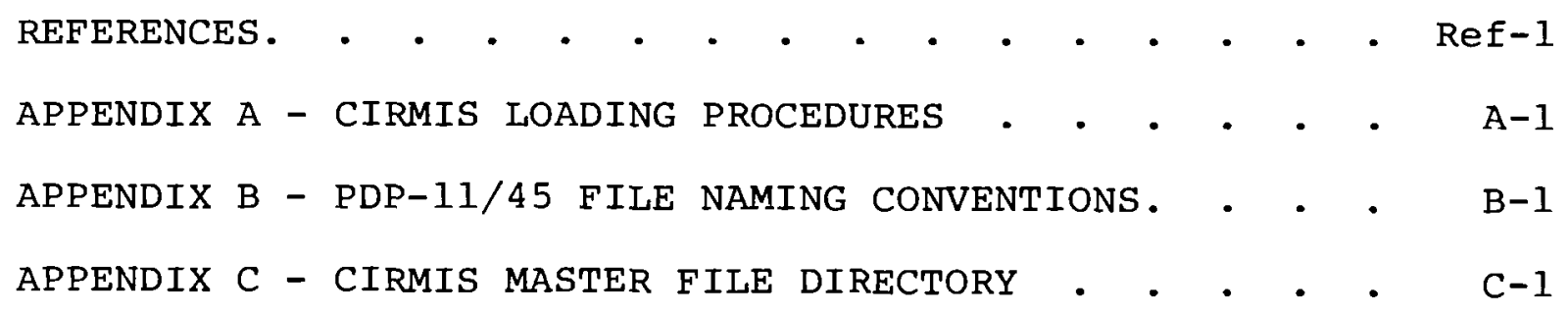




\section{F IGURES}

$1-1$

$1-2 \mathrm{~A}$

$1-2 \mathrm{~B}$

$1-2 \mathrm{C}$

$1-3$

$1-4$

$1-5$

$1-5 \mathrm{~A}$

$1-6$

$1-7$

$1-8$

$1-8 \mathrm{~A}$

$1-9$

$1-10$

$1-11$

$1-12$

$1-13$

$1-14$

$1-15$

$1-16$

$1-17$

$1-18$
CIRMIS Monitor Control Page

Error Report Messages

Error Report Messages

Error Report Messages

Well Selection

Individual Well Selection Using Keyboard

Mode

Data Type and Output Device Page. .

Data Type and Output Device Page for Contaminant Data

Contaminant Data Selection Page.

Water Level History Display

Contaminant History Display

Contaminant History With Joined Data Points.

Well Structure Display

Calcomp Plot of Water Level History.

Calcomp Plot of Contaminant History.

Calcomp Plot of Well Log Data.

Gould Plot of Well Log Data

Gould Plot of Well Log Data

Gould Plot of Contaminant History

Line Printer Listing of Water Level History .

Line Printer Listing of Contaminant History .

Line Printer Listing of Well Log Data.
$1-1$

$1-3$

$1-3$

$1-3$

$1-4$

$1-4$

$1-5$

$1-5$

$1-5$

1-7

1-7

1-9

1-9

1-11

1-12

1-13

1-14

1-15

1-16

1-17

1-17

1-18 


\section{FIGURES (Cont'd)}

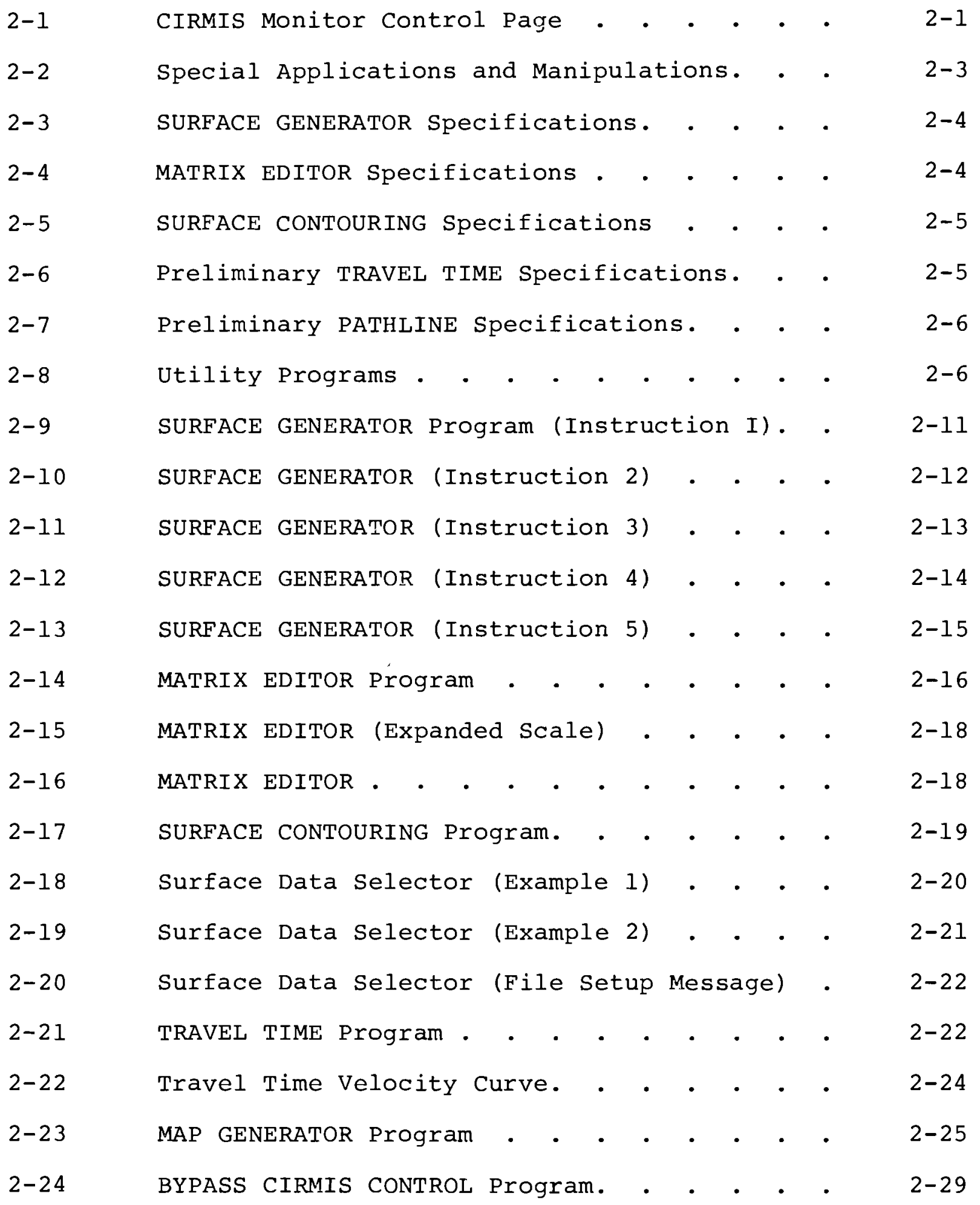




\section{FIGURES (Cont'd)}

$3-1$

$3-2$

$3-3$

$3-4$

$3-5$

$3-6$

$3-7$

$3-8$

3-9

$3-10$

3-11

$3-12$

$3-13$

$3-14$

$3-15$

$\mathrm{A}-1$

A-2
CIRMIS Monitor Control Page

Model Input Sequencing Routin

Preliminary Flowtube Specifications.

Surface Data Selector

Surface Data Selector (File Setup Message) .

Initial Flowtube Display . . . . .

Determining Area of Flowtube Convergence.

Setting up Reference Line

Selected Reference Lin

Flowtube from Selected Wells Intersecting

Reference Line.

Calculated Hydraulic Conductivity Values

at Reference Line.

Best Fit Curve of Hydraulic Conductivity

Along Reference Line.

Initializing Region Where Conductivity Values Are to be Calculated.

Completion of Region.

Calculating Hydraulic Conductivity Values Within Selected Region

Disc Unit Setup Command.

CIRMIS Monitor Control
$3-12$

$3-1$

$3-2$

$3-3$

$3-6$

$3-7$

$3-7$

$3-10$

$3-11$

3-11

$3-13$

$3-13$

$3-14$

$3-15$

$3-16$

$A-3$

A-3 


\section{ACKNOWLEDGMENTS}

The author would like to thank the following people for their efforts and assistance:

J. R. Raymond and D. A. Myers for their advice and encouragement throughout the development of the CIRMIS system;

S. W. Ahlstrom for his assistance in the early development of the well-based data portion;

D. D. Hostetler and D. W. Damschen for their contributions to the CIRMIS system and associated backup programs;

The Atlantic Richfield Hanford Company for their support of special groundwater models;

Sue Gano who provided editorial assistance;

Charlene Detrick who assisted in organizing the many drafts and final reports; and

Ivadell Daer, Judy Goodrich and Jan Hufferd who typed the final reports.

The development and continuing update of this system is sponsored by the Environmental Protection Branch, Safety and Environmental Protection Division of the Energy Research and Development Administration, Richland Laboratories. The author is especially grateful for the assistance and direction provided by J. A. Fernandez, Environmental Engineer; and M.W. Tiernan, Chief of the Environmental Protection Branch. 


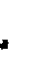
. 


\section{INTRODUCTION}

This manual describes the user interaction with the CIRMIS system. The portions of the system have been divided into three sections as follows:

Section 1.0 Well-Based Data

Section 2.0 Special Applications and Manipulations

Section 3.0 Model Input Sequencing

A complete description of the CIRMIS hardware and software configurations and data storage and retrieval techniques is given in a companion report. 
This section describes the procedures involved in the retrieval of well-based data. Capabilities are available to graphically display various types of information relating to wells and/or obtain hard copy plots and line printer listings of these data.

All of these functions are controlled by the PDP-9 computer through graphic user interaction with a PDP-11/45 computer. The well based data is stored on a disc mass storage unit which is a peripheral to the $\mathrm{PDP}-11 / 45$ computer.

\section{INITIAL STARTUP PROCEDURES}

To operate the programs in this section the CIRMIS loading procedures described in Appendix A must be followed. Once these procedures have been completed, the display in Figure 1-1 will appear.

The programs in this section are defined as WELL BASED DATA RETRIEVAL shown under the heading SELECT A FUNCTIONAL CATEGORY .

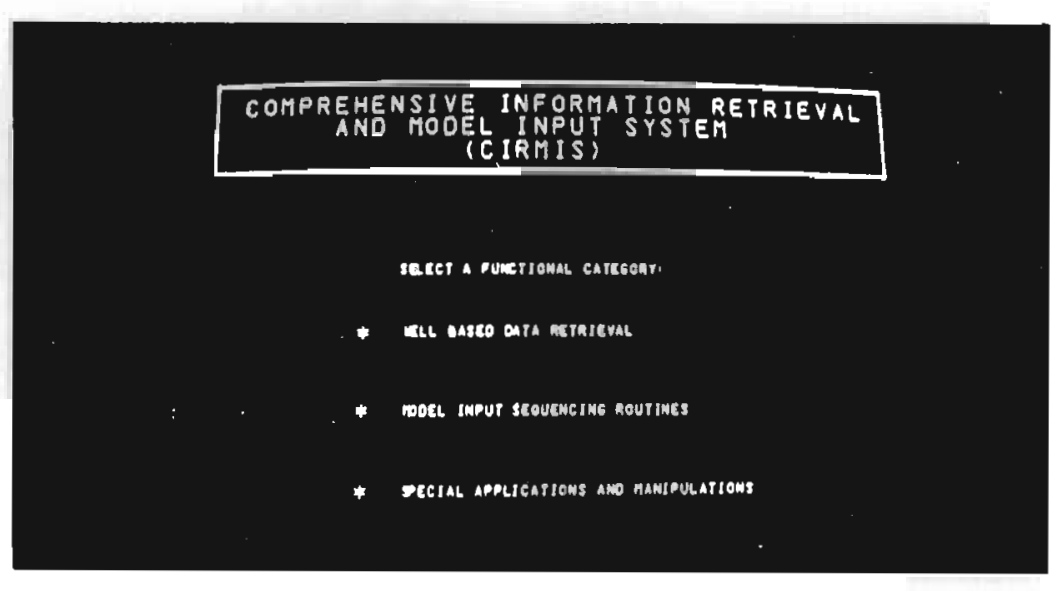

FIGURE 1-1. CIRMIS Monitor Control Page 
MONTR9 monitors the PDP-11/45 and provides the user with information as to data availability, program availability, program status, and various other error messages (Figures 1-2A through $1-2 \mathrm{C}$ ).

Monitor Operation

- The user selects the option WELL BASED DATA RETRIEVAL as shown in Figure 1-1. The present display page is replaced with that shown in Figure $1-3$.

- The user selects the first option shown under the title CHOOSE A METHOD OF WELL SELECTION. (The second and third options have been developed to some extent but have not been completed.) The present display page is replaced with that shown in Figure 1-4.

- The user may now enter a well designation on the scope console keyboard (example: 6992020 ).

- Upon getting acknowledgment that the selected well exists, the user may select the CONTINUE option. The present display is replaced with that shown in Figure 1-5.

- Figure 1-5 shows the data type and output devices presently available for the selected well. The user then selects a data type and output device from a box within the matrix. For all data types except contamination histories, the user selects RETRIEVE DATA and the data will be output to the selected device. For contamination data the RETRIEVE DATA option shown in Figure $1-5$ is replaced with CONTINUE as shown in Figure 1-5A.

- If contamination history data was selected and upon hitting CONTINUE, the present display will be replaced with that shown in Figure 1-6 where available contaminant data will appear with a preceding star. Upon hitting RETRIEVE DATA with the light pen, the data will be output to the selected device. 
OATA ACCESS ERRDR AEPORT

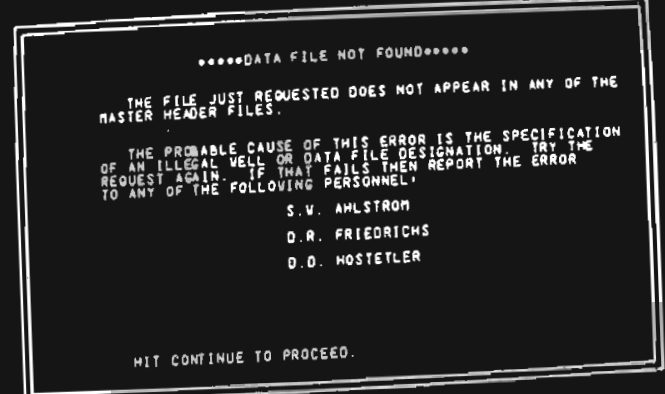

contrines

\section{FIGURE 1-2A.}

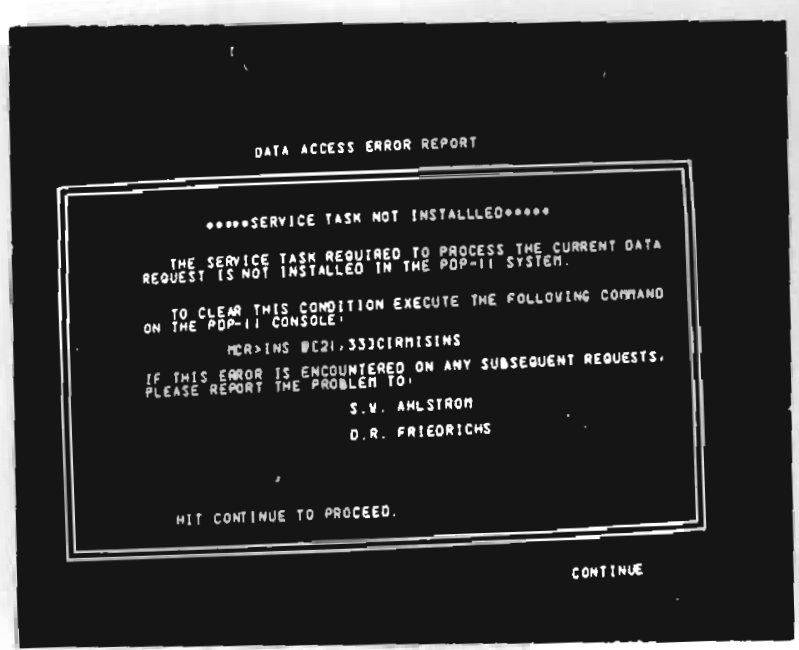

FIGURE 1-2B.

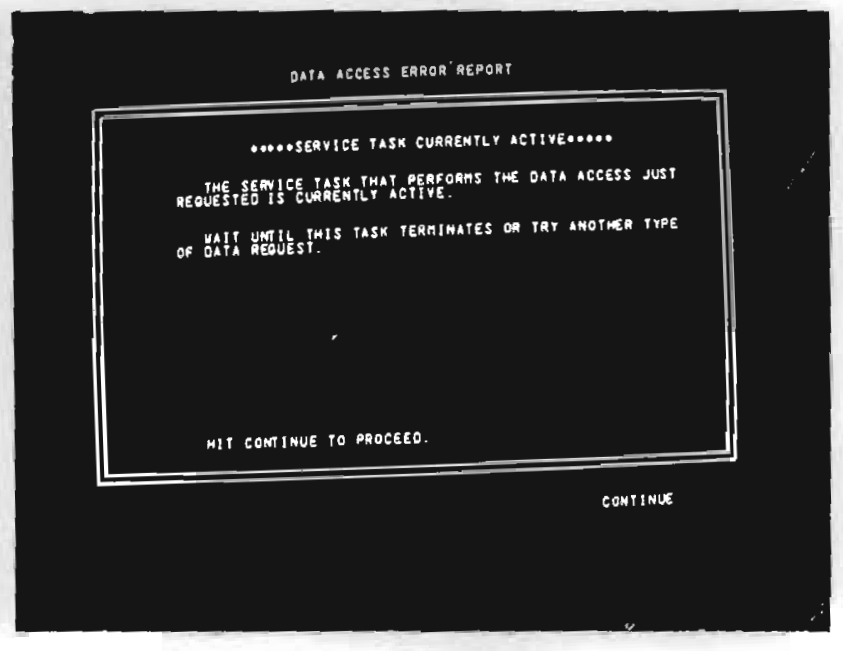

FIGURE 1-2C.

Error Report Messages 


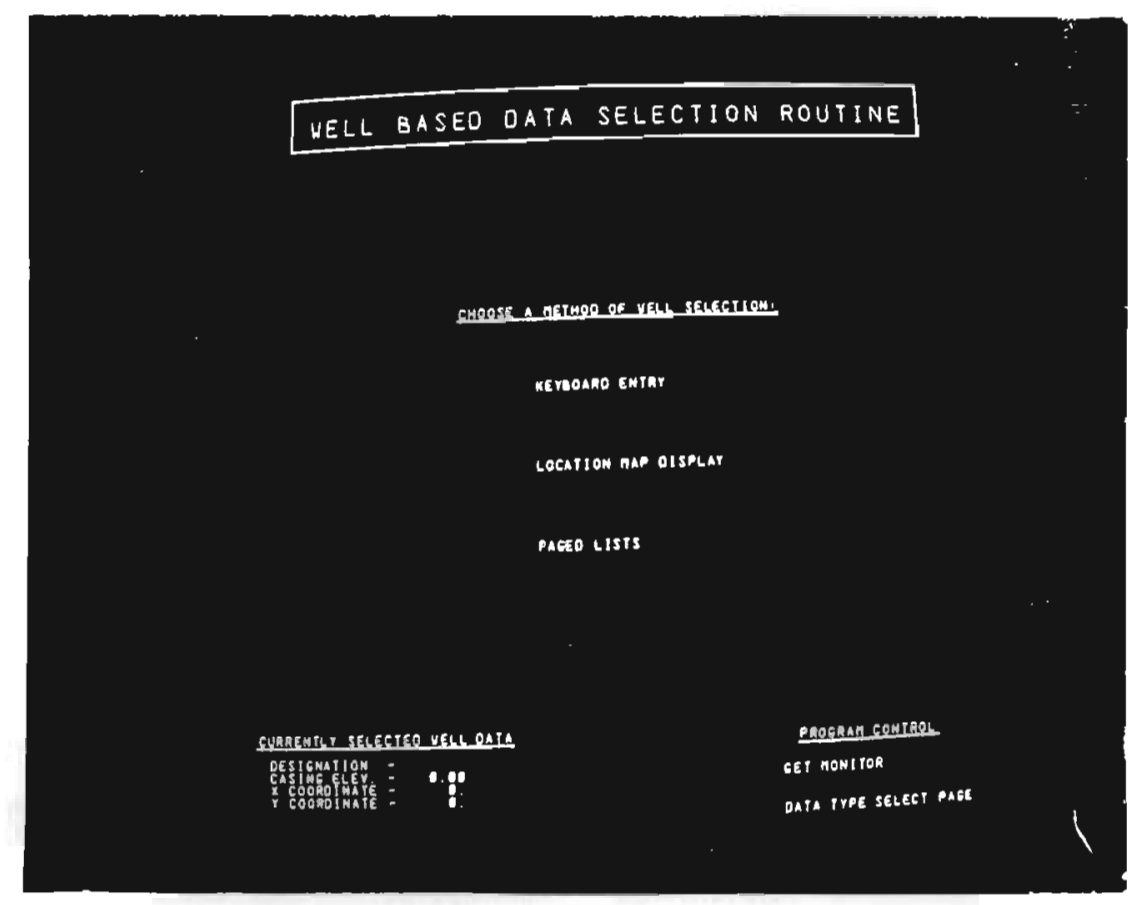

FIGURE 1-3.

Well Selection Modes

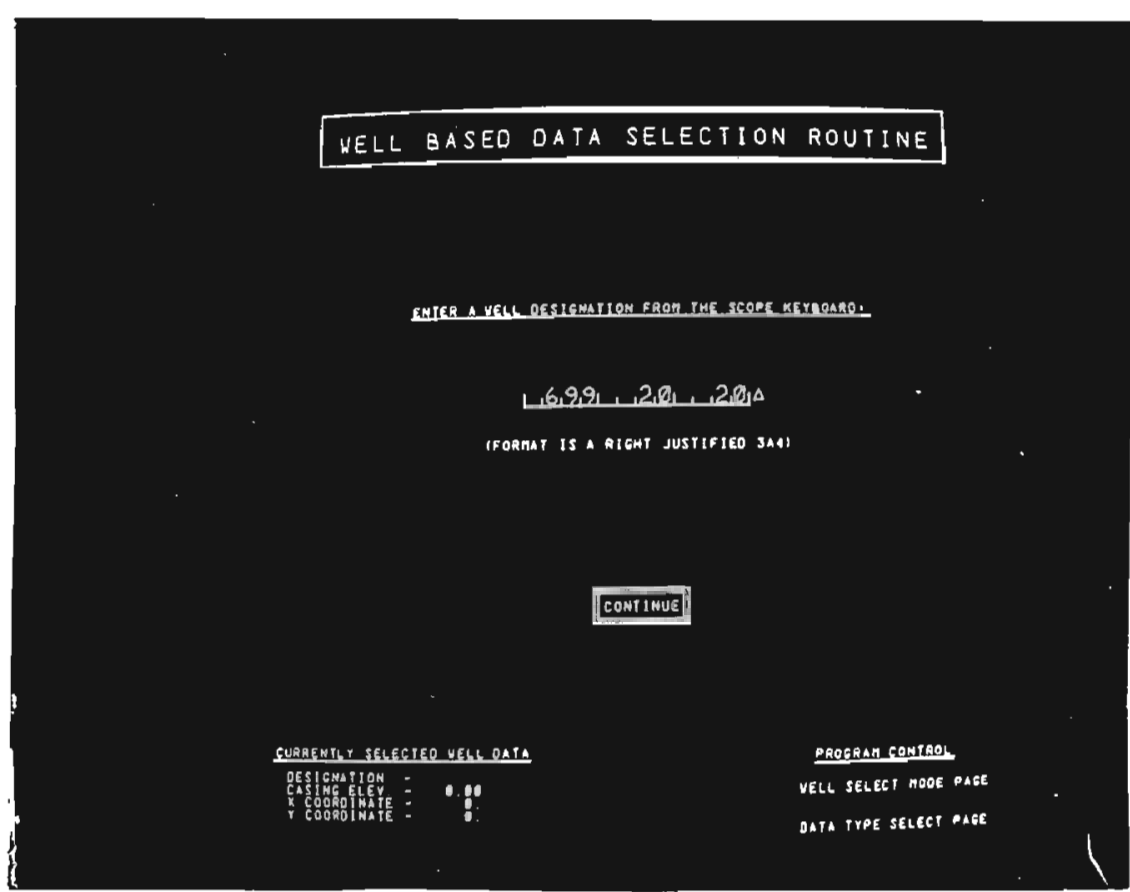

FIGURE 1-4.

Individual Well Selection Using Keyboard Mode 


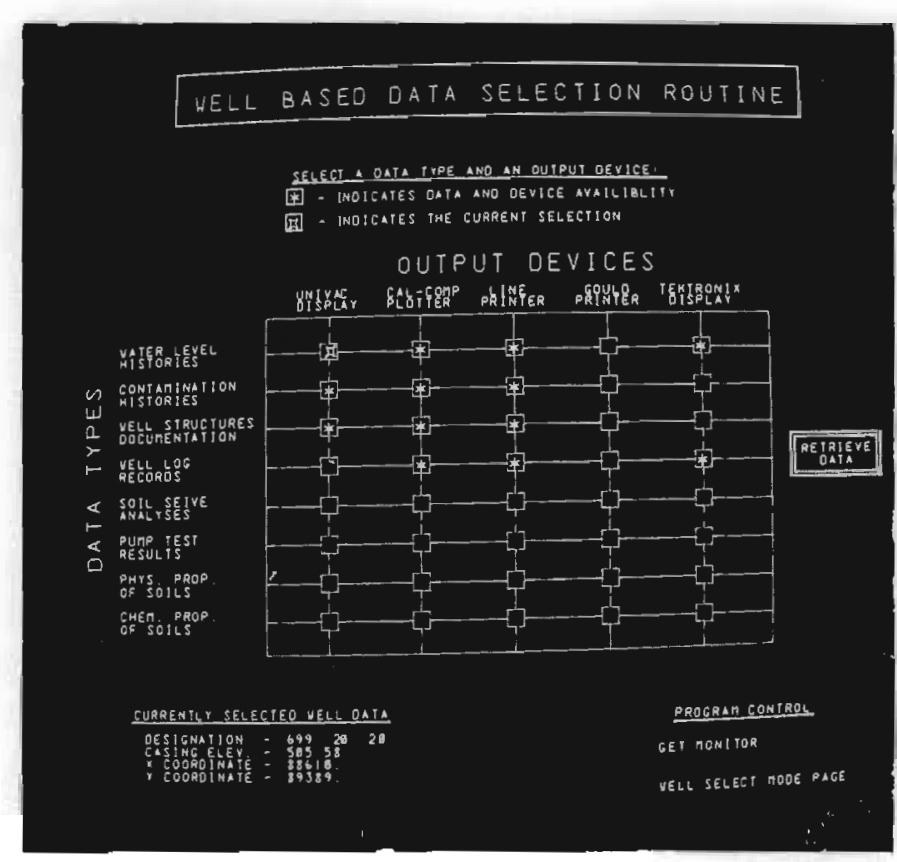

FIGURE 1-5.

Data Type and output Device Page

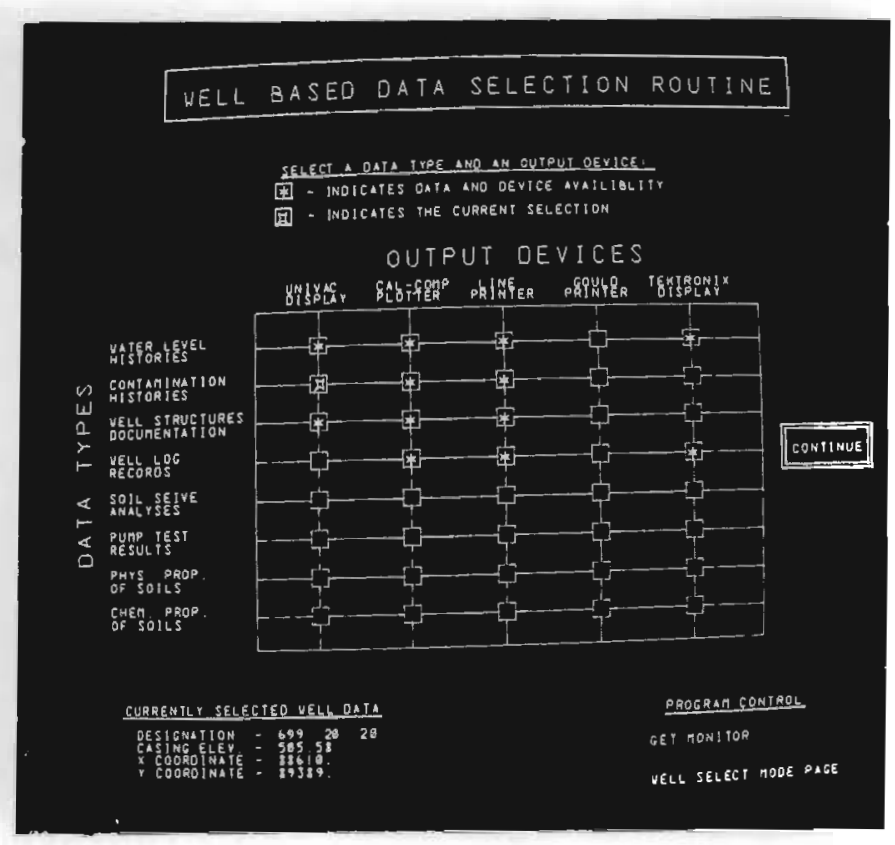

\section{FIGURE 1-5A.}

Data Type and output Device Page for Contaminant Data

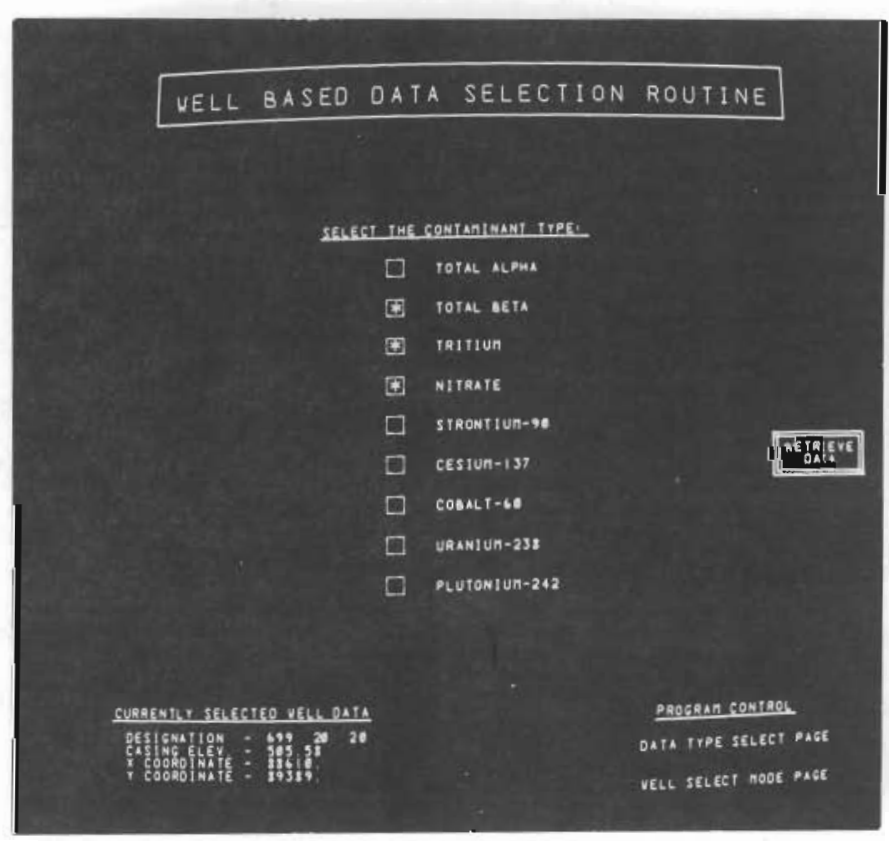

FIGURE 1-6.

Contaminant Data Selection Page 


\section{DATA TYPES}

The following is a description of program control operations for specified data types while displayed on the UNIVAC 1558 scope: HYDSCP - Well Hyarograph (Figure 1-7)

The options to the right of the graph are light pen interactive and are described as:

- ELEV. SCALE - the user may change the elevation scale by selecting this option and entering the desired elevation range on the keyboard as shown in the displayed example

- TIME SCALE - the user may change the time scale by selecting this option and entering the desired time range in years on the keyboard as shown in the displayed example

- CALCOMP

- the user may obtain a hardcopy Calcomp plot of the present hydrograph by selecting this option

- GOULD

- not operational (waiting for Gould software)

- MONITOR

- the user may return to the PDP-9 monitor (see Figure 1-1)

- WELL SELECT - the user may return to select a different data type or output device for the presently selected well (Figure 1-5)

- VTT OVERLAY - the user may select this option to retrieve and display data obtained from the VTT program as an overlay with the hydrograph

\section{CTMSCP - Contamination History (Figure 1-8)}

The options to the right of the graph are light pen interactive and many of the options are similar to those described in HYDSCP. They include: 
- CONC. SCALE - the concentration scale may be changed by selecting this option and entering the exponent of the desired range (i.e., $+2 ;+4$

- TIME SCALE - same as HYDSCP

- CALCOMP - same as HYDSCP

- TEKTRONIX - the present display may be transferred to the Tektronix memory scope

- MONITOR - same as HYDSCP

- WELL SELECT - same as HYDSCP

- JOIN PTS - the displayed concentration values may be joined for better visibility using this option* (Figure 1-8A)

- LEAST SQ. - not operational

*Note: This program also has the option of deleting or reinserting light pen selected points from the connected graph. WDCSCP - Well Structure Documentation (Figure 1-9)

WDCSCP provides visual display of a well structure. The options to the right of the displayed well structure cross section are light pen interactive and are described as:

- GET MONITOR - same as HYDSCP

- Well SELECTion - same as HydsCP

- CAlCOMP-PLOT - same as hydscP

- ALL

- this option displays all of the information described in the following options if the information is available

- CASING

- displays casing data

- perforation

- displays casing perforation data

- SCREEN

- displays screen data

- piezOMETERS

- displays all available piezometer data 


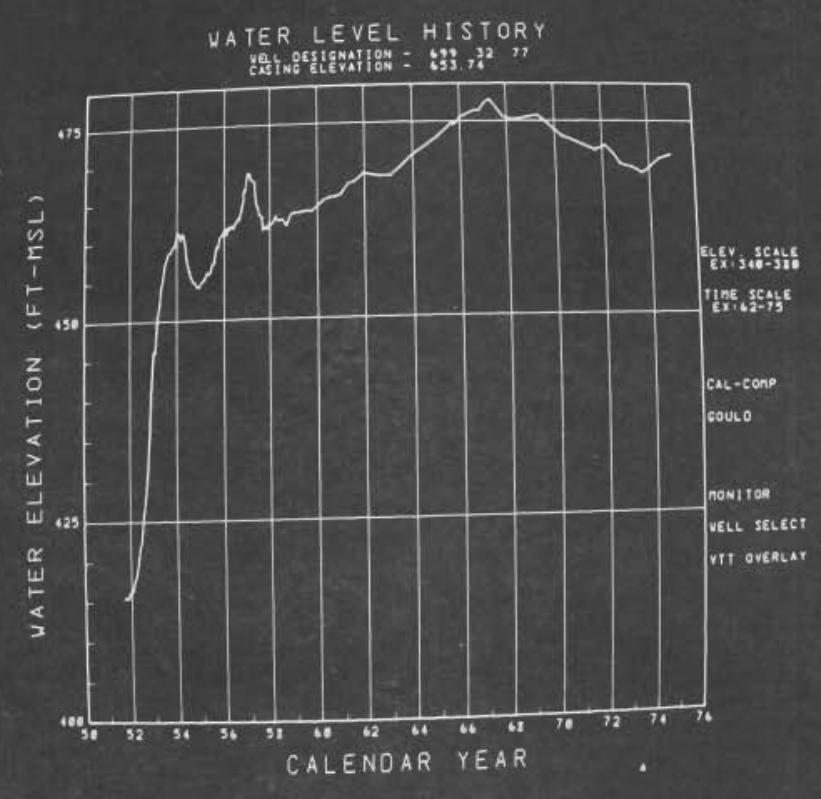

FIGURE 1-7.

Water Level History Display

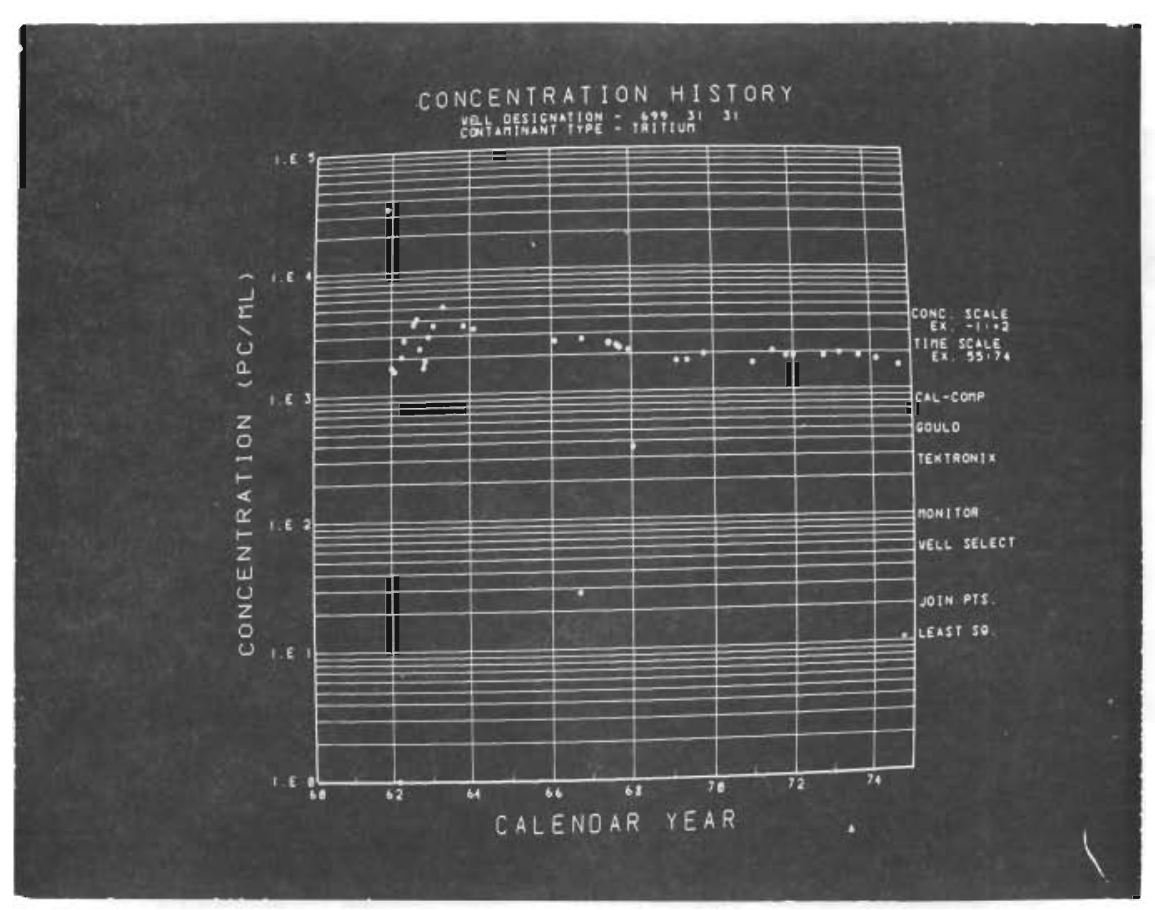

FIGURE 1-8.

Contaminant History Display 


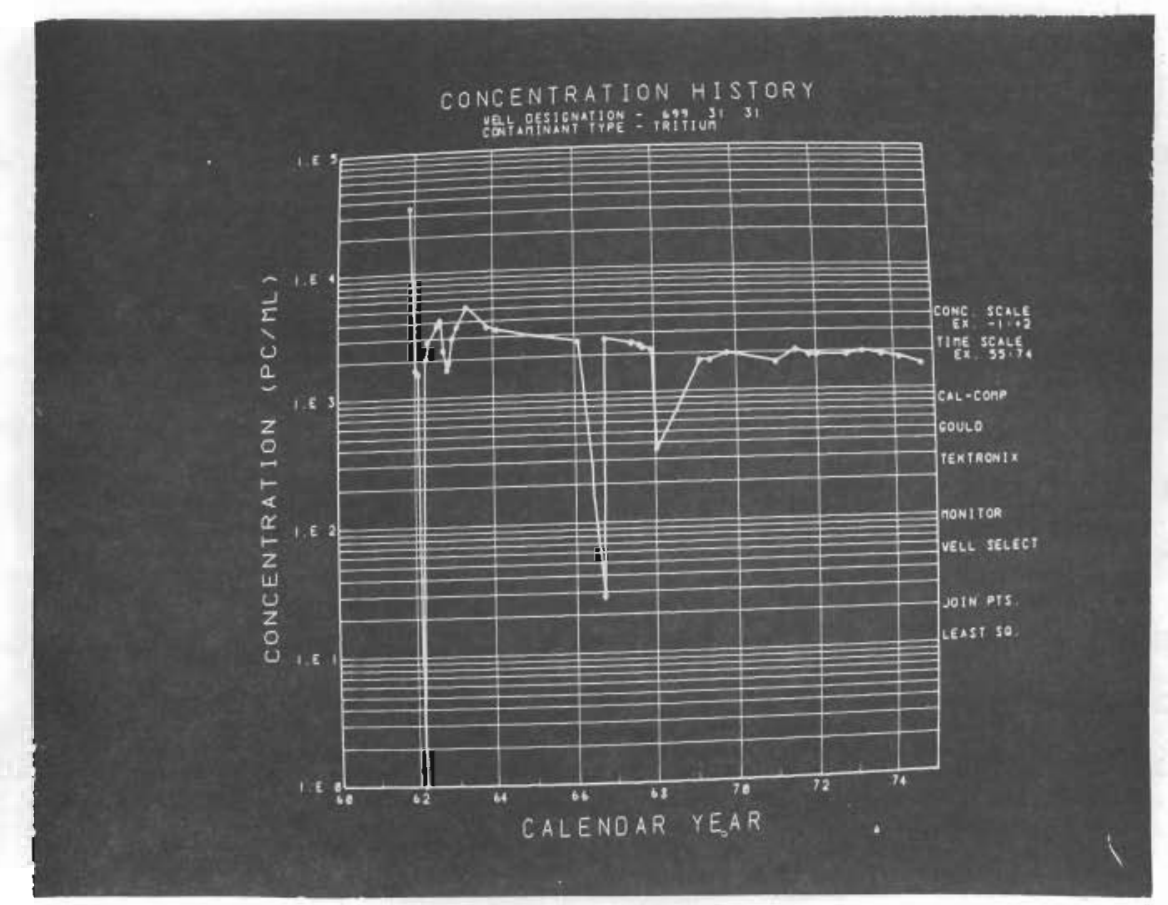

FIGURE 1-8A.

Contaminant History With Joined Data Points

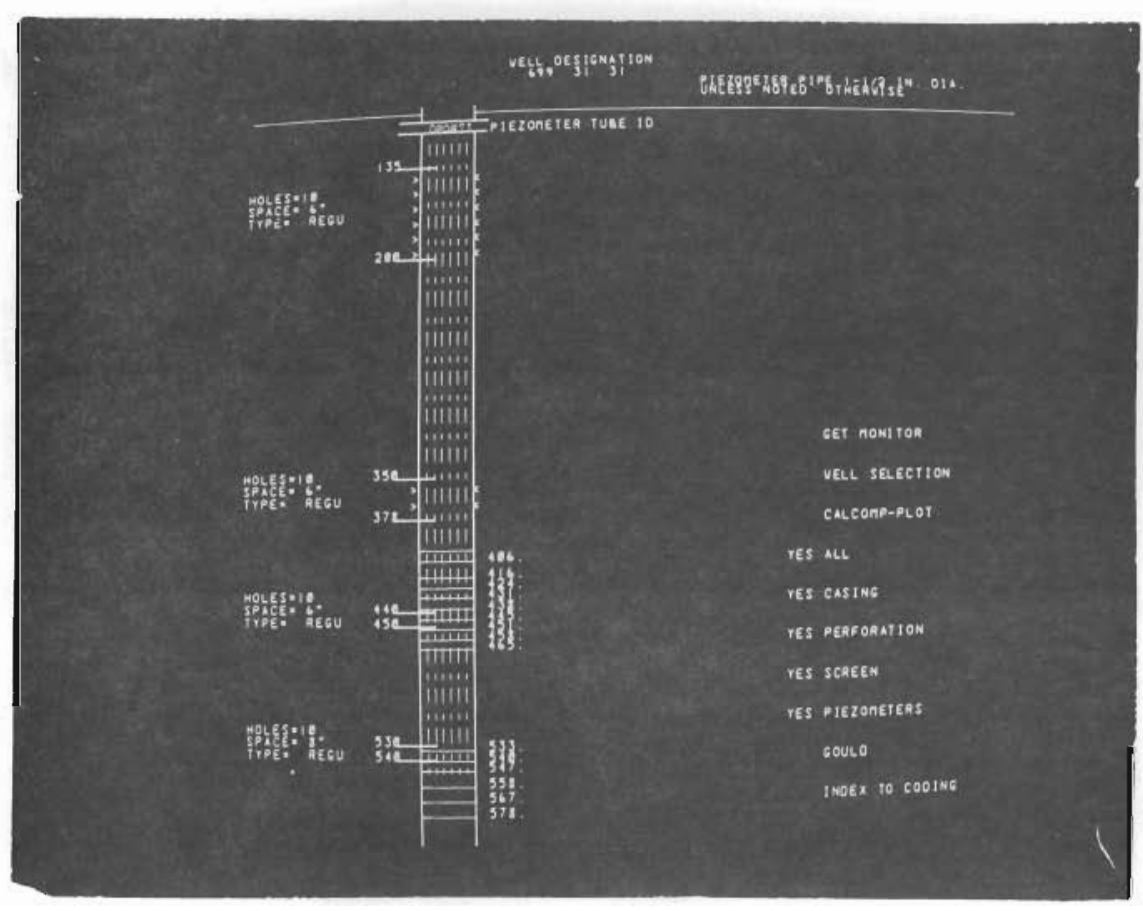

FIGURE 1-9.

Well Structure Display 
OUTPUT DEVICES

The CIRMIS system has five output devices available to the user. These are shown under the title OUTPUT DEVICES in Figures 1-5 and $1-5 \mathrm{~A}$ and are activated with the light pen in the same manner as for output to the interactive scope.

The previous section discussed mainly the interactive scope for output, and Figures 1-7 through 1-9 are displays of various data on this device. The other output devices (except for the Tektronix display) are used for hardcopy output.

The Calcomp plotter is used for high resolution report quality plots. The Calcomp has a 33-inch bed with three selected pens. Figures 1-10 through $1-12$ are plots produced on the Calcomp.

The Gould is a rapid output electrostatic plotter. This plotter has a 22-inch bed and is used for producing quick plots; however, the quality is not as good as the Calcomp. Figures 1-13 through 1-15 are plots produced on the Gould.

The line printer is used to produce tabular output for the requested data type. Figures 1-16 through $1-18$ are examples of line printer listings for various data types. 


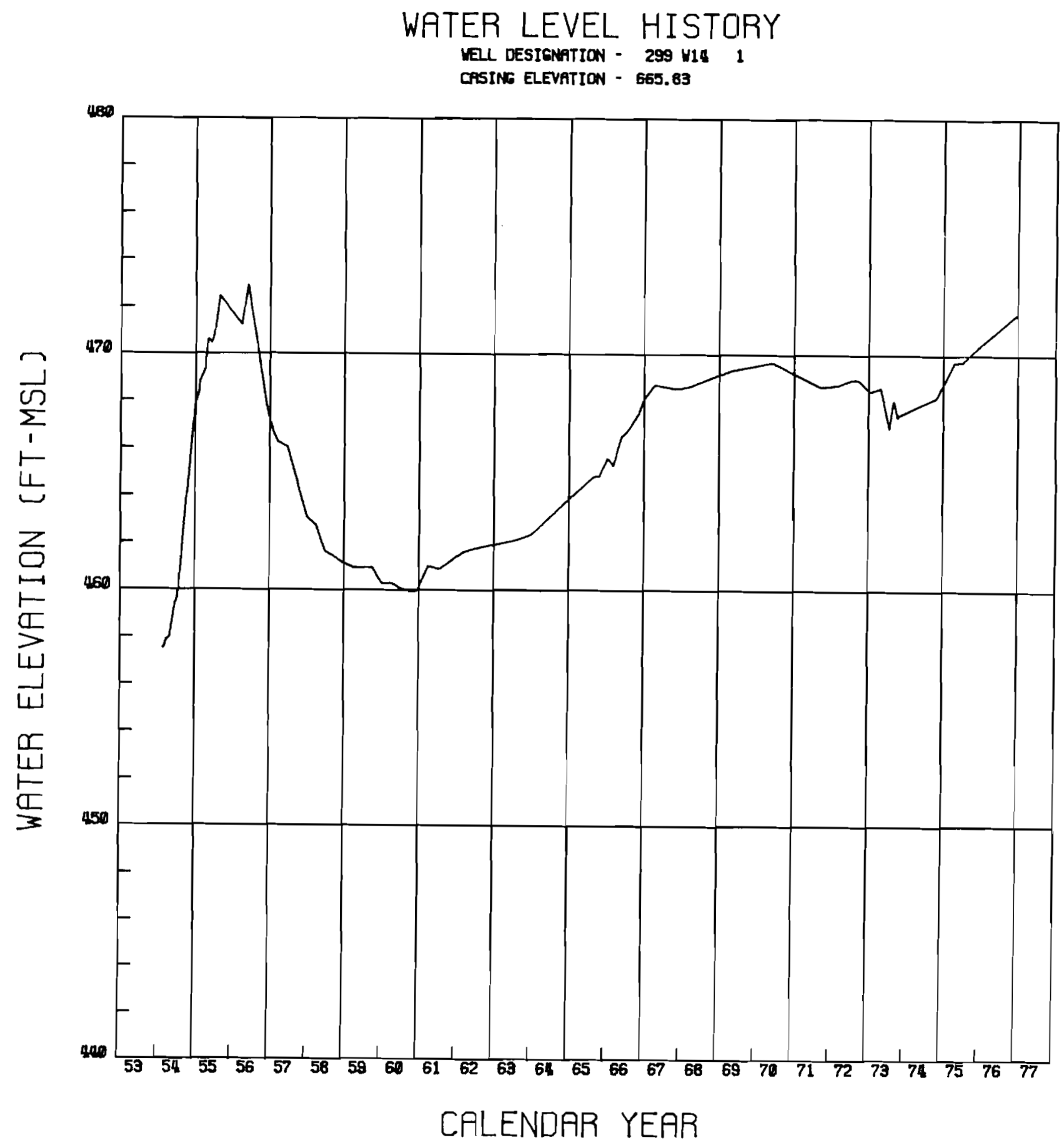

FIGURE 1-10. Calcomp Plot of Water Level History 


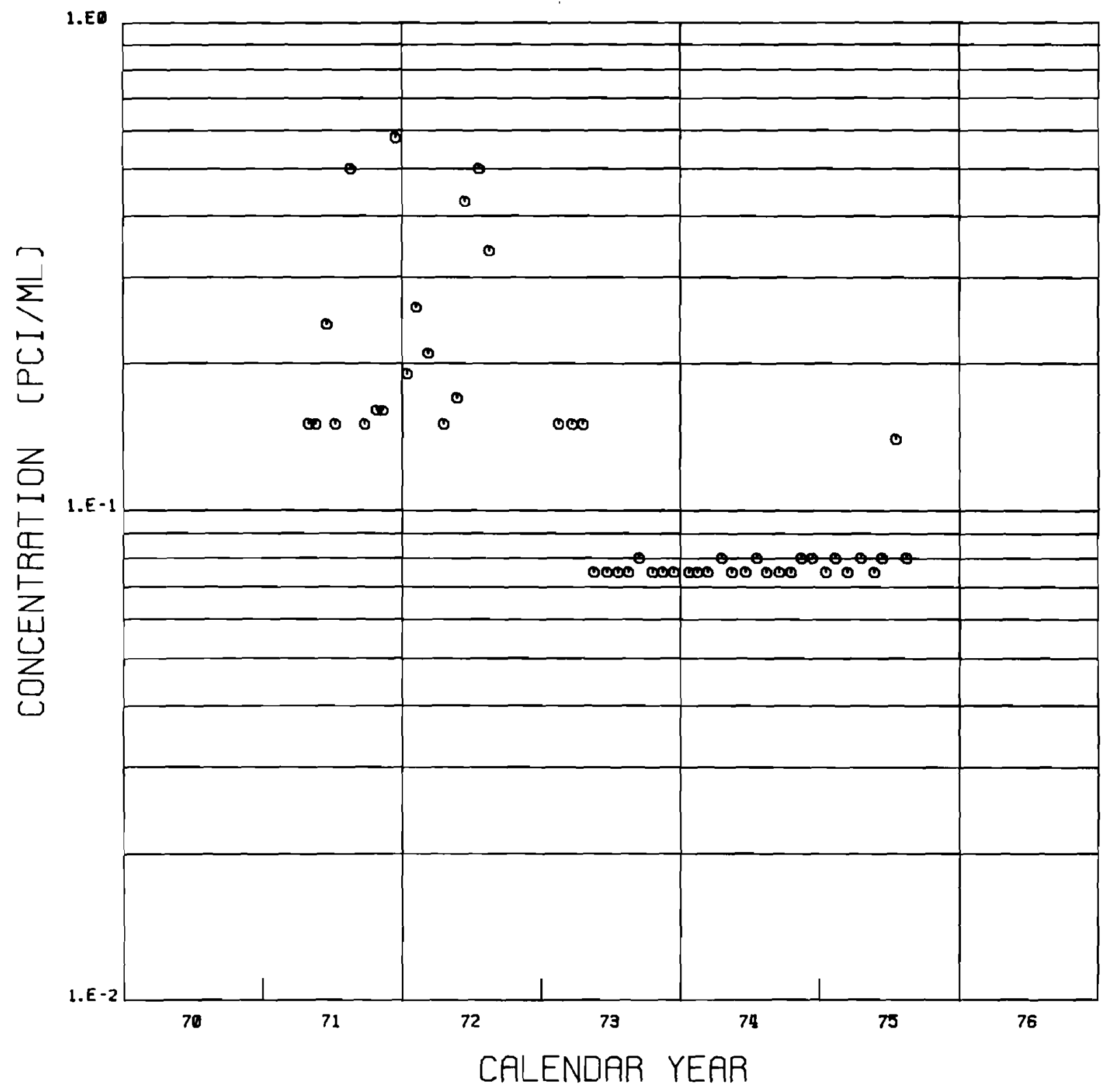

CONCENTRATION HISTORY -.- TOTAL BETA

NELL DESIGATIION - 299 E25 13

FIGURE 1-11. Calcomp Plot of Contaminant History 
WELL NO. $\quad 399 \quad 1 \quad 2 \quad 18$-FEB-77 1000019

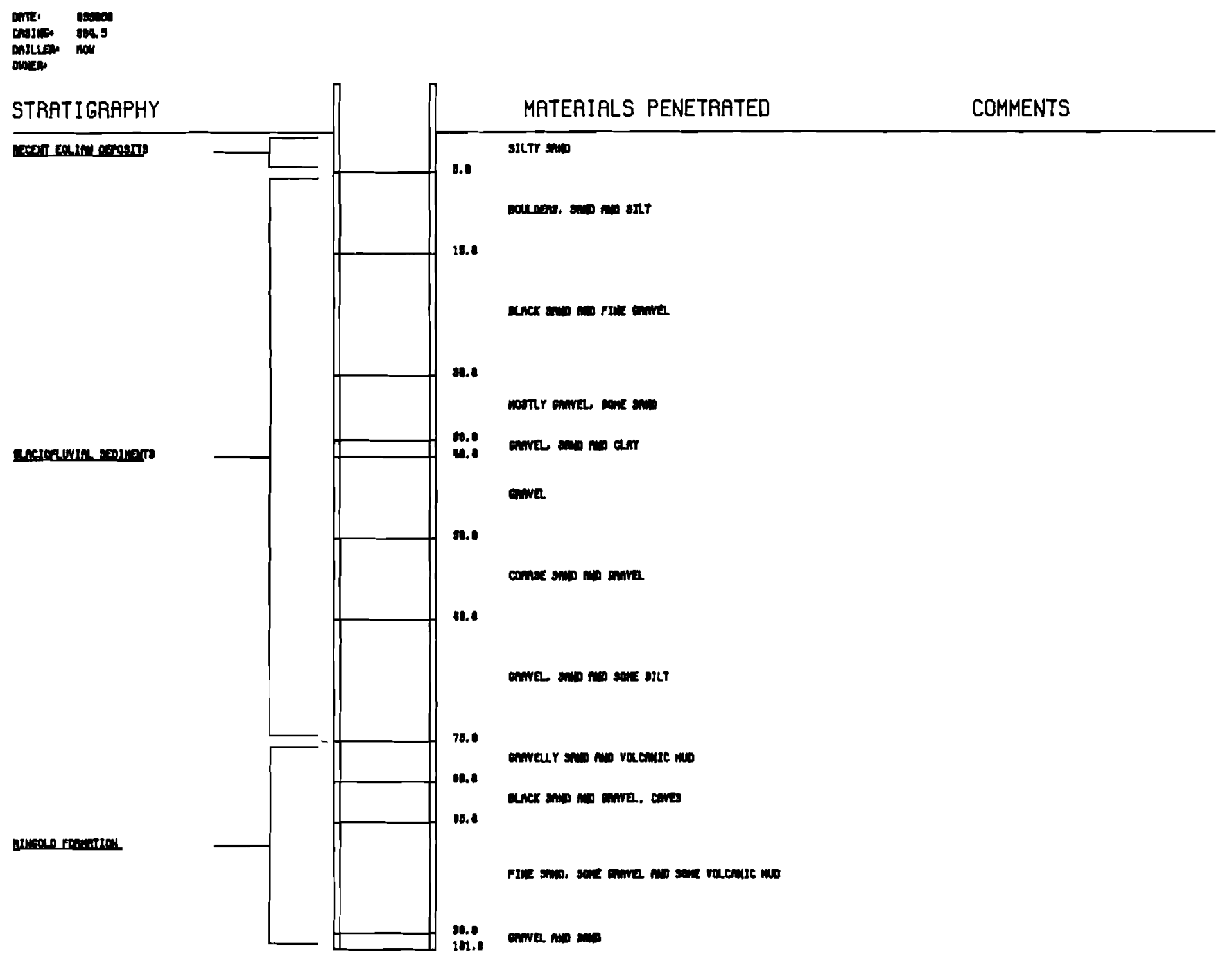

FIGURE 1-12. Calcomp Plot of Well Log Data 


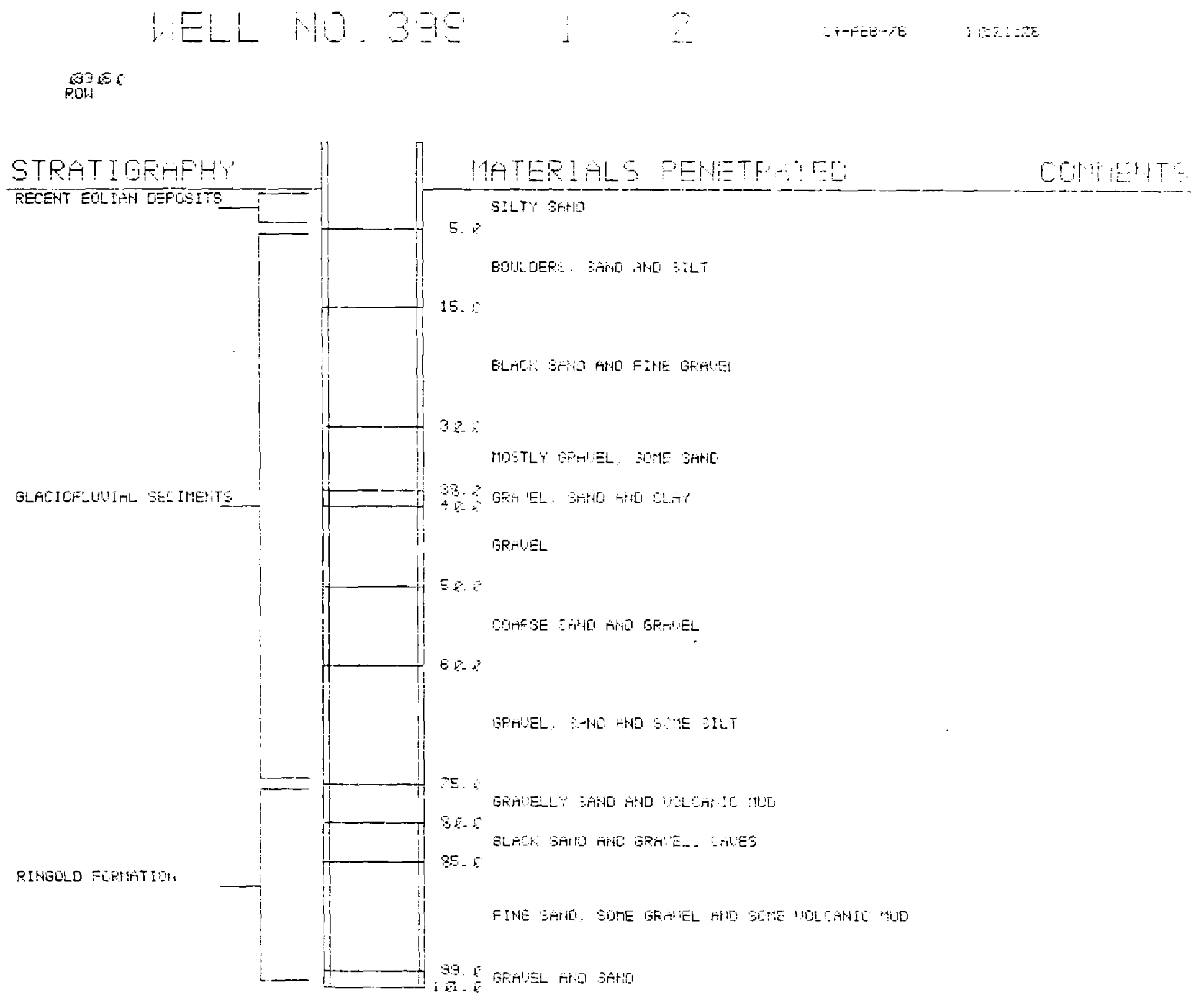

FIGURE 1-13. Gould Plot of Well Log Data (without shading) 


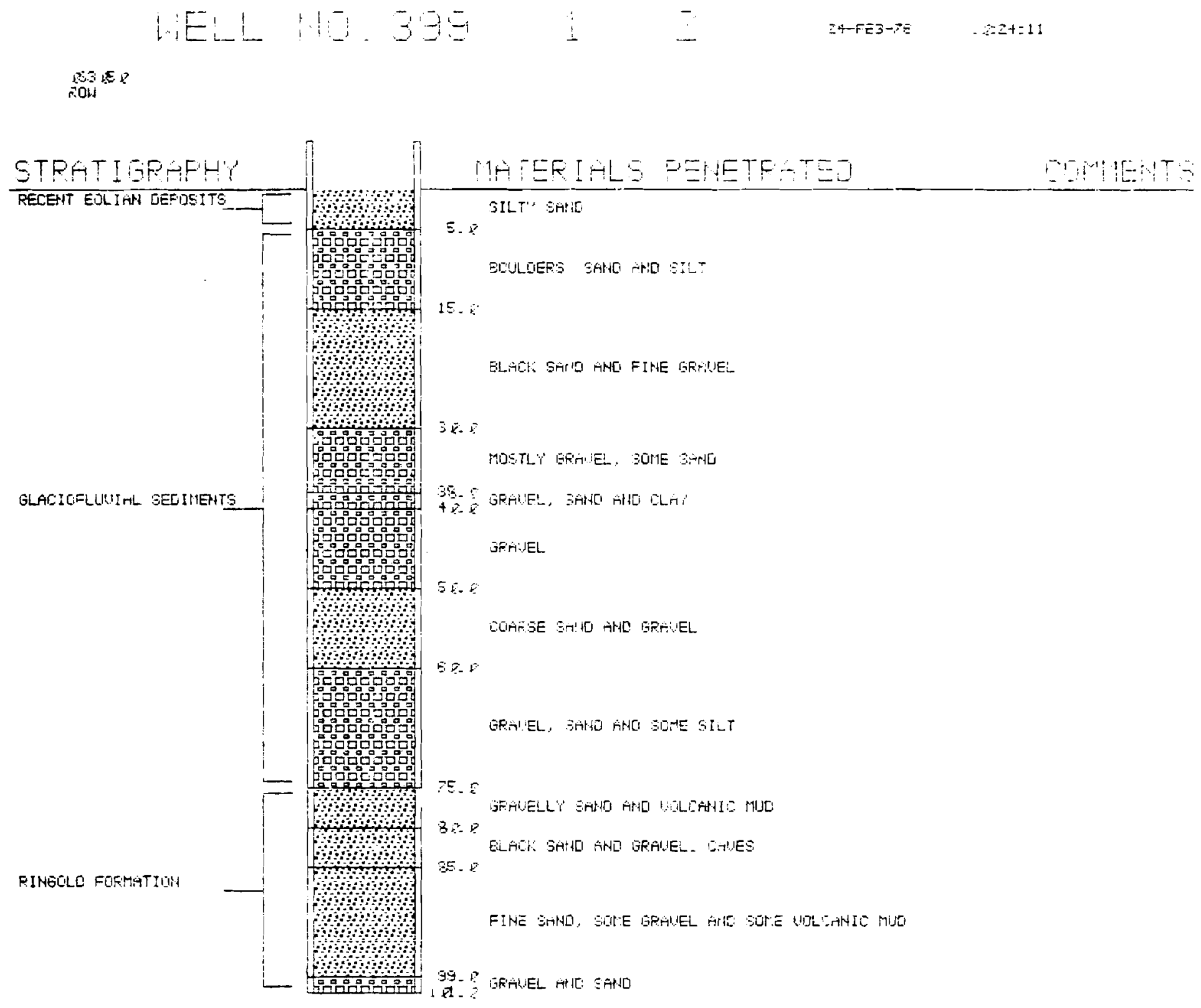

FIGURE 1-14. Gould Plot of Well Log Data (with shading) 


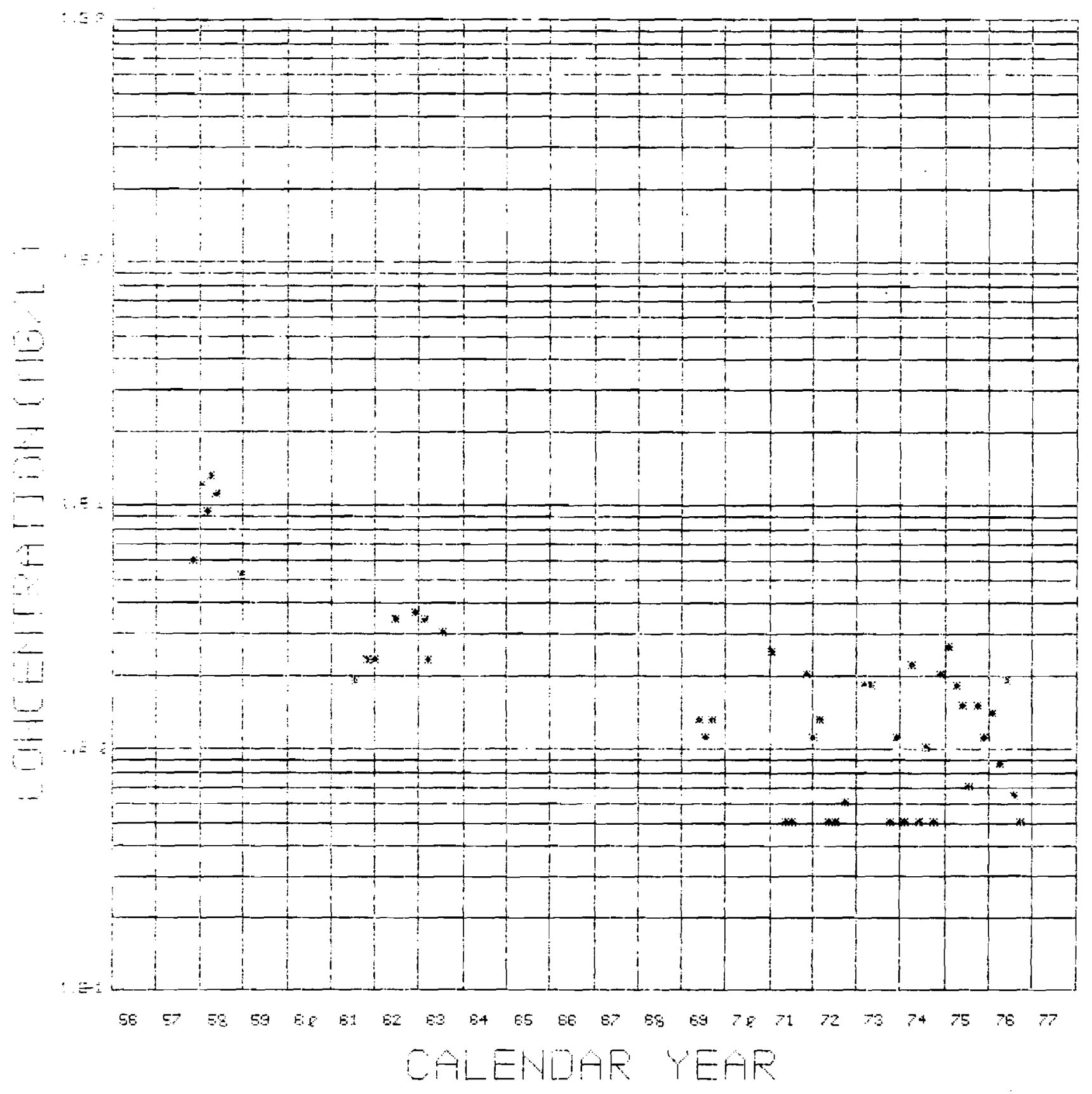

CONCENTRATIOH HISTORY --- NITRATE

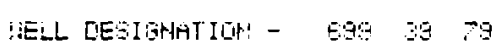

FIGURE 1-15. Gould Plot of Contaminant History 
MYUHOGRAPH DATA - WELL NO, 0993979

MEASURMENTS TO DATE 199

\begin{tabular}{|c|c|c|c|c|c|c|c|c|c|}
\hline $\begin{array}{l}1 H-N O V-48 \\
28-A P K-49 \\
25-S E R-49 \\
23-F E B-5 A \\
27-J U L-5 B \\
2 B-D E C-5 D \\
29-M A Y-51 \\
3 Q-O C T-51 \\
26-M A R-52 \\
26-A U L-52 \\
27-J A N-53 \\
38-J U N-53 \\
24-N O V-53\end{array}$ & $\begin{array}{l}425.63 \\
422.44 \\
423.33 \\
425.17 \\
426.46 \\
428.44 \\
439.25 \\
432.64 \\
435.53 \\
437.87 \\
449.56 \\
440.56 \\
451.37\end{array}$ & 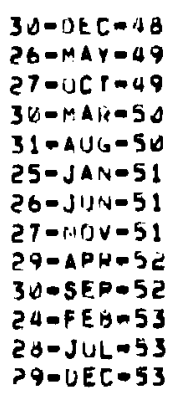 & $\begin{array}{l}421.14 \\
422.73 \\
423.47 \\
425.18 \\
426.55 \\
428.92 \\
459.97 \\
453.14 \\
436.26 \\
438.47 \\
442.74 \\
447.42 \\
453.17\end{array}$ & $\begin{array}{l}27-J A N=49 \\
30-J U N-49 \\
25-N O V=49 \\
27-A P K-50 \\
2 B-S E P-50 \\
27-F E B-51 \\
31-J U L-51 \\
26-O E C-51 \\
27-M A Y-52 \\
2 B-O C T-52 \\
24-M A R-53 \\
25-A U G-53 \\
26-J A N-54\end{array}$ & $\begin{array}{l}421.28 \\
422.52 \\
424.15 \\
425.69 \\
426.84 \\
429.36 \\
431.28 \\
434.18 \\
436.60 \\
439.17 \\
443.92 \\
448.28 \\
453.72\end{array}$ & $\begin{array}{l}24-F E Y-49 \\
28-J U L=49 \\
29-O E C-49 \\
25-M A Y-50 \\
26-O C T-50 \\
27=M A R-51 \\
28-A U G-51 \\
24-J A N-52 \\
24-J U N-52 \\
25-N O V-52 \\
28-A P R-53 \\
29-5 E P-53 \\
23-F E B-54\end{array}$ & $\begin{array}{l}421.64 \\
422.75 \\
424.67 \\
425.55 \\
427.62 \\
429.44 \\
432.01 \\
434.82 \\
437.06 \\
439.86 \\
444.82 \\
449.22 \\
455.11\end{array}$ & $\begin{array}{l}31-M A R=49 \\
25-A U G-49 \\
26-J A N-50 \\
29-J U N-50 \\
24-N O Y-5 U \\
24-A P R-51 \\
25-S E P-51 \\
26-F E H-52 \\
29-J U L-52 \\
3 U-U E C-52 \\
26-M A Y-53 \\
27-O C T=53 \\
3 U-M A R-54\end{array}$ & $\begin{array}{l}421.89 \\
422.96 \\
424.24 \\
426.02 \\
427.62 \\
430.20 \\
432.45 \\
435.41 \\
437.62 \\
441.23 \\
445.57 \\
450.45 \\
456.42\end{array}$ \\
\hline
\end{tabular}

COMTIMINANT UATA - WELL NO. 399 \& 2

CONTAMINANT TYPE -- NITRATE

CONTAMINANT COUE "
MEASURMENTS TO DATE 37

\begin{tabular}{|c|c|c|c|}
\hline & & & \\
\hline & & & \\
\hline & $\begin{array}{l}0 \\
0\end{array}$ & 0 & \\
\hline $3 i-J \cup L-13$ & $\theta$ & 6 & \\
\hline $\begin{array}{l}1-A P R=74 \\
5-N O V=74\end{array}$ & $\theta$ & a & \\
\hline$S-N Q V=\}$ & 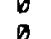 & 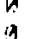 & \\
\hline$I D M A R=76$ & & & $9 E+0$ \\
\hline
\end{tabular}

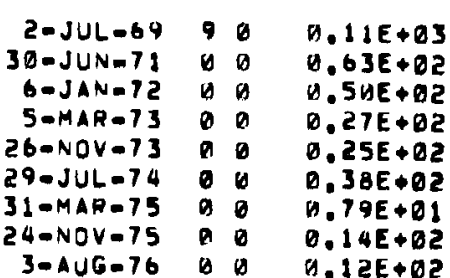

FIGURE 1-17. Line Printer Listing of Contaminant History 


$$
\text { WELL NU. } 39912 \text { TOTAL DEPTH= } 201.00
$$

OATE: W33155

DRJLLER: ROW

FUKIMA:

RECEMT EOLIAU UEROSTTS

$$
\begin{aligned}
& \text { DEPIH MATEPIALS PENETHATEU } \\
& \text { 5. SILTY SANU }
\end{aligned}
$$

GLACIUFLUVIAL SEOLMETHS

$$
\begin{aligned}
& \text { DEPTH MATERIALS PENETKATEU } \\
& \text { 15. GOULUEKS, SAND AND SILT } \\
& \text { 30. BLACK SARL AND FINE GHAVEL } \\
& \text { 3\%. MOSTLY GHAYEL, SOME SANO } \\
& \text { 4V. GRAVEL, SANG ANI CLAP } \\
& \text { 5\%. ISPAVEL } \\
& \text { Ob. CUARSE SAMU ANU GRAVEL } \\
& \text { 75. GFarel, SANJ aND SOME SILT }
\end{aligned}
$$

RINGCLO FOHMATION

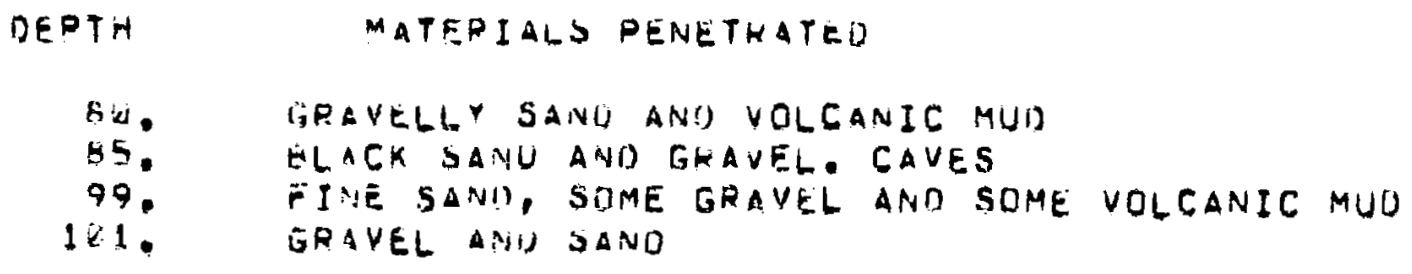

FIGURE 1-18. Line Printer Listing of Well Log Data 


\subsection{SPECIAL APPLICATIONS AND MANIPULATIONS}

This section describes the procedures involved in the generation and manipulation of surface files, the generation and use of map boundary files, special computer models that utilize these data and special utility programs.

Most of these functions are controlled by the PDP-9. However, some special applications programs are used only on the 11/45. All of these programs and user applications are outlined in the following pages.

\section{INITIAL STARTUP PROCEDURES}

To operate the programs in this section the CIRMIS loading procedures described in Appendix A must be followed. Once these procedures have been completed, the display in Figure 2-l will appear.

The programs in this section are defined as SPECIAL APPLICATIONS AND MANIPULATIONS shown under the heading SELECT A FUNCTIONAL CATEGORY.

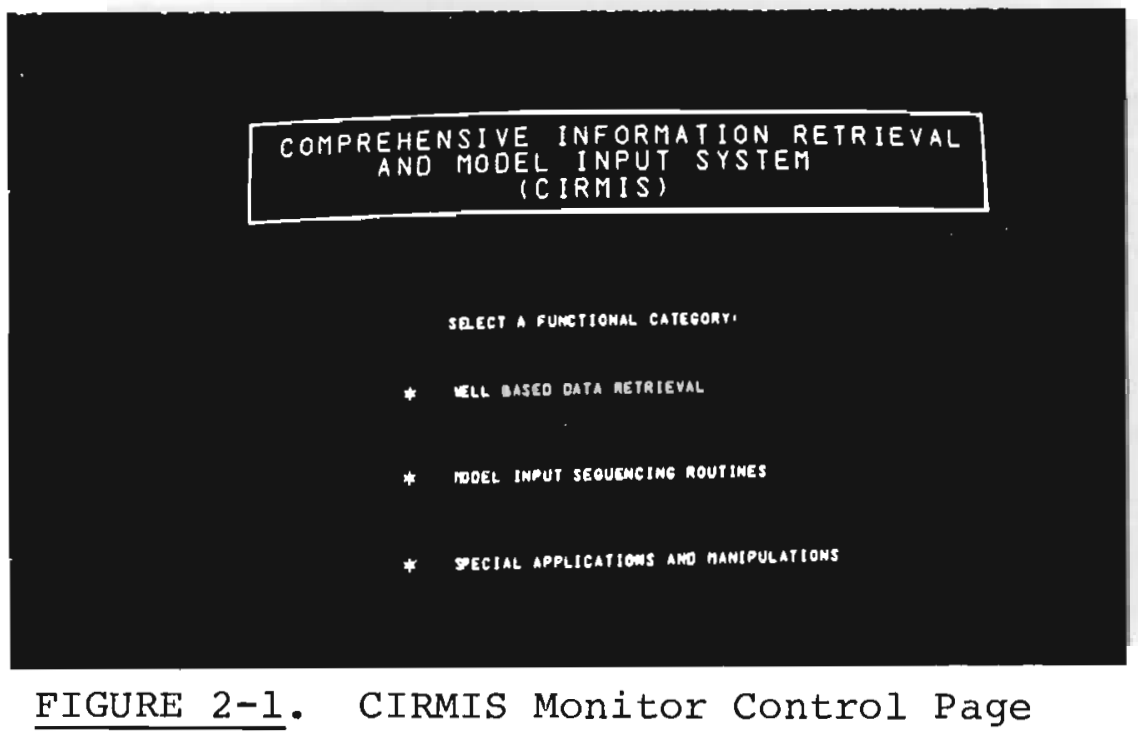


NORMAL CIRMIS OPERATION

All operations under PDP-9 control normally interact with the 11/45 system. Because of this, specific projects and associated surfaces and maps can be filed at the 11/45 for easy access and the user can obtain complete specification requirements for any given project operation (see UPDATE under Operating the special Function Programs) . Inadvertent generation of files with erroneous specifications is prevented with this method because error messages advise the user of any discrepancies between user input specifications and the specifications already in the master file header. This preserves the integrity of the data by assuring that the proper specifications are adhered to.

\section{BYPASSING CIRMIS OPERATION}

At times it is desirable to bypass the normal file structured operations provided by CIRMIS, as when a single surface or map is required for use at the $11 / 45$ by a specific program or model. A program called BYPASS CIRMIS CONTROI provides for this. This program is described in detail in the UTILITY Program section under operating the Special Function Programs. These procedures must be strictly adhered to.

\section{ABBREVIATED OPERATING SEQUENCE}

- To begin operation of this portion of the CIRMIS system the user selects the option SPECIAL APPLICATIONS AND MANIPULATIONS shown in Figure 2-1. The present display page is replaced by that shown in Figure 2-2. Figure 2-2 shows the functions available to the user and the general project specifications presently being used. 


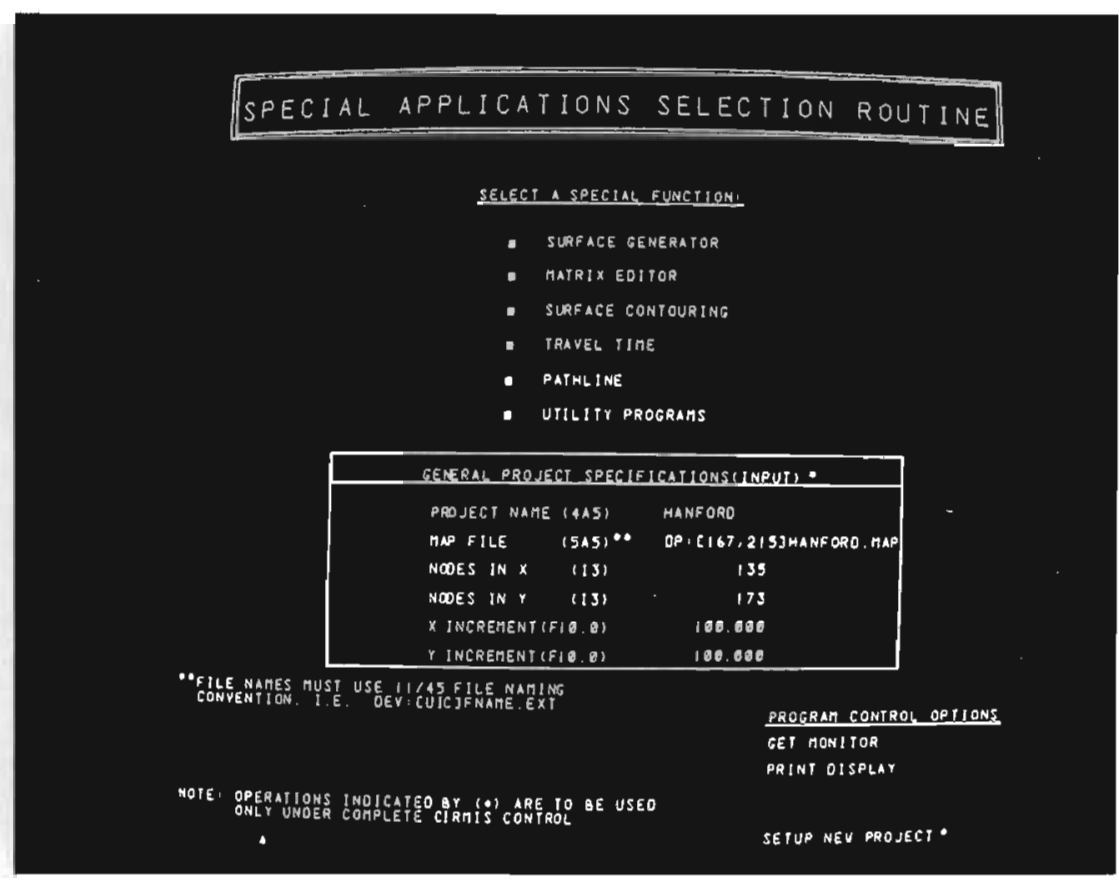

FIGURE 2-2. Special Applications and Manipulations

- If normal CIRMIS operation is desired, the user selects the proper specifications under GENERAL PROJECT SPECIFICATIONS (see Appendix $C$ ) with the light pen and inputs the desired value on the CRT keyboard.

- The user then makes a selection under the title SELECT A SPECIAL FUNCTION and the display is replaced by a display correlated with this function (Figures 2-3 through $2-8$ )

- If required, the user selects the function specification(s) with the light pen and inputs the desired value on the CRT keyboard.

- The user then selects the START PROGRAM option.

- CIRMIS now queries the 11/45; if all specifications are correct, the program initializes the proper SPECIAL FUNCTION. 


\section{SURFACE GENERATOR}

INPUI SUPSACE SPECIFICAIIONS

Surface file igas) $\cdots$

MINIMUN VALUE (FI0.0\%

maXinun VALUE (FIe.o)

300.00

500.01

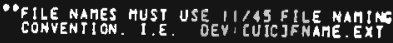

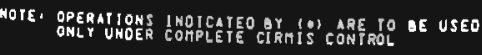

PROGRAM CONTROL GRTIONS

Get MONITOR

print OISPLAT

RETURN FIRST PAGE

START PROGRAN

SENO SURFACE $1011 / 43$

FIGURE 2-3. SURFACE GENERATOR Specifications

MATRIX EDITOR

WFUt SUGace SeEcifications,

SURFACE FILE (5A3) *

QP, [167, 215]HANQT] PTI

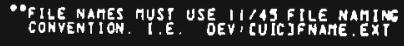

PROARAT CONIROL OEILIOES

GET MONITOR

orint oisplar

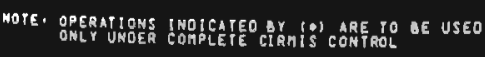

AE TUAN G IRST PAGE

START PROGRAH

SEnO SURFACE $1011119^{\circ}$

FIGURE 2-4. MATRIX EDITOR Specifications 


\section{SURFACE CONTOURING}

INPUT SUESACE SPECIFICATIONS:

SURFACE FILE ISADI)

OPI C167.2193HANQ73,PT1

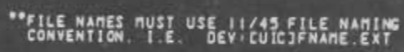

PROFRAT COMTROL OPTHONS

GET MONITOR

PRINT OISPLAY

nOTE, operations IMOICATEO OY (o) ARE TO ME USEO DE TURN FIRST PAGE

START PROGRAR

SEMO SURFACE TO $11 / 45^{\circ}$

FIGURE 2-5. SURFACE CONTOURING Specifications

\section{TRAVEL TIME}

INPUT SULSACE SPECIEICATIONS.

STEP SIZE IN FEET
IIME INCREMENT IN YEARS
IO.0.00

RETURN FIRST PAGE

START PROGRAH

SENO SURFACE TO $11 / 45$ :

FIGURE 2-6. Preliminary TRAVEL TIME Specifications

$$
2-5
$$


IMPUT SUESACE SPECIFICATIOHS

STEP SIZE IN FECT TINE IMCESHEMT IN TEARS

DeGIN hOMIHIEx:

DEGIN YEM IEX: 195I)

ENO HONTH IEX: 111

ENO YEAR (EX: 1955)

Ho. of SURFACES IEX:50

1000.00

20.00

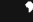

1951
10

1995

90

NOTE OPERAIJOMS INDICATEO BY 'P' ARE TO BE USEO Get hoNITOR

PEINT DISPLAY

RETURM FIRST PAEE

START PROERAM

SEMO SURFACE TO $11 / 45^{\circ}$

FIGURE 2-7. Preliminary PATHLINE Specifications

\section{UTIL ITY PROGRAMS}

To cenenater

a itass cianis control

tocate zenos

FILL zeras

BROERAI COHTROL OPILNS

GET HONITOR

PRINT OISPLAY

RETURM FIRST PAEE

NOTE OPERAIJOMS IMPICATED BY (P) ARE TO OE USEO

START PROGRAH

SEMO SURFAEE $1011149^{\circ}$

FIGURE 2-8. Utility Programs

$2-6$ 
DETAILED OPERATING SEQUENCE

Special Applications Selection Routine (Figure 2-2)

This routine has three modes of control and input which are described as follows:

1. SELECT A SPECIAL FUNCTION - All of the Functions (i.e. Special Application programs) under this label are light pen interactive and when selected replace the display shown in Figure 2-2 with one shown in Figures 2-3 through 2-8 (see SPECIAL FUNCTION OPTIONS and SPECIAL FUNCTION INPUT SPECIFICATIONS described below).

2. GENERAL PROJECT SPECIFICATIONS (INPUT) - is used only under complete CIRMIS control. This category is light pen interactive and values are input on the CRT keyboard.

- PROJECT NAME (4A5) - Each project has a descriptive name.

- MAP FILE (5A5) - Map file to be used as background display must be entered in standard $11 / 45$ naming convention (see Appendix B). Up to ten (10) maps are allowed.

- NODES IN X (I3) - Number of nodes in the X direction (fence posts, not spaces).

- NODES IN Y (I3) - Number of nodes in the $\mathrm{Y}$ direction.

- X INCREMENT (F10.0)- Map units per node in the $\mathrm{X}$ direction.

- Y INCREMENT (F10.0)-Map units per node in the Y direction. 
3. PROGRAM CONTROL OPTIONS

- GET MONITOR

- PRINT DISPLAY

- SETUP NEW PROJECT
- When selected, returns control to the monitor (Figure 2-1).

- Prints present display on the Info-max Printer/Plotter.

- Used only under normal CIRMIS enter a new project into the $11 / 45$ project file header according to the present project specifications. NOTE: If the project already exists it cannot be overwritten except by special consideration.

Special Function Options (Figures 2-3 through 2-8)

Inputs to the special functions are shown in Figures 2-3 through 2-8. The functions may require input specifications as shown in these figures. The options for these functions are described below.

PROGRAM CONTROL OPTIONS

- GET MONITOR

- PRINT DISPLAY

- RETURN FIRST PAGE

- $\quad$ start program
- Described above.

- Described above.

- Replaces present display with that shown in Figure 2-2.

- The selected special function program is initialized. NOTE: If Program is operating under normal CIRMIS control the $11 / 45$ project file header is monitored to see if input specifications match selected project. 
- SEND SURFACE To $11 / 45$ - Used only under normal control to send a surface file to the $11 / 45$.

\section{Special Function Input Specifications}

The following special functions may require surface name input. This input must adhere to the naming conventions described in Appendix B.

SURFACE GENERATOR (Figure 2-3)

- SURFACE file (5A5)

- See Appendix B.

- minimum Value (F10.0)

- Minimum value or less expected to appear on surface being used.

- maximum value (F10.0)

- Maximum value or greater expected to appear on surface being used.

MATRIX EDITOR (Figure 2-4)

- SURFACE FILE (5A5)

- See Appendix B.

SURFACE CONTOURING (Figure 2-5)

- SURFACE FILE (5A5)

- See Appendix B.

TRAVEL TIME (Figure 2-6)

- STEP SIZE IN FEET

- Constant step size to be used along a streamline.

- TIME INCREMENT IN DAYS - Constant time increment to be used. Supersedes constant step if greater than 0 .

PATHLINE (Figure 2-7)

- STEP SIZE IN FEET

- Same as travel time, above.

- TIME INCREMENT IN YEARS - Same as travel time.

- BEGIN MONTH (Ex:9)

- Month of first time plane. 
- BEGIN YEAR (Ex:1951)

- END MONTH (Ex:10)

- END yeAR (Ex:1955)

- NO. OF SURFACES (Ex:50)
- Year of first time plane.

- Month of last time plane.

- Year of last time plane.

- Total number of surfaces (time planes) to be used within the above time period.

UTILITY PROGRAMS (Figure 2-8)

MAP GENERATOR, BYPASS CIRMIS CONTROL, LOCATE ZEROS AND FILL ZEROS are light pen interactive labels. When selected a star will appear to the left of the label. The MAP GENERATOR may be used under CIRMIS control or after returning from the BYPASS CIRMIS option.

All of these special functions are described in greater detail in Category III of operating the special Function Programs.

\section{OPERATING THE SPECIAL FUNCTION PROGRAMS}

The Special Functions are divided into three discrete categories, each of which serves a distinct function. The functions in the first and third categories may be used under complete CIRMIS control or by bypassing CIRMIS control, while the calculational programs in Category II must be used only under complete CIRMIS control. These three categories are described as follows:

Category I - Surface File Manipulation

This category allows the user to generate, edit and display a surface file for use with other programs or models.

\section{SURFACE GENERATOR Program}

This program makes it possible to digitize a surface depicted by isopleths and form a matrix of values. This procedure may be used to generate new matrices or modify existing matrices. Figure 2-9 is a display of the surface Generator Program and its associated options. 


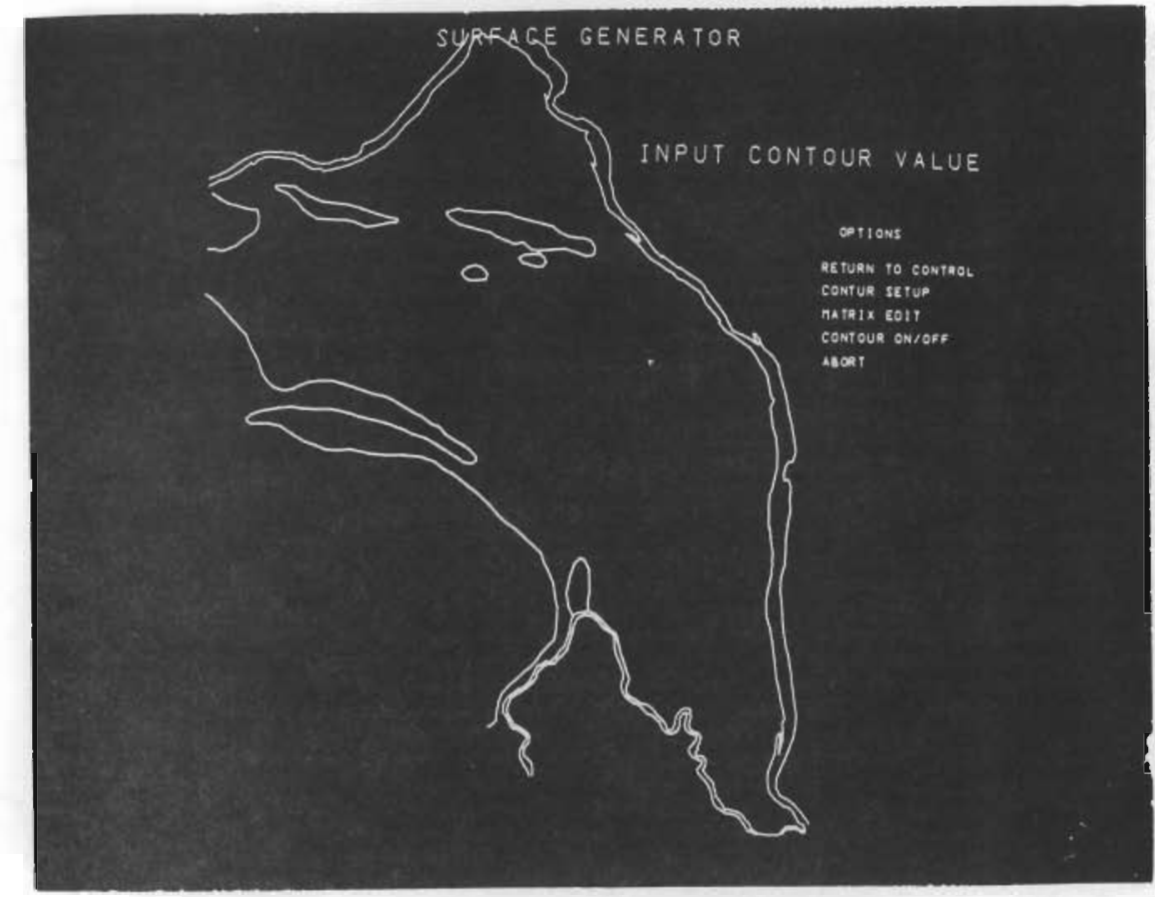

FIGURE 2-9. SURFACE GENERATOR Program (Instruction 1)

The options shown in Figure 2-9 are described as follows:

- RETURN TO CONTROL - Returns to special application and manipulation (Figure 2-2).

- CONTOUR SETUP

- Transfers control to the Contouring Program.

- MATRIX EDIT

- Transfers control to the Matrix Editor Program.

- contour on/OFF

- Displays or turns off contours generated and saved by the contouring Program.

- $\mathrm{ABORT}$

- Aborts certain sequences of the digitizing sequence.

When the user is ready to digitize a surface he must follow this displayed instruction, INPUT CONTOUR VALUE, (i.e., as shown in Figure 2-9). 
The value of the contour to be digitized is entered on the digitizer keyboard in floating point notation. When this been done the instruction, DIGITIZE IJNE, shown in Figure 2-10 appears .

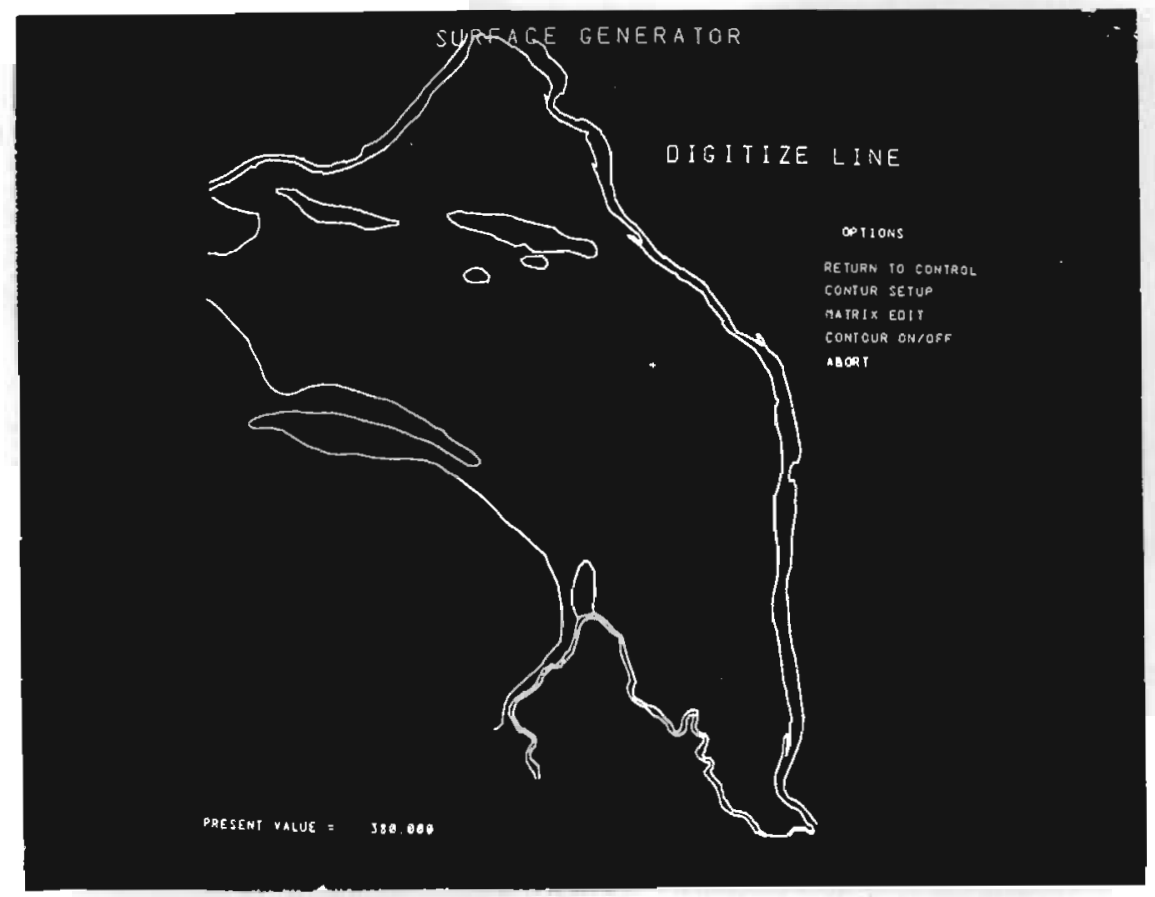

\section{FIGURE 2-10. SURFACE GENERATOR Instruction 2}

The user then digitizes the contour. When ready to terminate the Iine he digitizes the last point twice.* When this has been done the instruction, DIGITIZE START PT ON NEXT CONTOUR OR FIRST PT TO CLOSE REGION, shown in Figure 2-11 appears.

If the user has another contour to digitize before closing a region he digitizes the start point on the next contour and the sequence continues as shown in Figures 2-9, 2-10, and 2-11.

* See Note on page 2-15. 


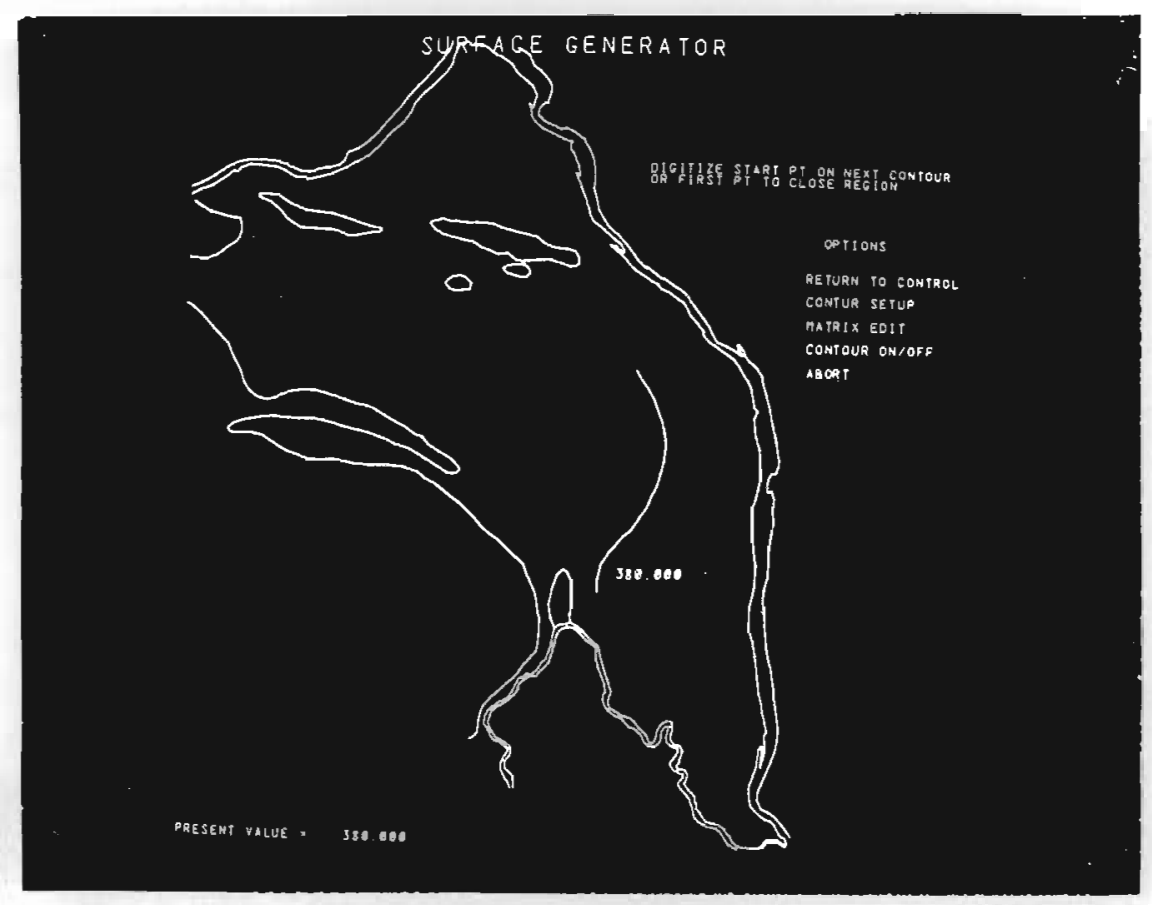

\section{FIGURE 2-11. SURFACE GENERATOR Instruction 3}

This can be done for any number of contours, as in a saddle region. The user must always digitize in a circular pattern; i.e., each complete digitizing sequence must follow either a clockwise or counter-clockwise rotation. In this way, a complete digitizing sequence has the form of a continuous closed loop in which the starting point on one digitized line is adjacent to the end point on the previous digitized line. When the last point on the last of the contour lines defining a region has been digitized, the message shown in Figure 2-ll will again appear. The user then closes the region by digitizing the first point on the first contour line. The program will begin interpolating to calculate the nodal values contained within the closed loop defined by the digitizing contours, as shown in Figure 2-12. 


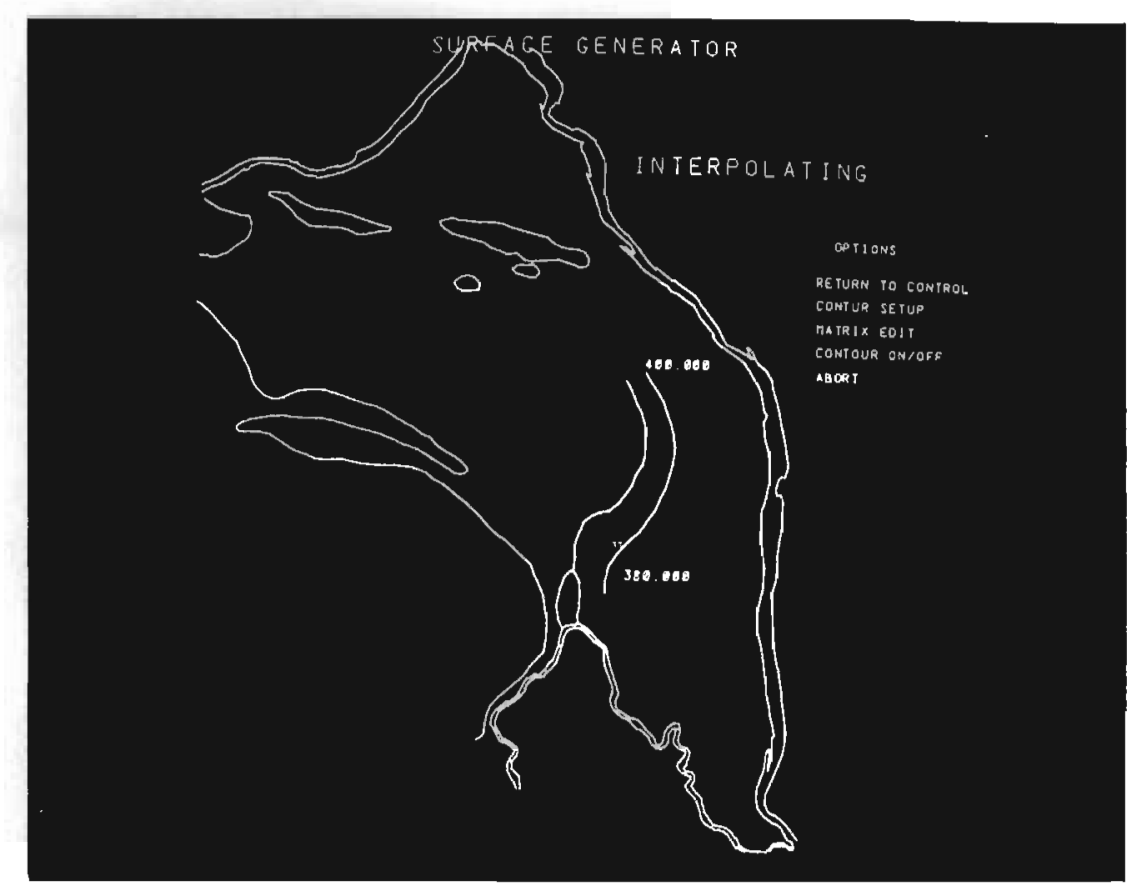

FIGURE 2-12. SURFACE GENERATOR Instruction 4

When the interpolation has been completed the message shown in Figure 2-13 will appear. The user may then use any of the light pen interactive options or begin digitizing a new region. If the user chooses to continue digitizing he must enter an option number followed by a carriage return on the digitizer keyboard. The two option numbers presently active are:

1) $\mathrm{OPTION}=1$ start new digitizing sequence.

2) OPTION=2 Save last digitized line so this sequence can continue.

The entire sequence is then repeated (Figures 2-9 through 2-13) until the entire map has been digitized. 


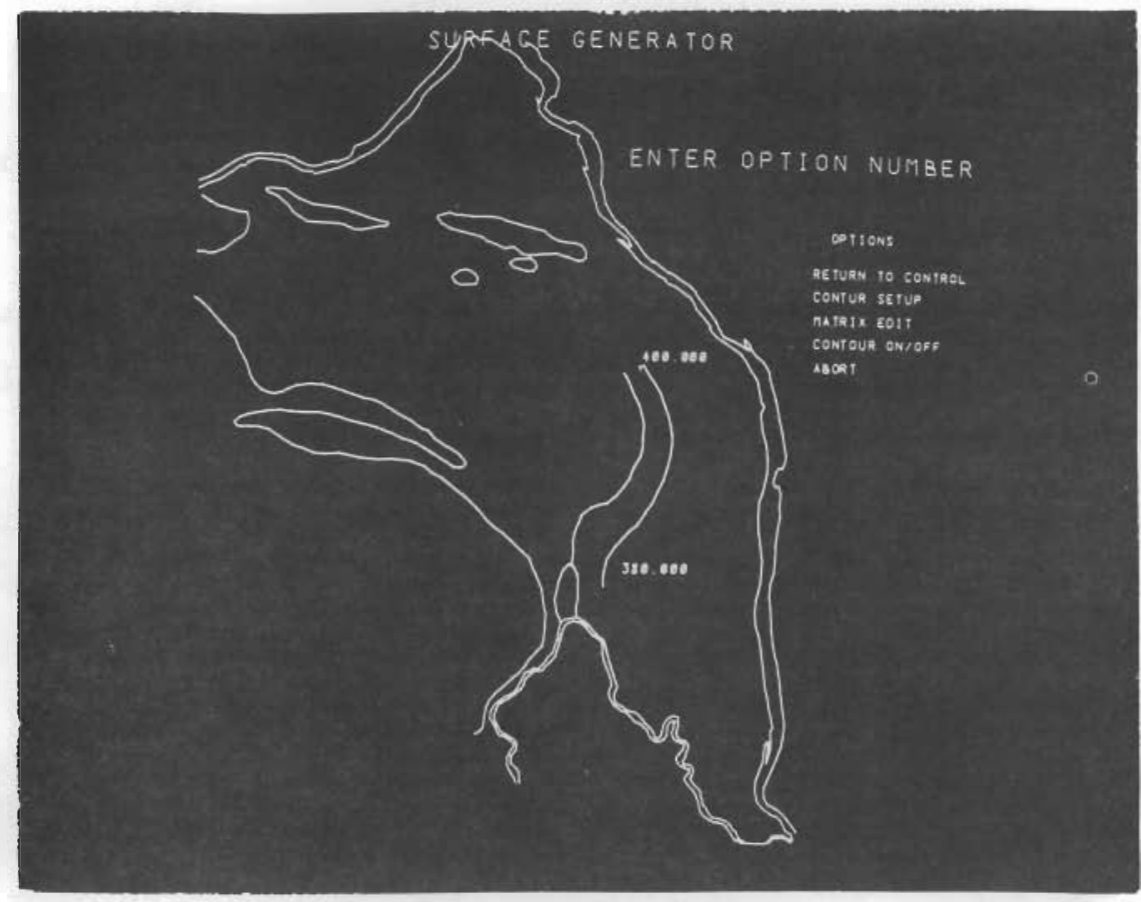

FIGURE 2-13. SURFACE GENERATOR Instruction 5

NOTE: This procedure is used when digitizing lines (either line pairs or saddle regions with more than 2 lines). When digitizing concentric circles the digitizing sequence starts at the center point and radiates outward, as follows:

a) Enter value at center as requested.

b) Digitize center of circle twice.

c) Enter value of next concentric circle.

d) Digitize circle.

e) When the entire circle has been digitized, terminate the sequence by digitizing the start point on the circle.

This entire procedure is described in detail in Reference 2. The exception to the procedure given in this document is that both circular and line contours now use options \#l and \#2 described above.

\section{MATRIX EDITOR Program}

This program allows the user to view a surface matrix as either a horizontal or vertical matrix line cross section. The program has two basic modes of operation, AUTO SCAN and selected LINE mode. 
In the AUTO SCAN mode the program displays each line (horizontal or vertical) of the matrix at a preset time delay, stepping through the matrix until all lines have been scanned.

In the LINE mode the user may select any horizontal or vertical matrix line and display it on the graph, along with the line preceding and the line following.

Figure 2-14 is a display of the MATRIX EDITOR Program and its associated option controls. After an option is selected with the light pen, any input values required are entered on the CRT keyboard.

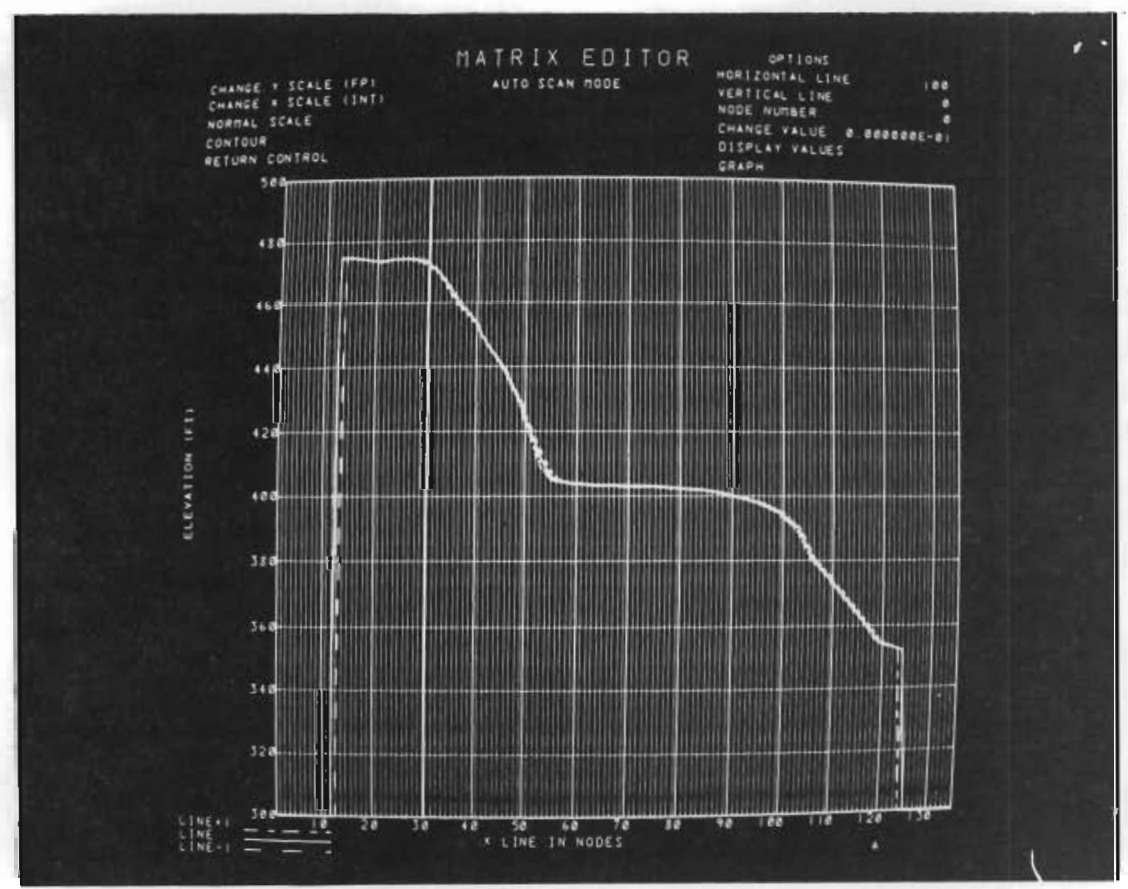

FIGURE 2-14. MATRIX EDITOR Program

The options shown in Figure 2-14 are:

- CHANGE Y SCALE (FP) - The minimum and maximum values of the graph ordinate may be changed to expand the graph for better detail (Figure 2-15). 
- CHANGE X SCALE (INT) - The minimum and maximum values of the graph abscissa may be changed (Figure 2-15).

- normal SCALe

- Changes $X$ and $Y$ scaling back to that originally assigned (Figure 2-14).

- cONTOUR

- Transfers control to the contouring program (Figure 2-5).

- RETURN CONTROL

- Transfers control back to the Special Applications Program (Figure 2-2).

- auto scan mode

- Scans and displays each matrix line as specified. NOTE: Upon selecting this option the matrix line specification will appear.

- HORIZONTAL LINE

- Displays the horizontal line (solid) which has been entered on the CRT keyboard along with the preceding line (dashed) and the following line (center line).

- Vertical line

- Same as above, in the vertical direction.

- NODE NUMBER

- When this option is selected and a node number is entered, the following operations can then be selected for that node.

- CHANGe value

- When this option is selected and a value is entered on the keyboard, the node specified above changes to the new value.

- display values

- The display on the CRT is replaced by that shown in Figure 2-16. This display shows the actual values of five matrix lines with the node of the selected line defined by a small small box in the middle. 

with that shown in Figure 2-14 or 2-15.

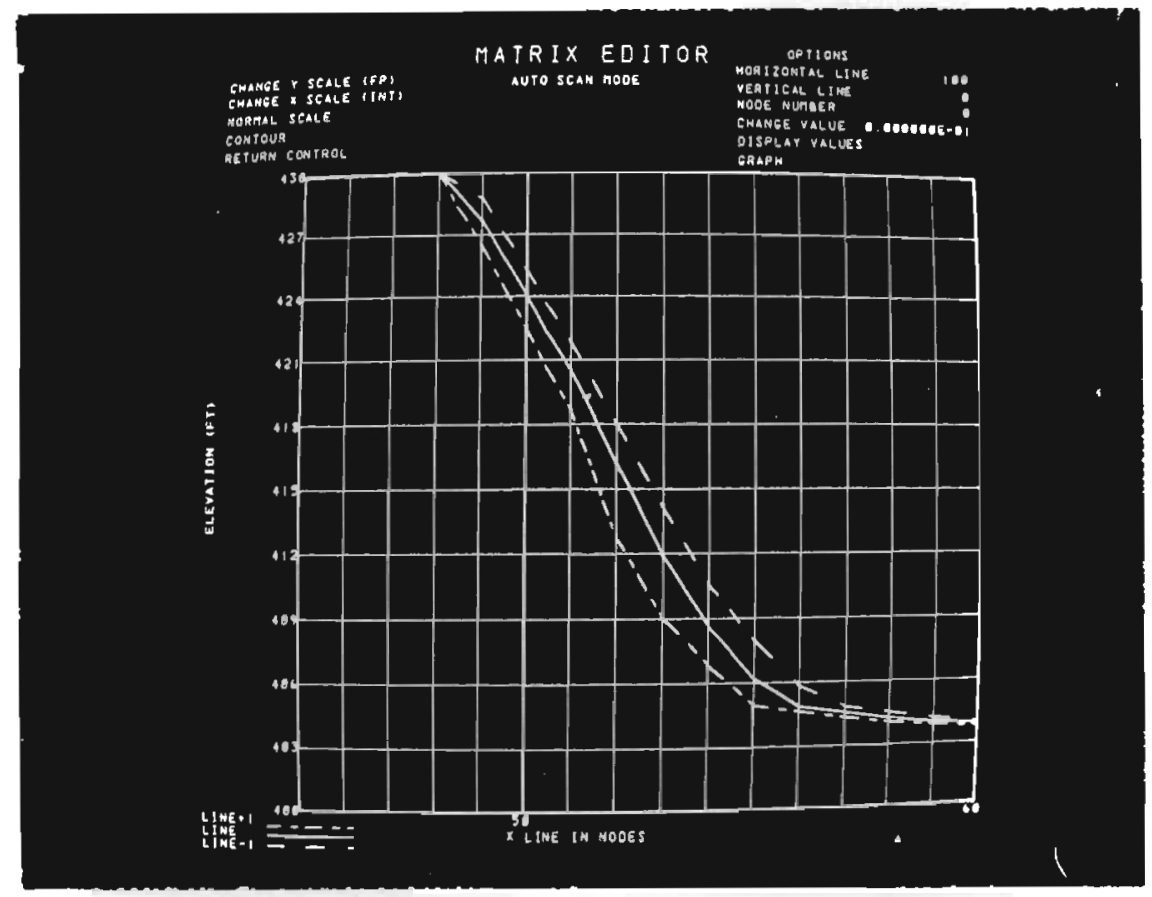

\section{FIGURE 2-15. MATRIX EDITOR (Expanded Scale)}

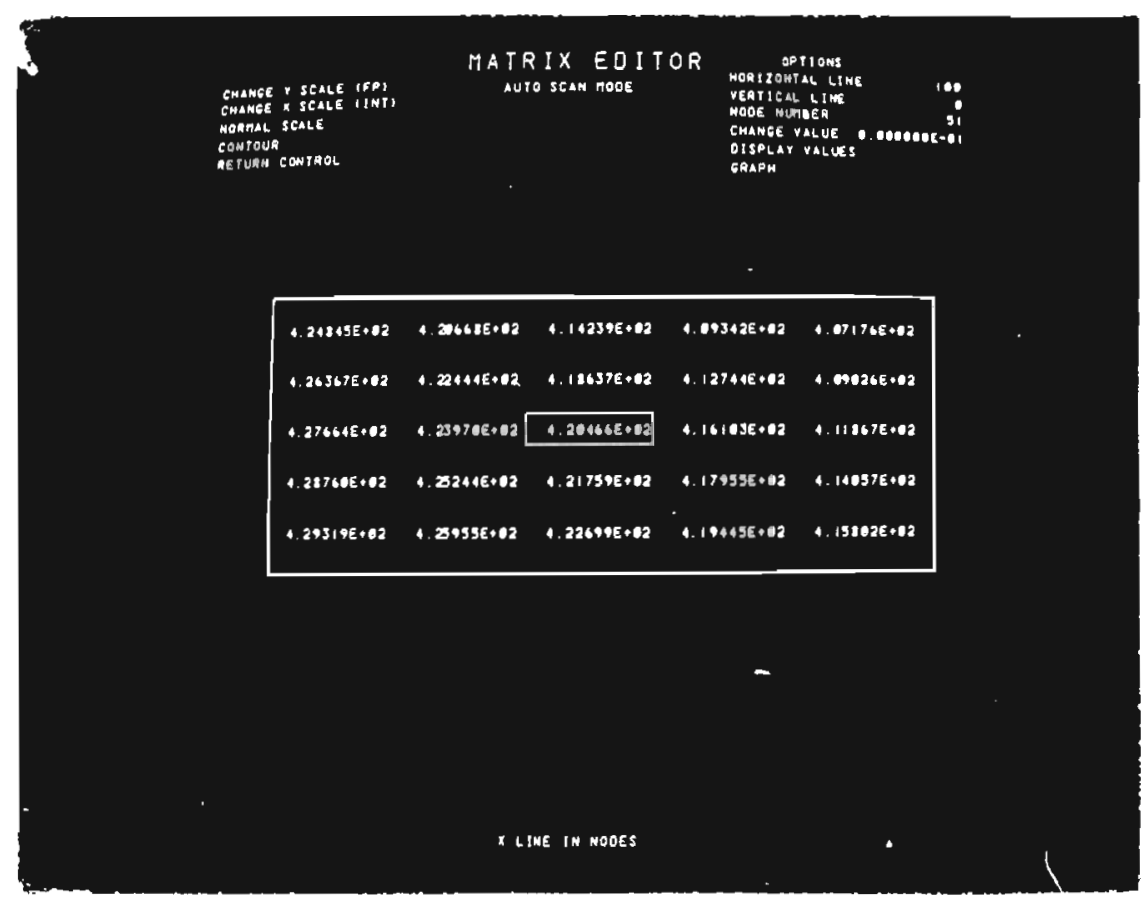

FIGURE 2-16. MATRIX EDITOR 


\section{SURFACE CONTOURING Program}

This program provides a rapid method of displaying any contour level of the surface being operated on. Any level within the range of surface values may be entered on the CRT. Figure 2-17 is a display of the SURFACE CONTOURING Program and associated option controls. When the contour program is requested by the MATRIX EDITOR a labeled horizontal or vertical line will be displayed as shown in Figure 2-17. This depicts the line presently being operated on by the MATRIX EDITOR and the labels depict the nodes along this line.

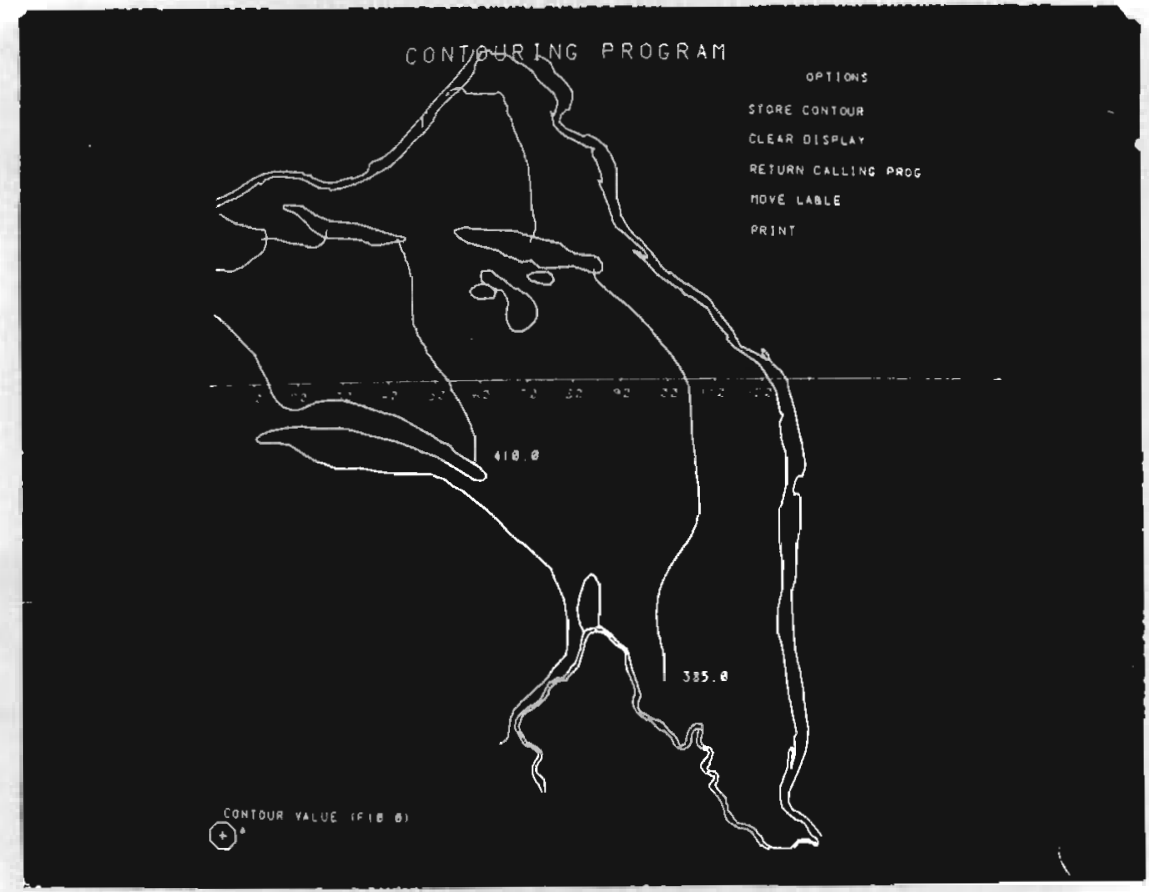

FIGURE 2-17. SURFACE CONTOURING Program

The options shown in Figure 2-17 are:

- STORE CONTOUR

- clear dispiay

- RETURN CALLING
- Store contour just generated for display by the calling program.

- All contours presently displayed will be removed from the screen.

- The sPECIAL FUNCTION Program which was in operation prior to the contouring program will be restored. 
- MOVE LABEL

- PRINT
- Moves label depicting value of the contour to the location of the tracking cross.* This must be done after generation and display of a contour and prior to the generation of another.

- Print the current display on the Info-max Printer/Plotter.

Category II - Calculation Programs

The calculational programs enable the user to calculate the path a particle takes from a preselected input location to a model boundary and its travel time along this path. These models are dependent upon complete CIRMIS interaction and no attempt should be made to bypass this interaction.

These programs require three types of surface data: 1) potential, 2) hydraulic conductivity, and 3) storage coefficient (Figures 2-18 and 2-19).

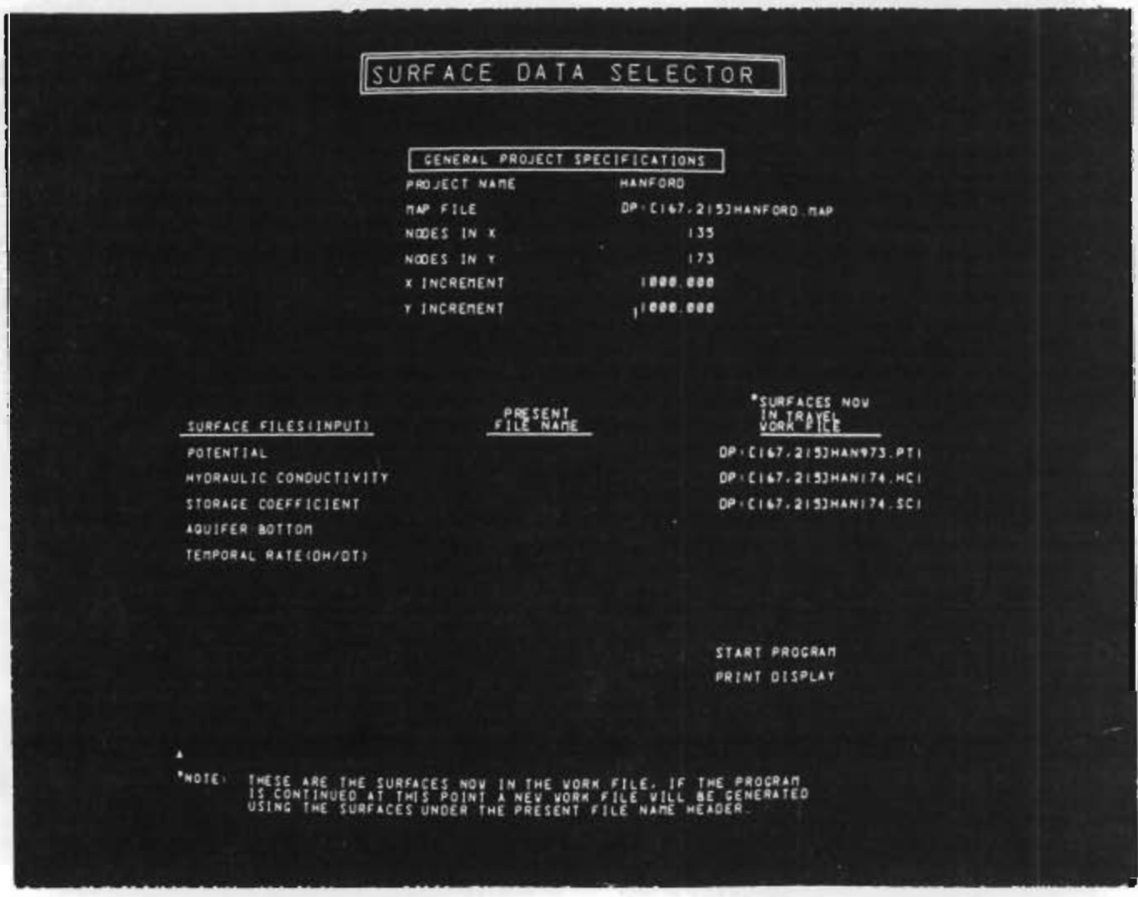

FIGURE 2-18. Surface Data Selector (Example 1)

*The tracking cross is light pen interactive and may be directed to any location on the screen by using the light pen. 


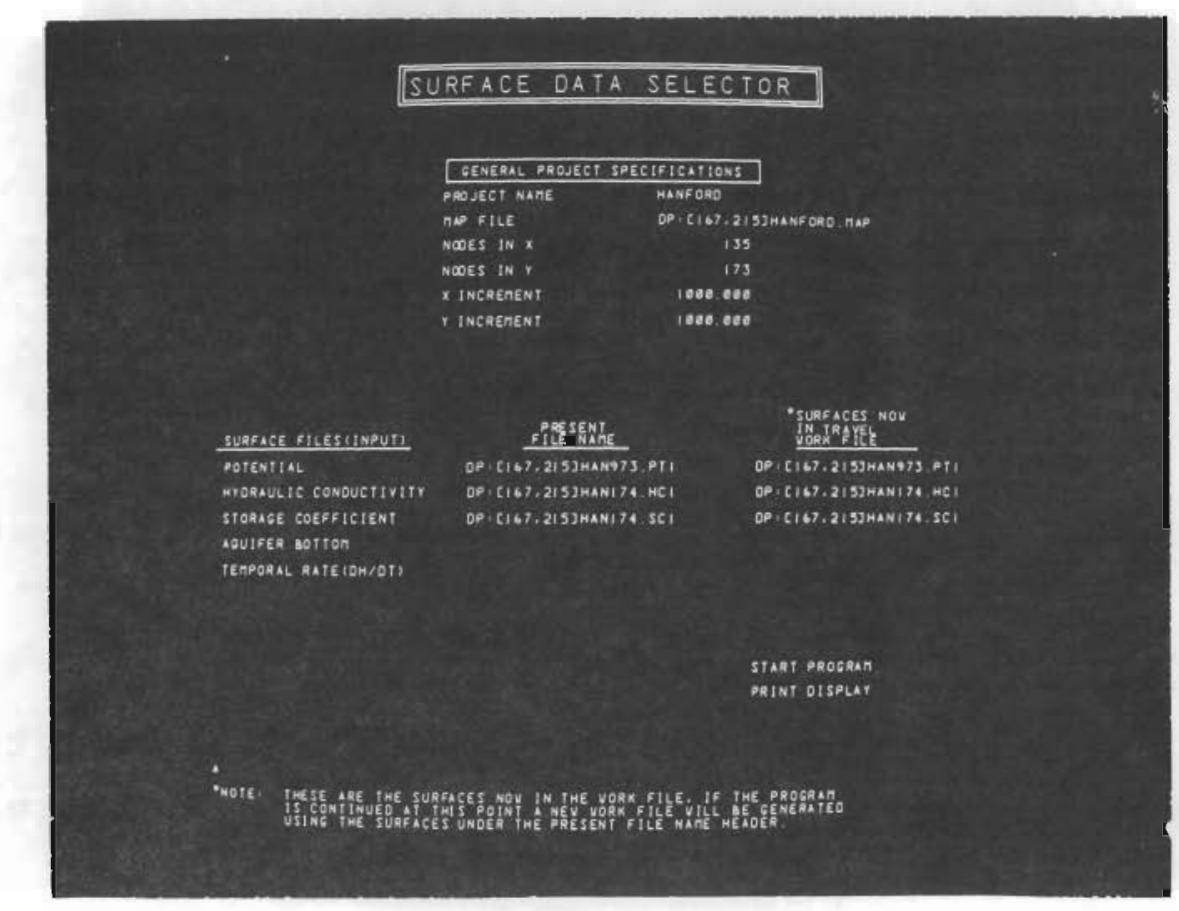

FIGURE 2-19. Surface Data Selector (Example 2)

When the desired program is started, as described under SPECIAL FUNCTION OPTIONS, the surface data selector display will appear (i.e., Figures 2-18 and 2-19). These displays show which files have already been set up in the surface work files at the $11 / 45$ (if any). If a different surface is to be used the desired title under SURFACE FILES (INPUT) is selected and the new name is entered on the CRT keyboard, where the naming convention should match that described in Appendix $B$. When ready to proceed the user selects the START PROGRAM option. If the files do not match those presently in the 11/45 work file, Figure 2-20 appears. This display remains on the screen until a new work file has been generated, after which the selected program will be initialized. 


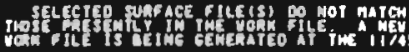

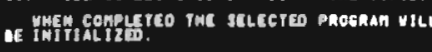

FIGURE 2-20. Surface Data Selector (File Setup Message)

\section{TRAVEL TIME Program}

This program calculates a streamline and time of travel for a steady state condition and displays the results on the CRT screen (Figure 2-21).

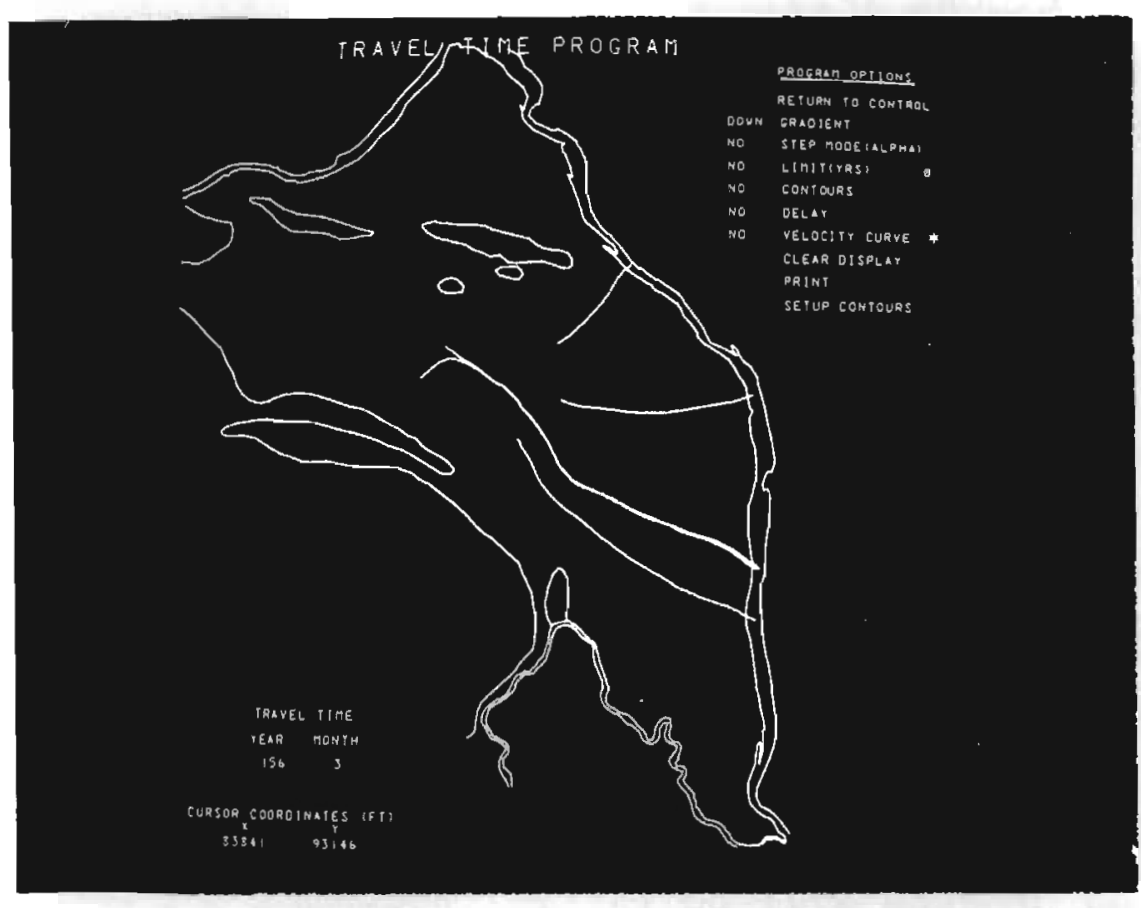

FIGURE 2-21. TRAVEL TIME Program 
This program has several options, all of which are light pen interactive:

- return to CONTROL

- GRADIENT

- STEP NODE (ALPHA)

- LIMIT (YRS)

- CONTOURS

- DELAY

- VELOCITY CURVE

- clear display

- PRINT

- SETUP CONTOURS
- Transfers control back to the Special Applications Program (Figure 2-2) .

- Changes direction of streamline to up or down gradient of the potential surface.

- Causes the streamline to progress one step at a time when the ALPHA key on the CRT keyboard is depressed.

- The streamline terminates when the travel time exceeds the time limit entered on the CRT keyboard.

- Displays contours which have been set up and saved using the contour program.

- Delays each step momentarily so that the streamline progress may be scrutinized more closely.

- When activated, allows the user to observe the velocity along a streamline. This is done by selecting the asterisk to the right of the label. Figure 2-22 will appear.

- Removes all of the streamlines presently being displayed from the screen.

- Outputs the present display to the Info-Max Printer/Plotter.

- Transfers control to the contouring program (Figure 2-5). 


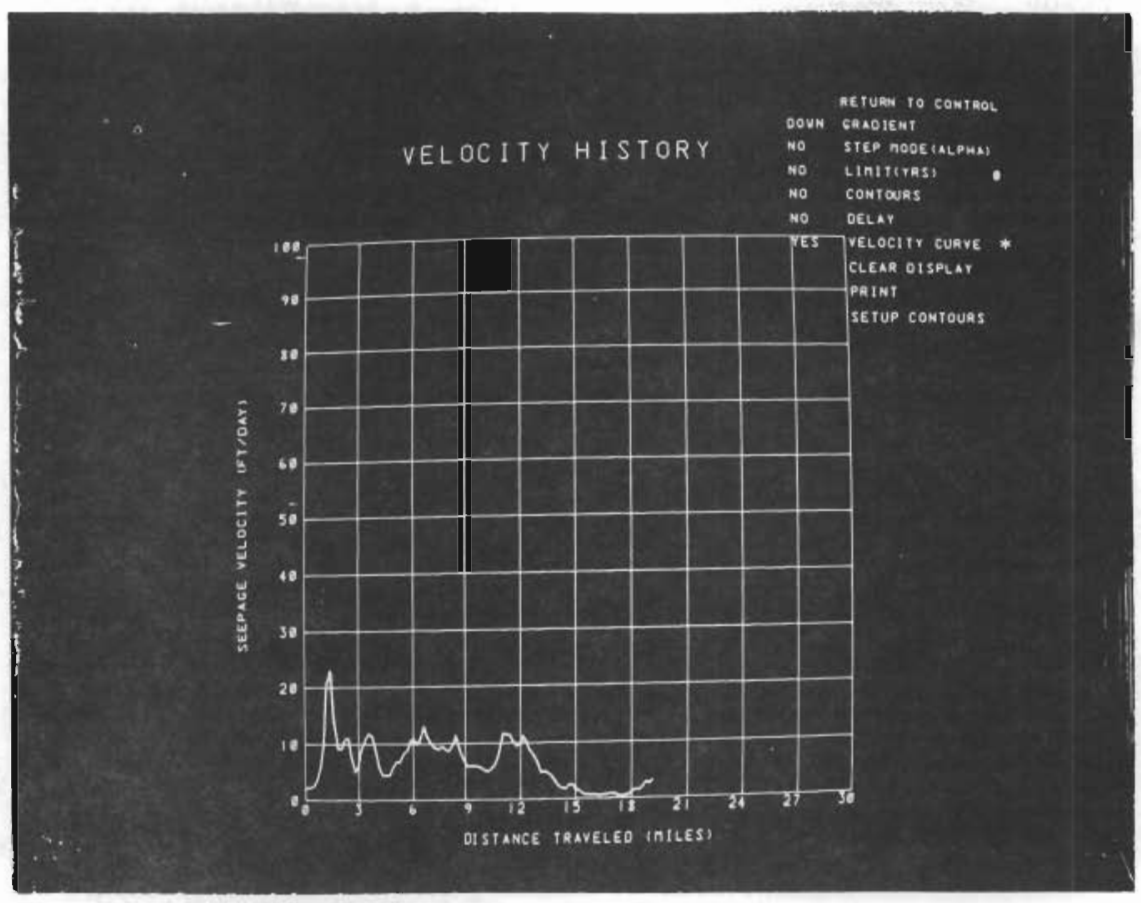

FIGURE 2-22. Travel Time Velocity Curve

\section{PATHLINE Program}

This program calculates a streamline and time of travel for a transient potential surface. This transient behavior is defined by a number of surfaces which have been set up using the VTT Program on the 11/45. Only the name of the first potential surface need be input along with the hydraulic conductivity and storage coefficient (Figures 2-18 and 2-19). The program control options are the same as for TRAVEL TIME, described above. The input specifications are described on pages $2-9$ and 2-10.

\section{Category III - Utility Programs}

This category contains infrequently used functions that provide special capacilities. Some of these are selected from those shown in Figure 2-8. Others are operated from the 11/45. They are described as follows: 


\section{MAP GENERATOR Program}

This program uses the graphic digitizer to digitize map boundaries. These are used with the CIRMIS Special Function programs as background displays or by the $11 / 45$ programs as background maps to be plotted on the calcomp or displayed on the Tektronix scope. The graphic digitizer provides input and the Univac scope provides display and control. The program allows for digitizing of lines depicting a boundary or the input of labels on a map. The MAP GENERATOR Program and associated options are shown in Figure 2-23.

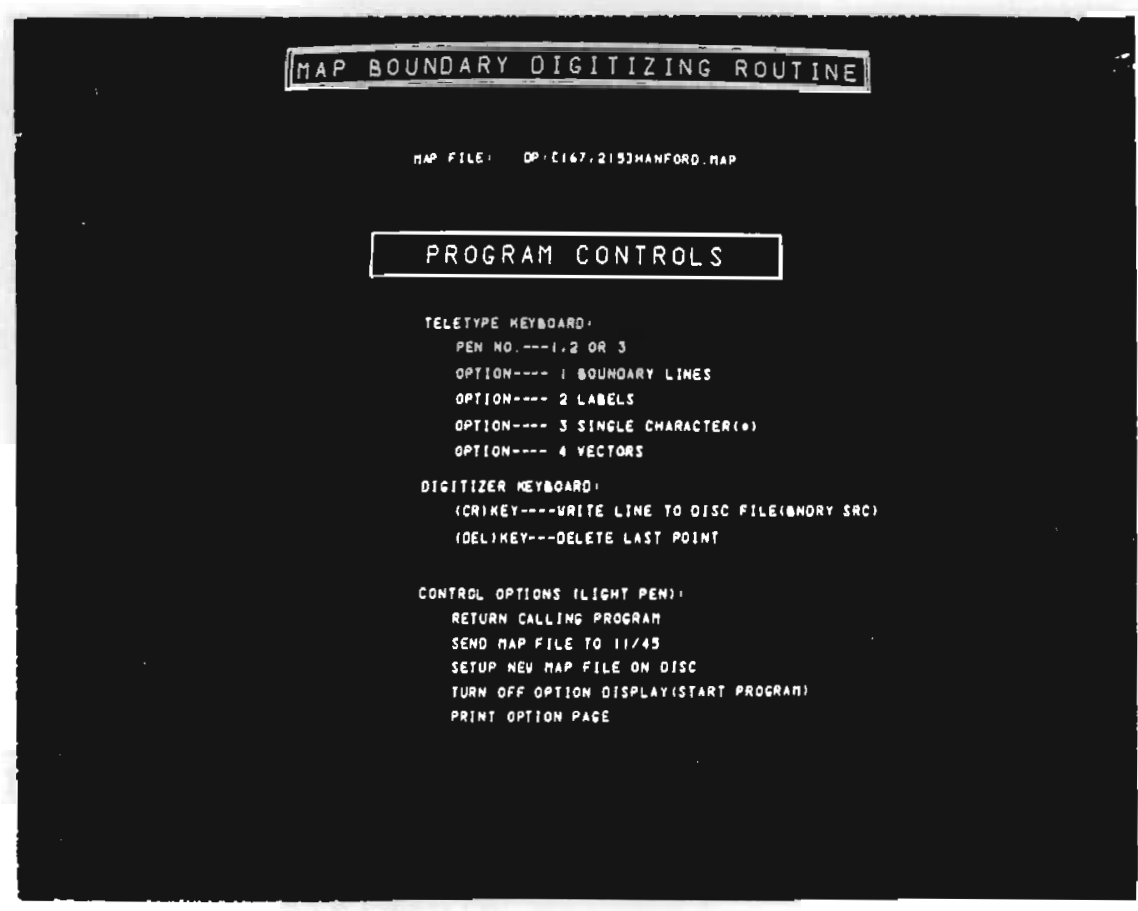

FIGURE 2-23. MAP GENERATOR Program

The three types of controls shown in Figure 2-23 are:

\section{1) TELETYPE KEYBOARD}

Pen number and option are entered on the teletype as requested.

2) DIGITIZER KEYBOARD

The carriage return key (CR) terminates this portion of sequence and writes it out to the disc file. The delete 
key (DEL) allows the user to delete as many points as desired of a digitized line prior to writing it to the disc file.

3) CONTROL OPTIONS (LIGHT PEN)

The options shown under this title are light pen interactive and are described as:

- RETURN CALLING PROGRAM - Transfers control back to the Special Application Program (Figure 2-2).

- SEND MAP FILE TO 11/45 - Use this option only under complete CIRMIS control.

Transfers the new digitized map to $11 / 45$ and enters it in the master project file. See below for bypassing CIRMIS control.

- SET UP NEW MAP FILE ON - Initializes a new map source DISC file (BNDRY SCR) on Disc 1 in preparation for generating a new one.

- TURN OFF OPTION DISPLAY - Turns off option display page in preparation for digitizing a map boundary. After digitizing the minimum (bottom) left) and maximum (top right) corners of the map the digitizing sequence may begin.

- PRINT OPTION PAGE - Not active.

Following is a brief description of the sequence used in map generation:

Select: SETUP NEW MAP FILE ON DISC 
Then

\section{Select: TURN OFF OPTION DISPLAY}

The present display will be replaced by one asking the user to digitize the MINIMUM (bottom left), then the MAXIMUM (top right) on the map to be digitized. When this has been completed, the following message will be output to the teletype:

INPUT PEN NO. \& OPTION, THEN DIGITIZE POINTS(2I1)*

After the user inputs the pen number and option the following light pen interactive message will appear on the screen:

\section{DISPLAY PROGRAM CONTROLS}

This will return the program to the control page (Figure 2-23) when the user desires to terminate the sequence. If he elects to continue generating a boundary he digitizes the line (or types a label on the teletype as requested) and writes it to disc with a (CR) on the digitizer keyboard. The INPUT PEN NO. \& OPTION message will again be typed and he may again continue or terminate and return to the control option. If the user wishes to terminate he selects the DISPLAY PROGRAM CONTROLS with the light pen and Figure 2-23 again appears.

Sending the Map File to the 11/45. The user has two options for doing this: 1) complete CIRMIS control, or 2) bypassing CIRMIS control. These are described as follows:

\section{CIRMIS Control}

The user selects

SEND MAP FILE TO $11 / 45$

When this has been completed program control will return to Special Applications (Figure 2-2).

*NOTE: Always do label options last so they will be stored at the end of the file. 


\section{Bypass CIRMIS Control}

The user selects

RETURN CALLING PROGRAM

Figure 2-2 will appear:

Control $\mathrm{C}(\uparrow C)$

PIP - now transfer file to $11 / 45$

$>\mathrm{T}$ DL $\leftarrow$ DKI BNDRY SCR (CR)

Go to $11 / 45$ :

MCR > HEL [UIC]

MCR > PIP-receive file from PDP-9

$>$ MAPNAME. EXT $=$ DL:

Now use PIP to strip labels off end of file and place them in the command file. The boundary map is now ready for use with the CONTUR or BLOWUP programs.

\section{BYPASS CIRMIS CONTROL Program}

This function provides the capability to bypass complete CIRMIS control, thereby adding flexibility to map boundary and surface file generation and use. As mentioned before, using complete CIRMIS control presupposes that the user has a specific project, along with associated maps and surface files, already in the 11/45 master data files or plans to set one up. However, this may not be the case. A user may only require a map boundary or surface file and may not be interested in the capabilities provided by the complete CIRMIS file structure. If this is the case and either a map or surface is required, this program must be called from the SPECIAL APPLICATIONS Program (Figures 2-2 and 2-8) prior to any further operations. Once this program has been started the display shown in Figure 2-24 will appear. 


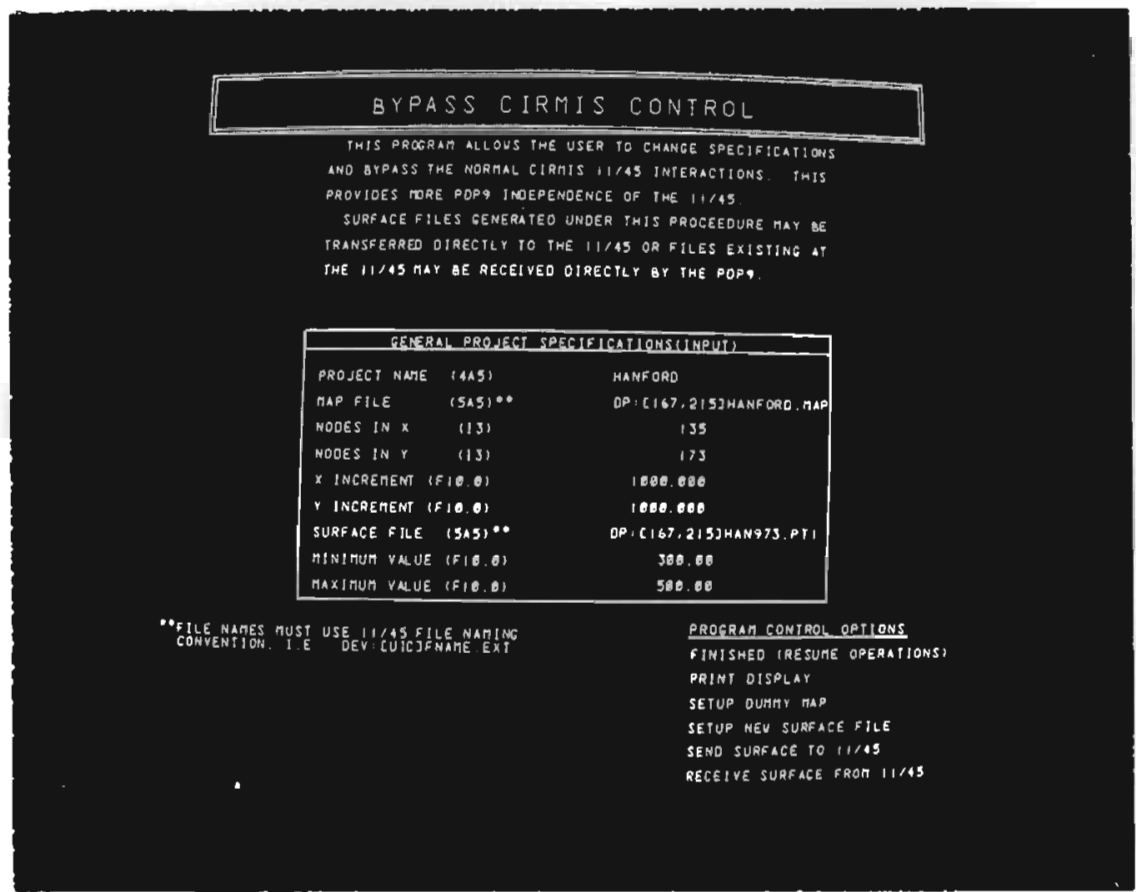

FIGURE 2-24. BYPASS CIRMIS CONTROL Program

The GENERAL PROJECT SPECIFICATIONS shown in Figure 2-24 are light pen interactive and the values are input on the CRT keyboard. They are:

- PROJECT NAME (4A5)

- MAP NAME (4A5)

- NODES IN X (I3)

- NODES IN Y (I3)

- $\mathrm{X}$ INCREMENT (F10.0)

- $Y$ INCREMENT (FI0.0)

- SURFACE file (5A5)
- Optional: the user may wish to enter a project name for his own reference.

- Optional: the user may wish to enter a map name for his own reference.

- Number of nodes in the $\mathrm{x}$ direction (fence posts, not spaces).

- Number of nodes in the $\mathrm{Y}$ direction

- Map units per node in X direction.

- Map units per node in $Y$ direction.

- If the user is to transfer a surface file to or from the 11/45, the convention shown by the 
example in Figure 2-24 (i.e.,

UNIT: [UIC] NAME.EXT) must be

used.

- Minimum VAlue (F10.0)

- Minimum value or less expected to appear on surface being used.

- maximum VAlue (F10.0)

- Maximum value or greater expected to appear on surface being used.

The PROGRAM CONTROL OPTIONS shown in Figure 2-24 are light pen interactive and are:

- FINISHED (RESUME OPERATIONS)

- PRINT DISPLAY

- SETUP DUMMY MAP

- SETUP NEW SURFACE FILE

- SEND SURFACE TO $11 / 45$
- Return control to the Special Applications Program (Figure 2-2) .

- The present display will be output to the Info-Max Printer/Plotter.

- Sets up a rectangular background display. This must be done if a background map is not available or if one is not to be set up using the Map Generator Program.

- This must be done if a new surface is to be digitized using the Surface Generator Program.

- The surface presently being operated on will be transferred to the $11 / 45$ under the device, UIC, and name specified by the SURFACE NAME and using the other parameters shown under GENERAL PROJECT SPECIFICATIONS.

- RECEIVE SURFACE FROM $11 / 45$
- Transfers the surface that has been specified under GENERAL PROJECT SPECIFICATIONS to the PDP-9. 


\section{UPDATE Program}

This program is operated on the PDP-11/45 and is used to bypass CIRMIS control in updating the entries in the master file header. Normally entries are placed in the PDP-11/45 master file header using PDP-9 CIRMIS control; however, the user may wish to insert or delete projects and/or associated map or surface files directly. This can be done with the UPDATE program and the modified master file header can be accessed by the PDP-9 CIRMIS control as if it were originally set up using the special Application and Manipulation functions described in this manual.

This program can also be used to obtain only a listing of all projects and associated specifications contained in the master file header. Appendix $C$ is such a listing.

Use the following procedures for operation of the UPDATE program:

MCR > HEL $[167,215]$

MCR > RUN UPDATE

The UPDATE Program will now output a series of questions to the user's terminal. These questions are self explanatory and by answering them the user may make the desired modifications in the file.

If a new surface or map file name is inserted into the directory the standard 11/45 file naming convention must be used as described in Appendix B. In addition, the actual data file must exist as specified in this input name. 
.

. 


\subsection{MODEL INPUT SEQUENCING}

This section describes the procedures involved in setting up of input parameters and control of Major Predictive Models controlled by the CIRMIS system.

Due to the size of these models and the large amounts of data required, they are run on a $\mathrm{PDP}-11 / 45$ computer with large mass storage capabilities. Control of these programs is provided through the use of a smaller computer with visual interactive capabilities.

\section{MONTR9}

Figure 3-1 shows the first display page of the monitor. Various options of the CIRMIS system are shown under the title SELECT A FUNCTIONAL CATEGORY.

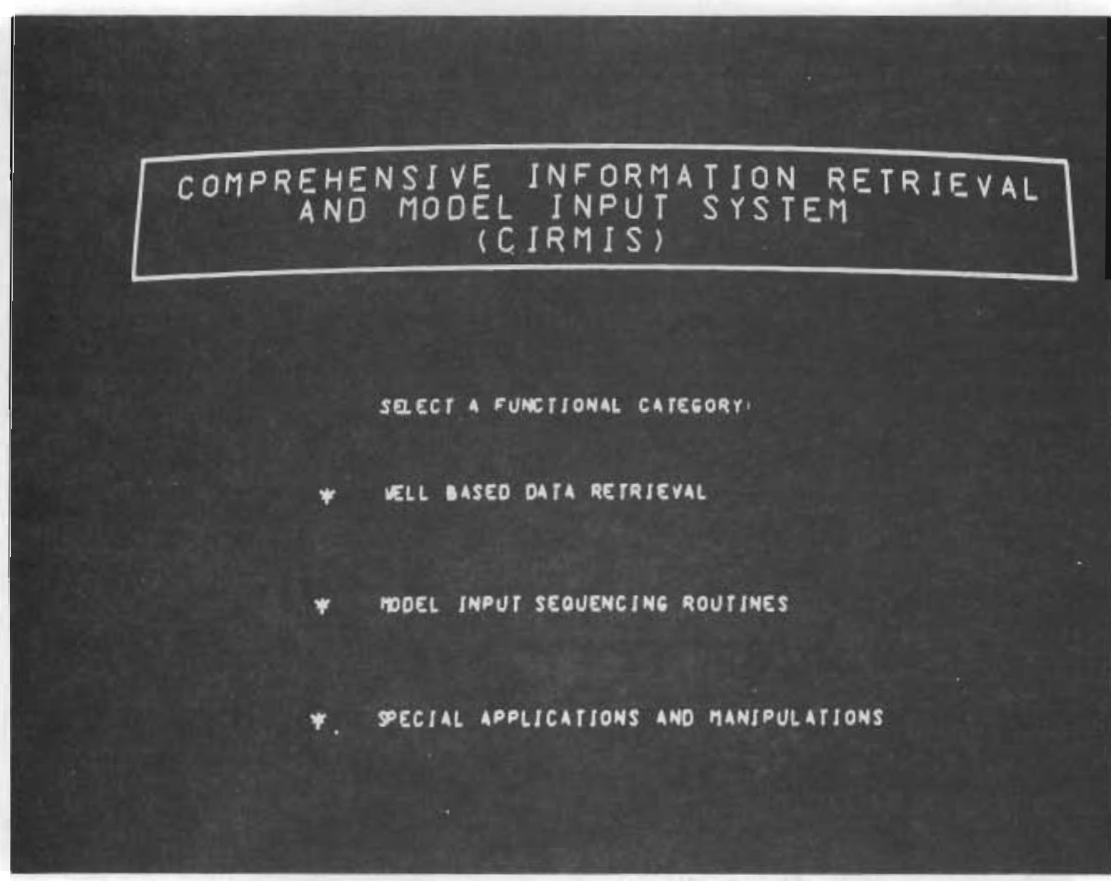

FIGURE 3-1. CIRMIS Monitor Control Page 


\section{CIRMIS STARTUP PROCEDURES}

This portion of the CIRMIS system controls model operations at the $11 / 45$ computer.

To begin operation, the user must follow the loading sequence described in Appendix A. Once this has been accomplished and the display shown in Figure 3-1 appears the user can begin operation as described below.

\section{ABBREVIATED OPERATING SEQUENCE}

- To begin operation of this portion of the CIRMIS system the user selects the option MODEL INPUT SEQUENCING ROUTINES shown in Figure 3-1. The present display page is replaced by that shown in Figure 3-2. Figure 3-2 shows the models available to the user and the general project specifications presently being used.

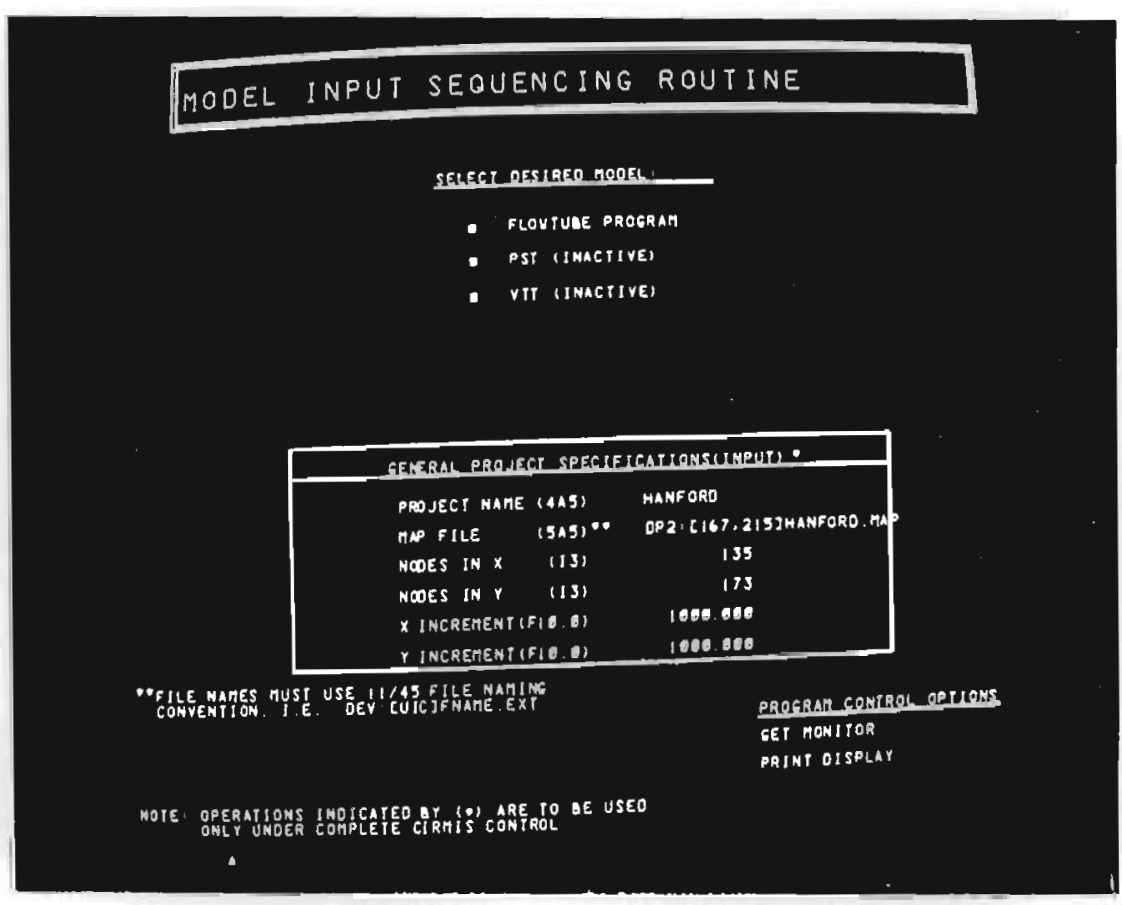

FIGURE 3-2. Model Input Sequencing Routine 
- The user then selects the proper specifications (under GENERAL PROJECT SPECIFICATIONS) with the light pen and inputs the desired value on the CRT keyboard (see Appendix $C$ for projects and specifications).

- The user then makes a selection under the title SELECT DESIRED MODEL and the display is replaced by a display correlated with the MODEL (Figure 3-3).

- If required, the user selects the model specification(s) with the light pen and inputs the desired value on the CRT keyboard.

- The user then selects the START PROGRAM option.

- CIRMIS now queries the 11/45; if all general project specifications are correct, the program initializes the proper model controller.

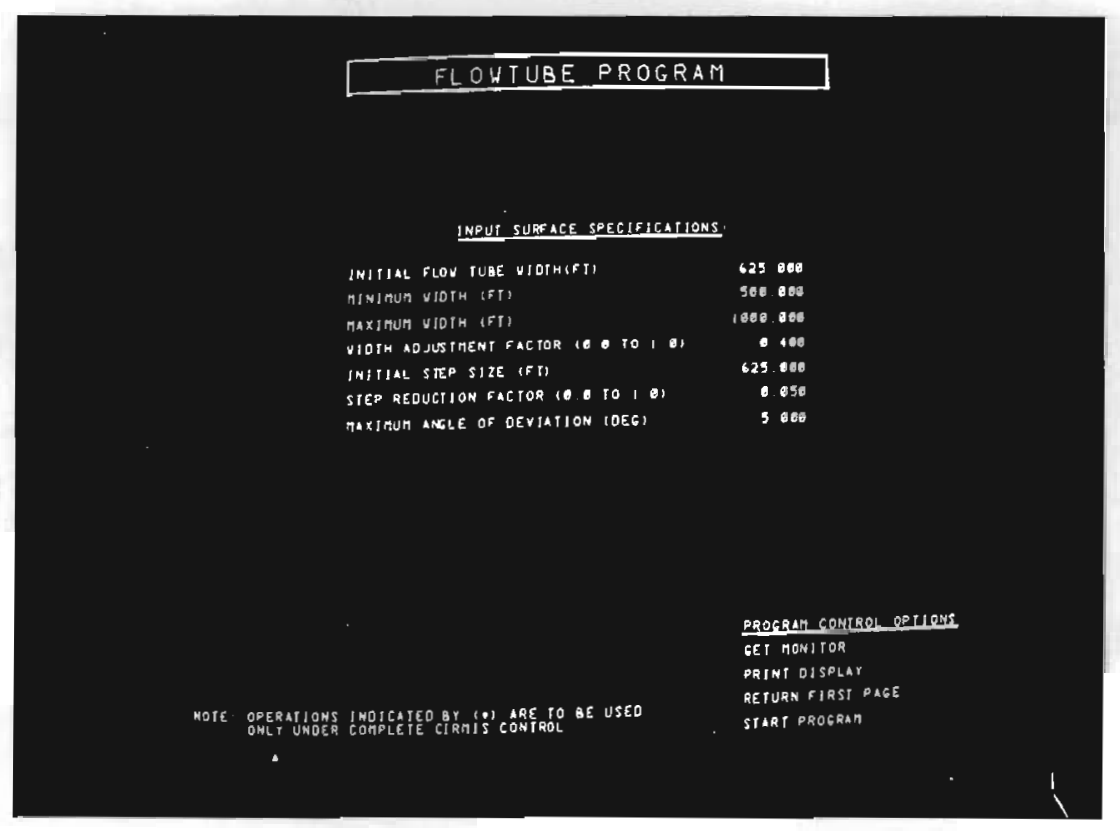

FIGURE 3-3. Preliminary Flowtube Specifications 
DETAILED OPERATING SEQUENCE

Model Input Sequence Routine (Fiqure 3-2)

This routine has three categories which are described as follows:

1. SELECT DESIRED MODEL - at this time only the FLOWTUBE model can be selected. When selected the current display page is replaced by that shown in Figure 3-3 (see MODEL SPECIFICATIONS PAGE).

2. GENERAL PROJECT SPECIFICATIONS (INPUT) - is used only under complete CIRMIS control. This category is light pen interactive and values are input on the CRT keyboard.

- PROJECT NAME (4A5) - Each project has a descriptive name (see Appendix C).

- MAP FILE (545) - Map file to be used as background display must be entered in standard $11 / 45$ naming convention (see Appendix B). Up to twelve (12) maps are allowed.

- NODES IN X (I3) - Number of nodes in the $\mathrm{X}$ direction (fence posts, not spaces).

- NODES IN Y (I3) - Number of nodes in the Y direction.

- $\mathrm{X}$ INCREMENT (FI0.0) - Map units per node in the $\mathrm{X}$ direction.

- $Y$ INCREMENT (F10.0) - Map units per node in the Y direction.

3. PROGRAM CONTROL OPTIONS

- GET MONITOR - When selected, returns control to the monitor (Figure 3-1).

- PRINT DISPLAY - Prints present display on the Info-max Printer/Plotter. 
Model Specification Page - Program Control Options (Figure 3-3)

The control options for this display page are light pen interactive and are described as:

PROGRAM CONTROL OPTIONS

- GET MONITOR - Described above.

- PRINT DISPLAY - Described above.

- RETURN FIRST PAGE - Replaces present display with that shown in Figure $3-2$.

- START PROGRAM - The selected Model is initialized. Note: The $11 / 45$ project file header is monitored to see if input specifications match selected project.

Model Specification Page - Model Input Specifications (Figure 3-3)

Each Model may require a unique set of input parameters. This category is light pen interactive and values are input on the CRT keyboard. Following is a description of these parameters. Flowtube (Figure 3-3)

- INITIAL FLOW TUBE WIDTh (FT) - 625.00

- MINIMUM WIDTH (FT) - 500.00

- MAXIMUM WIDTH (FT) - 1000.00

- WIDTH ADJUSTMENT FACTOR - 0.40

- INITIAL STEP SIZE (FT) - 625.00

- STEP REDUCTION FACTOR - 0.05

- MAXIMUM ANGLE OF DEVIATION (DEG) - 5.00

Once the Flowtube specifications have been entered the user selects the START PROGRAM option and the present display will be replaced with that shown in Figure 3-4. 


\section{OPERATING THE PREDICTIVE MODELS}

FLOWTUBE (Transmissivity Iterative Routine)

This program is designed to use mathematical modeling in conjunction with field data to deduce a hydraulic conductivity distribution and is described in detail in Reference 3.

Figure 3-4 shows the surface files already set up in the work file at the $11 / 45$ (if any). If a different surface is to be used the desired title under SURFACE FILES (INPUT) is selected and the new name is entered on the CRT keyboard, where the naming convention should match that described in Appendix B.

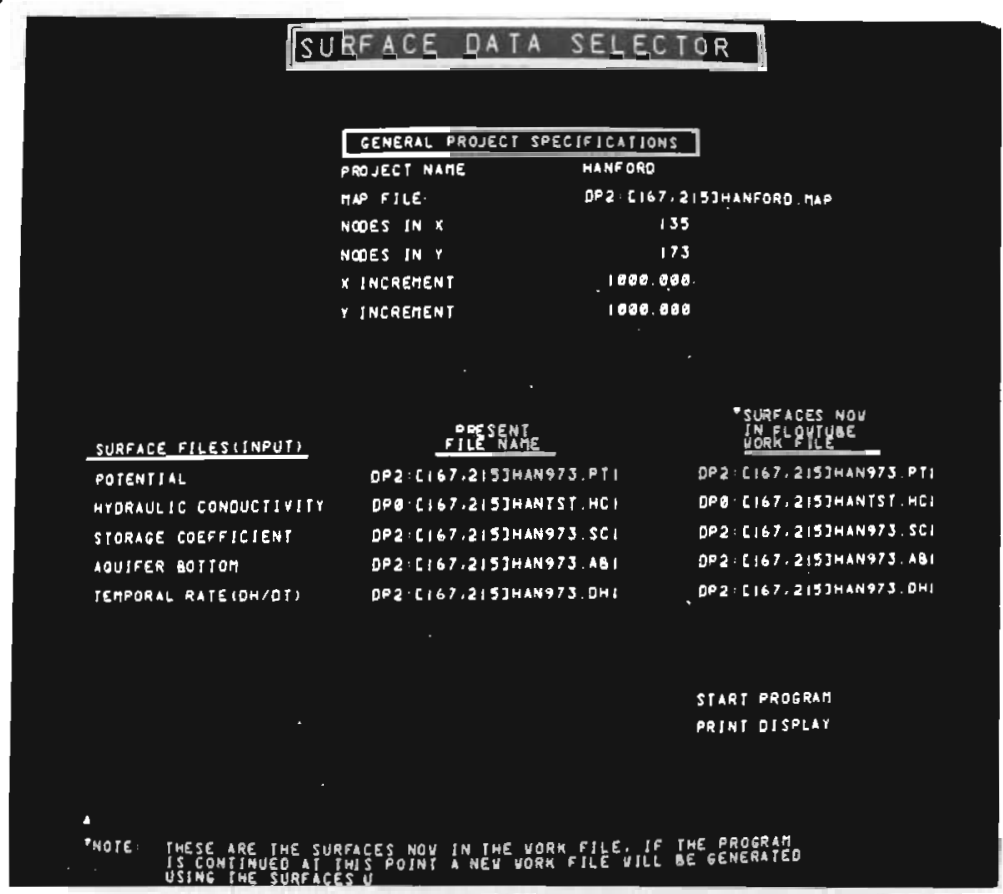

FIGURE 3-4. Surface Data Selector

The Flowtube Model requires all five types of surface data for operation. When ready to proceed the user selects the START PROGRAM option. If the files do not match those presently in the $11 / 45$ work file, Figure 3-5 appears. 
TLOSE ORE TED SURF ACE FILEIS) DO NOT MATCH YORK FILE IS BEING GENERATED AT THE IIIHS. YHEN COMPLETED THE SELECTED PROGRAM VILL

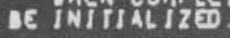

\section{FIGURE 3-5. Surface Data Selector (File Setup Message)}

Figure 3-5 remains on the screen until a new work file has been generated, after which the Flowtube program will be initialized (Figure 3-6).

Flowtube provides the user with the capability to generate flowtubes from input starting positions and hydraulic conductivity values and display the results on the CRT screen.

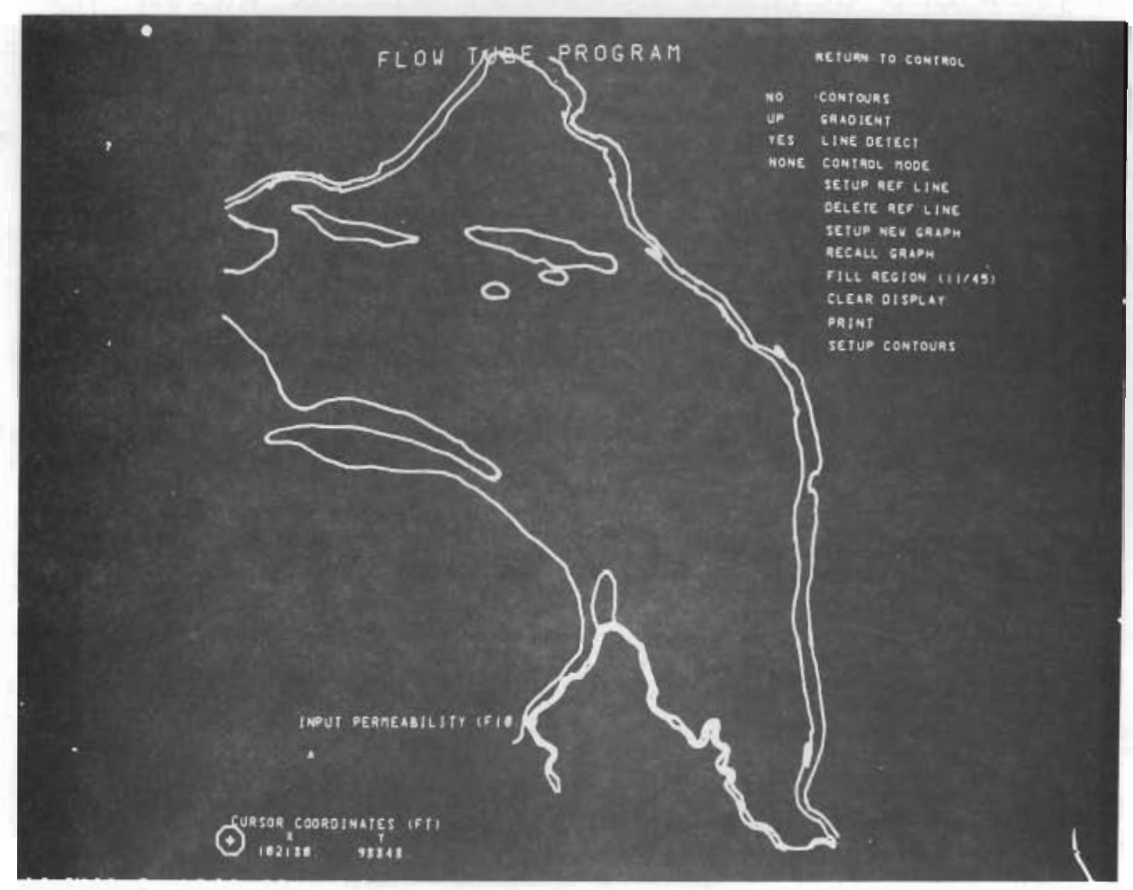

FIGURE 3-6. Initial Flowtube Display 
The technique employed here to obtain a hydraulic conductivity distribution is based on numerical integration of the Boussinesq equation along instantaneous streamtubes of flow using a measured water table potential surface and solving for the conductivity. Since advantage is taken of the convergence properties of the streamtubes toward infiltration sites and channels of high transmissivity, only a small number of fieldmeasured conductivities is required to obtain the entire distribution. Because it is not possible to use the same technique to obtain a storage coefficient distribution, it is necessary to either assume that it is constant or construct a distribution from available point measurements. The method, as used in the application to the Hanford unconfined aquifer, is very subjective and allows the hydrologist to use his knowledge on the hydrology of the aquifer in determining the hydraulic conductivity distribution.

\section{FLOWTUBE Options}

This program has several options, all of which are light pen interactive:

- RETURn to CONTROL - Transfers control back to the MODEL INPUT SEQUENCING PROGRAM. (Figure 3-2)

- GRADIENT - Changes direction of Flowtube to up or down gradient of the potential surface.

- LINE DETECT - When YES stops flowtubes at a reference line.

- CONTROL MODE - Has three options for use with Tracking Cross.

None: Normal control

Lines: Displays horizontal and vertical lines through center of T.C. for positionery purposes Box: Sets corners of region to be calculated 
- SETUP REF LINE - Selected twice for first and last points defining a reference line according to position of Tracking Cross.

- DELETE REF LINE - Removes reference line from screen.

- SETUP NEW GRAPH - Stores all flowtubes presently intersecting reference lines and replaces the present display with a new graph.

- RECALL GRAPH - Recalls a graph which has previously been set up.

- FILL REGION (1I/45) - Begins calculating hydraulic conductivity values using the present reference curve and defined box.

- clear Display - Removes all of the streamlines presently being displayed from the screen.

- PRINT - Outputs the present display to the Info-Max Printer/Plotter.

- SETUP CONTOURS - Transfers control to the contouring program.

\section{Detailed Operating Sequence-FLOWTUBE}

The techniques employed by the TIR method are to use wells at which field measured hydraulic conductivity values are available and to observe the flowtubes from these wells in order to establish reference lines at areas of convergence. Flowtubes from all of the wells with known conductivity which intersect an individual reference line are then calculated to establish a curve on this reference line. Once this curve has been established, the actual hydraulic conductivities at individual nodes can be calculated. 
To do this, the following steps are taken:

- Set LINE DETECT to NO;

- DELETE REFERENCE LINE;

- Select two wells which define the outer portions of an envelope of convergence and display the flowtubes on the screen by entering conductivity values on CRT keyboard then digitizing the well location on map (Figure 3-7);

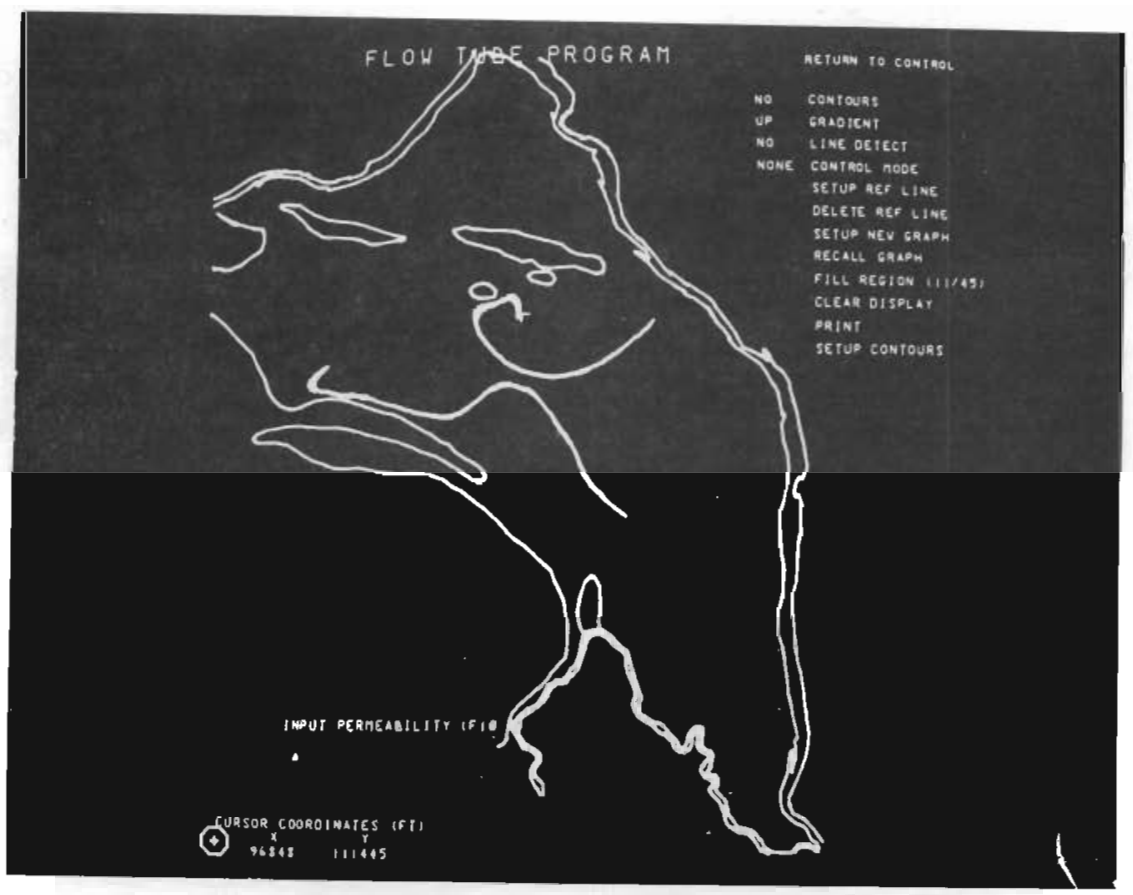

FIGURE 3-7. Determining Area of Flowtube Convergence

- Set up a reference line at some point orthogonal to these flowtubes by using the tracking cross to position the first desired line point then activating the SETUP REF LINE option. Move the tracking cross to the second desired location of the line and once again activate the SETUP REF LINE option (Figure 3-8); 


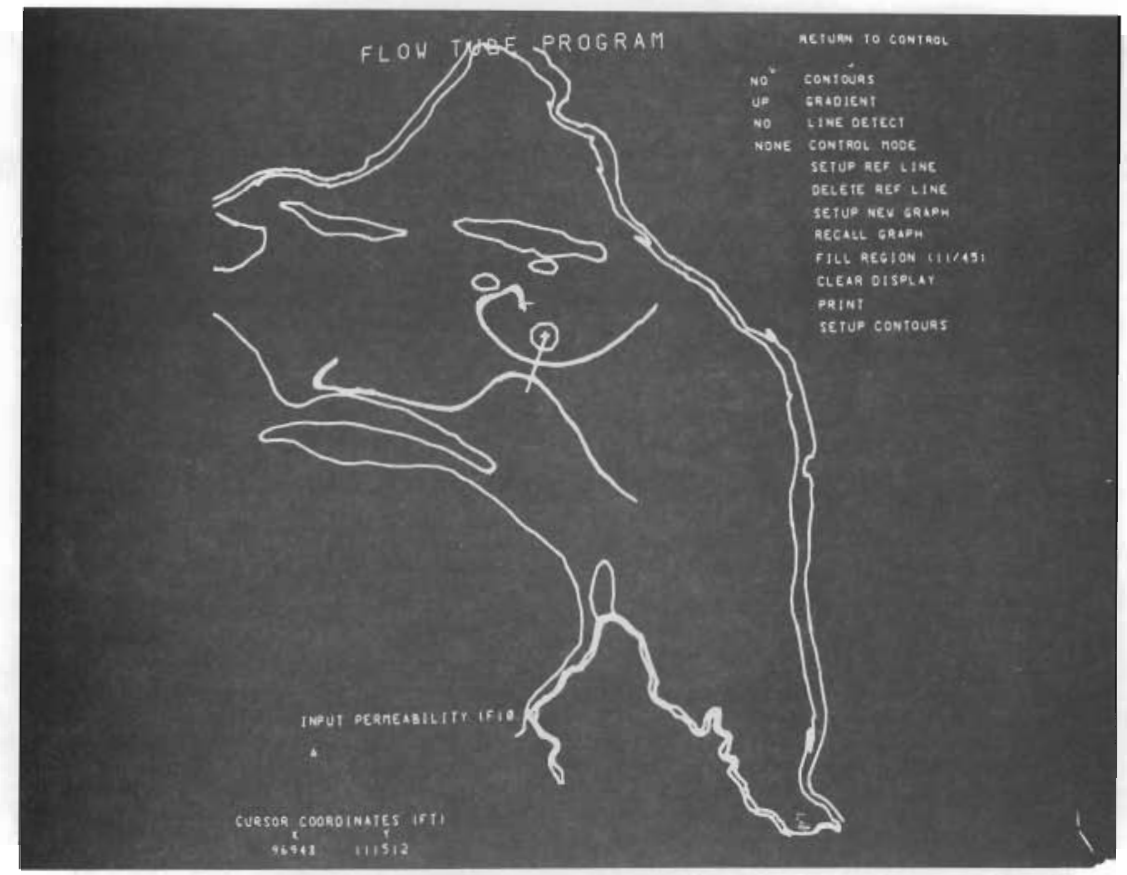

FIGURE 3-8. Setting up Reference Line

- clear Display - the flowtubes will disappear (Figure 3-9);

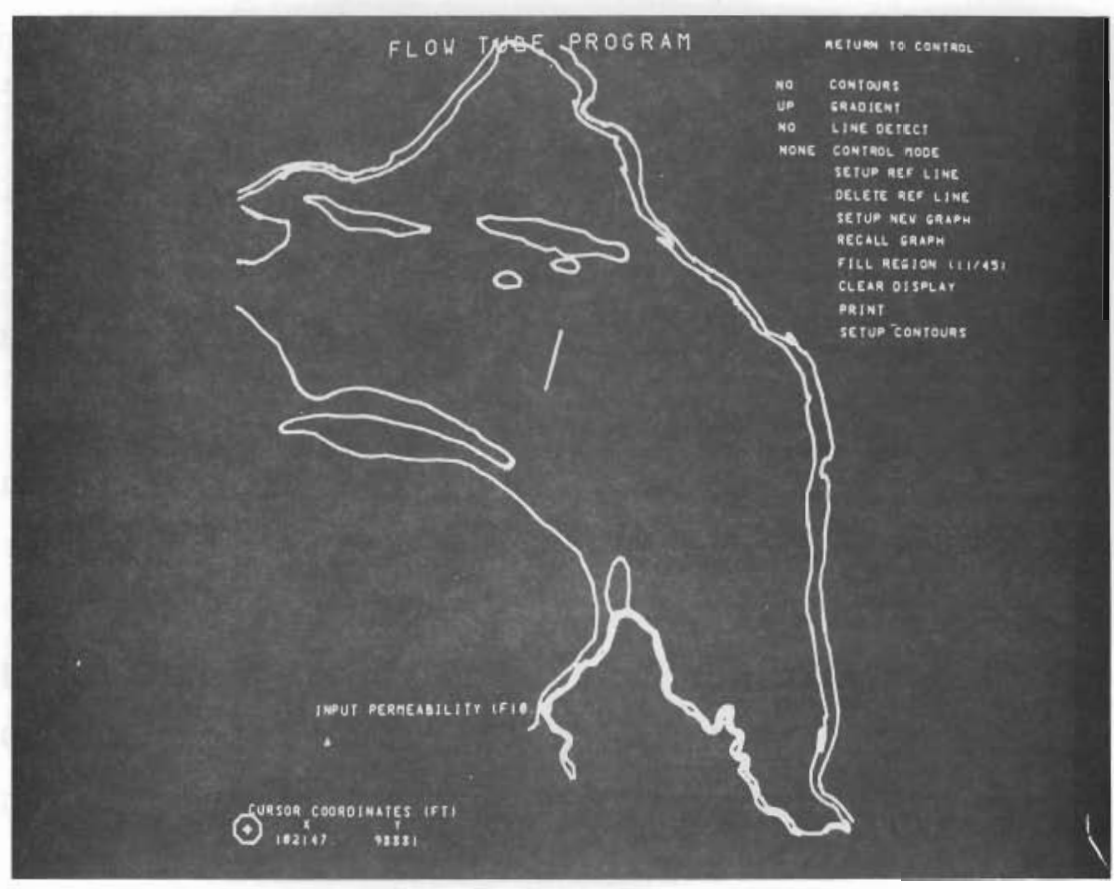

FIGURE 3-9. Selected Reference Line 
- Set LINE DETECT to YES;

- Begin generating flowtubes from the wells within the envelope with known hydraulic conductivities. The flowtubes will stop at the reference line (Figure 3-10);

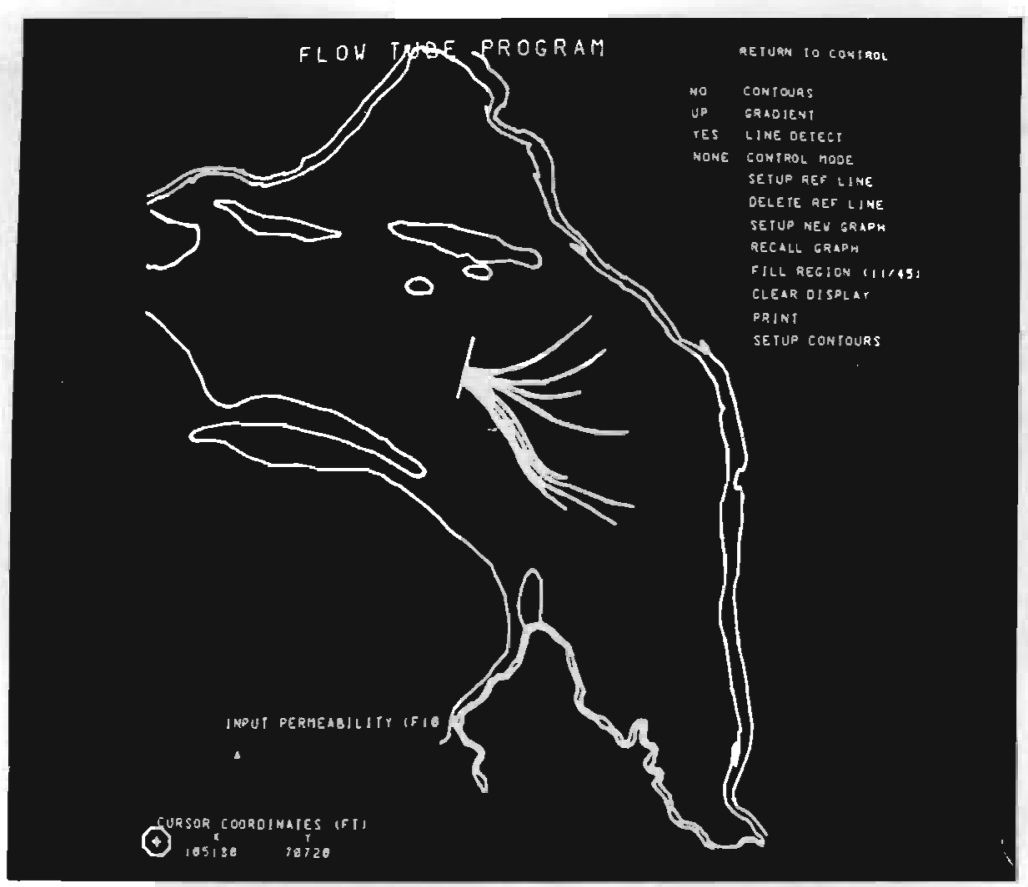

FIGURE 3-10. Flowtube from selected Wells Intersecting Reference Line

- When all of these flowtubes have been generated, select the SETUP NEW GRAPH option;

- The present display is replaced by that shown in Figure 3-11;

- The user then analyzes the data on the graph and then draws a curve through which he feels best describes the hydraulic conductivity distribution along the reference line. This is done by positioning the large tracking cross near to the left border of the graph where the start of the curve will begin. The DRAW LINE option is then selected and the large tracking cross will be replaced by a smaller one which is then used to draw the desired curve; 
- The user should become familiar with the Permeability graph options described on Page 3-16

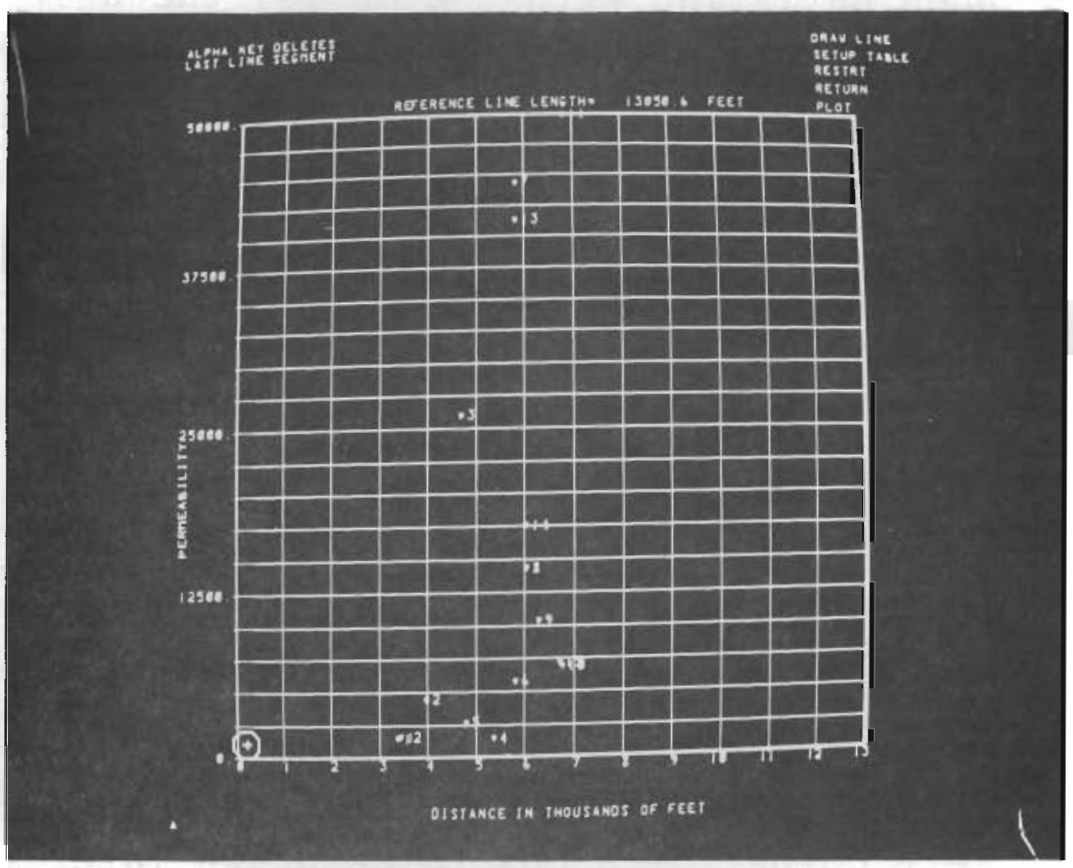

FIGURE 3-11. Calculated Hydraulic Conductivity Values at Reference Line

- Figure 3-12 shows a typical line drawn on the graph.

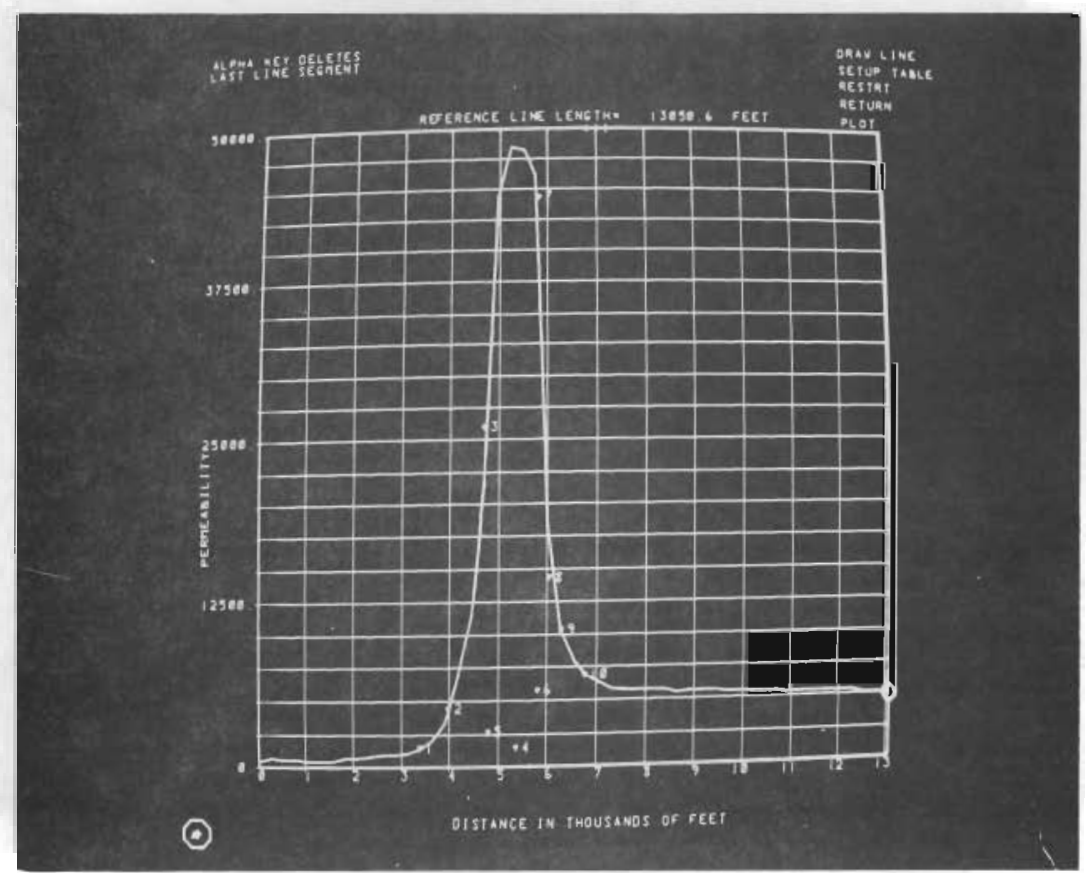

FIGURE 3-12. Best Fit Curve of Hydraulic Conductivity Along Reference Line 
- When satisfied with the curve, the user selects the SETUP TABLE option. This is a very important step for the values of the curve must be stored in the permanent table for further use;

- Once the computer indicates that the function table has been completed the user selects the RETURN option which replaces the present display once again with that shown in Figure 3-10;

- The user now activates the CONTROL MODE option and horizontal and vertical lines will appear on the screen intersecting at the center of the tracking cross (Figure 3-13). These lines move with the tracking cross and aid in positioning the bottom left corner of a box to be drawn later to define the region to be calculated;

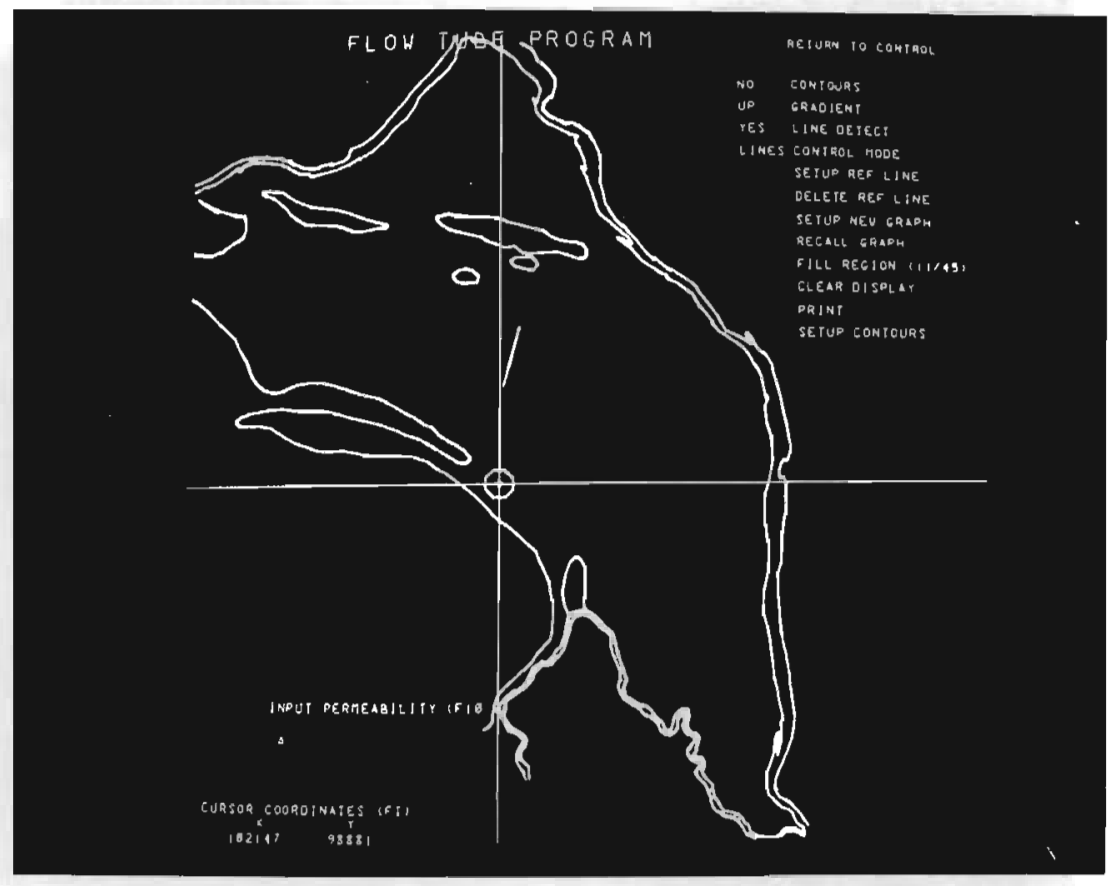

FIGURE 3-13. Initializing Region where Conductivity values Are to be Calculated 
- Once this has been done the user selects the CONTROL MODE option again and the lines will disappear. The bottom left corner of the box has now been set;

- The tracking cross is then moved and a box will appear on the screen (Figure 3-14);

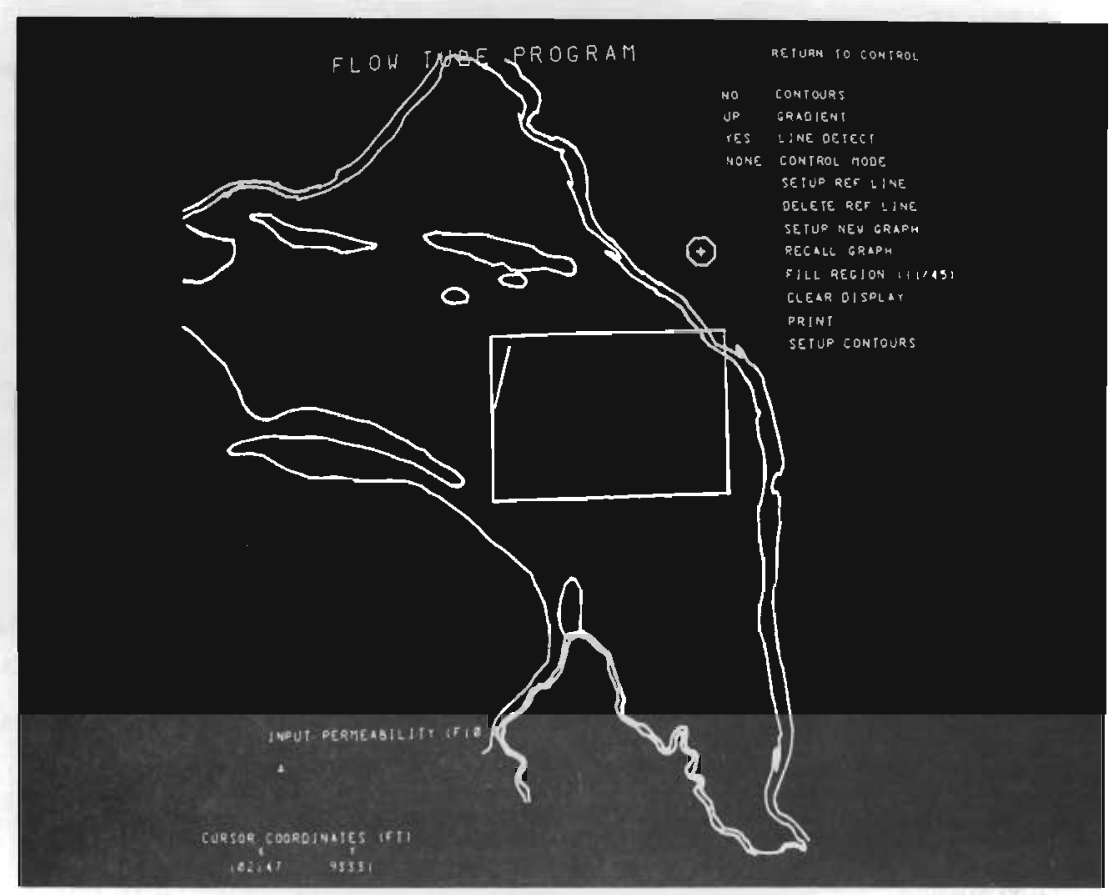

FIGURE 3-14. Completion of Region

- When the box defines the area desired for calculation, the CONTROL MODE option is again selected which then stores all of the parameters of the box;

- The FILL REGION (11/45) option is now selected and calculation of the nodes within the box is initiated (Figure 3-15);

- At any time during this calculation the status of the program can be monitored by raising $A C$ switch 0 on the PDP-9 console, which will display the flowtube currently being calculated. This mode of operation increases operation time and therefore should be used infrequently. The AC switch 0 should normally be down; and 


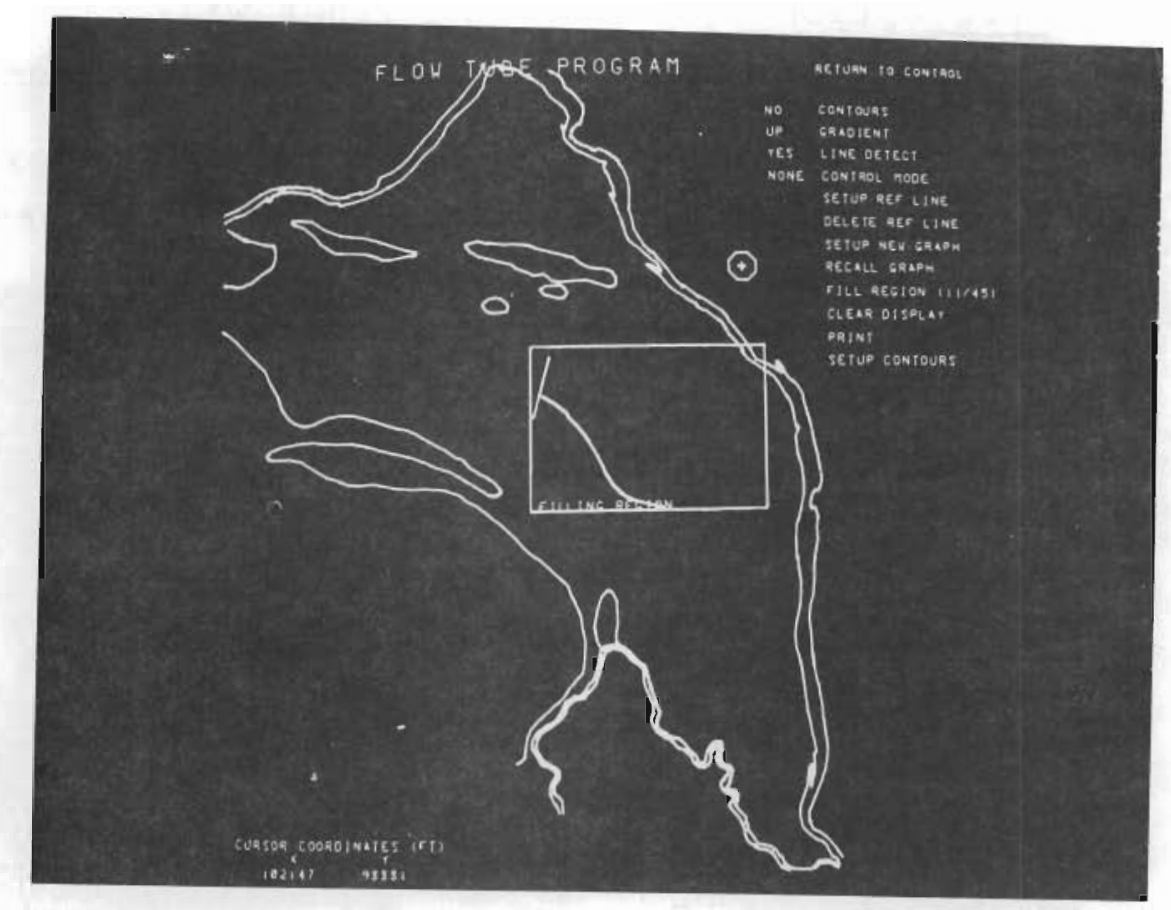

FIGURE 3-15. Calculating Hydraulic Conductivity Values Within Selected Region

- When the FILLING REGION label disappears from the screen, calculations have been completed and the user may continue with additional regions or return calling program to display the region already calculated (see SURFACE CONTOURING in the Special Applications section).

\section{Graph Option}

In order for the $11 / 45$ FLOWTUBE program to calculate a hydraulic conductivity distribution it is necessary to provide a function table containing a $K$ value distribution along the reference line. To do this the user must evaluate the information representing the well values on the permeability graph (Figures 3-11 and 3-12). These values were generated by Flowtube from wells with known hydraulic conductivity and are displayed 
on the graph as numbered stars. The user draws a line through what he feels best represents the actual $\mathrm{K}$ curve along the reference line.

To aid in operation, the graph program allows the user to change the scale in the $y$ direction. To do this the user simply types the minimum value then the maximum value on the CRT keyboard. Both of these are entered as floating point numbers followed by a carriage return (CR).

Several other options are provided for use with the permeability graph. These are light pen interactive and are defined as :

- DRAW LINE* - A small Tracking Cross replaces the larger one and may be used to draw a line on the graph. This should be drawn from the left to right.

- SETUP TABLE - Calculates and stores a function table defined by the hand drawn line.

- RESTRT - Deletes entire line and restarts large Tracking Cross

- RETURN - Returns control to FLOWTUBE

- PLOT - Plots present display on printer/plotter.

*The ALPHA key on the CRT Keyboard may be used to delete line segments at any time during the drawing procedure. 
. 


\section{REFERENCES}

1. D. R. Friedrichs, "Comprehensive Information Retrieval and Model Input Sequence (CIRMIS)," BNWL-2235, Battelle, Pacific Northwest Laboratory, 1977.

2. D. R. Friedrichs, "A Graphic Digitizer Program to Interpolate Matrix Grid Values: USERS Manual," BNWL-1652, Battelle, Pacific Northwest Laboratory, Richland, WA, 1973.

3. D. B. Cearlock, K. L. Kipp and D. R. Friedrichs, "The Transmissivity Iterative Calculation Routine - Theory and Numerical Implementation," BNWL-1706, Battelle, Pacific Northwest Laboratory, Richland, WA, 1972 (Updated 1975). 
APPENDIX A

CIRMIS LOADING PROCEDURES 


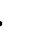

. 


\section{CIRMIS LOADING PROCEDURE}

Following is a detailed description of the procedures to be followed in order to activate the CIRMIS system for data retrieval:

$\underline{\mathrm{PDP}-11 / 45}$

- Put RSSl save disc onto disc No. 1, then;

MCR $>\underline{\text { MOU DPI: RSSI }}$

- Put CIRMIS File-Q disc pack onto disc No. 2, then:

$\mathrm{MCR}>\underline{\mathrm{MOU} D P 2: / \mathrm{CHA}=[\mathrm{FOR}, \mathrm{ATCH}]}$

$\underline{\text { PDP }-9}$

- Save the latest version of CIRMIS onto disc unit 2. There are two DEC tapes labeled COMPLETE CIRMIS, DK2-1 and DK2-2. Use the tape with the latest date. Place tape labeled DK2-1 on tape unit 1 and DK2-2 on tape unit 2. After transfer of the first tape has been verified and before hitting $\uparrow P$ (Control $P$ ), reverse the tape unit numbers.

$$
\$ \underline{\text { SAVE } \downarrow}
$$

DISC SAVE ROUTINE

$$
\begin{aligned}
& \text { INPUT DEV DT1 } \\
& \text { OUTPUT DEV } \underline{\text { DK2 }} \downarrow
\end{aligned}
$$

VERIF IED

MOUNT NEXT DECTAPE $\underline{\uparrow P}$

$\underline{\uparrow P}$

VERIFIED

DISC SAVE ROUTINE

INPUT DEV $\underline{\uparrow C}$

*Note: The user types those instructions that are underlined, the rest of the printout is output by the computer. 
- Disc unit 1 must be new directed as follows:

$\$ \underline{\text { NEWDIRECT L } \downarrow}$

Transfer the device availability file from disc unit 2 to disc unit 1

$\$ \underline{P I P \downarrow}$

PIP V13A

$>$ T DKl \& DK2 DEVAVL RAN $(B)$

$>\uparrow \mathrm{C}$

- Install CIRMIS routines using the data link batch file as follows:

$\$ \underline{\text { RSXTE } \downarrow}$

RSXTE

$>\underline{B A T C H}$ DK2 BATCH SRC $\downarrow$

The user now watches the scope and waits until all of the commands in the batch file have been sent to the 11/45. When $\uparrow z$ appears on the scope use the teletype and proceed as follows:

$>\uparrow \underline{C}$

- Start PDP-9 Monitor Program

$\$$ G 2 MONTR9 $\downarrow$

The message shown in Figure A-l will appear on the CRT. Since the CIRMIS File-Q data disc is on disc unit 2 at the 11/45, the user types a 2 on the CRT keyboard followed by a carriage return.

If all of the preceding steps have been followed, the display shown in Figure A-2 will appear and CIRMIS is operational. The procedures described in the text may now be initiated. 
INPUT FILE O DISC UNIT NUMBER WHERE CIRMIS DATA IS STORED

ENTER UNIT NO. (II)

\section{FIGURE A-1. Disc Unit Setup Command}

\section{COMPREHENSIVE INFORMATION RETRIEVAL
AND MODEL INPUT SYSTEM \\ (CIRMIS)}

SELECT A FUNCTIONAL CATEGORY:

* vell aaseo oata retrieval

* moel input seduencing routines

* special applications and manipulations

FIGURE $A-2$. CIRMIS Monitor Control Page

$$
A-3
$$




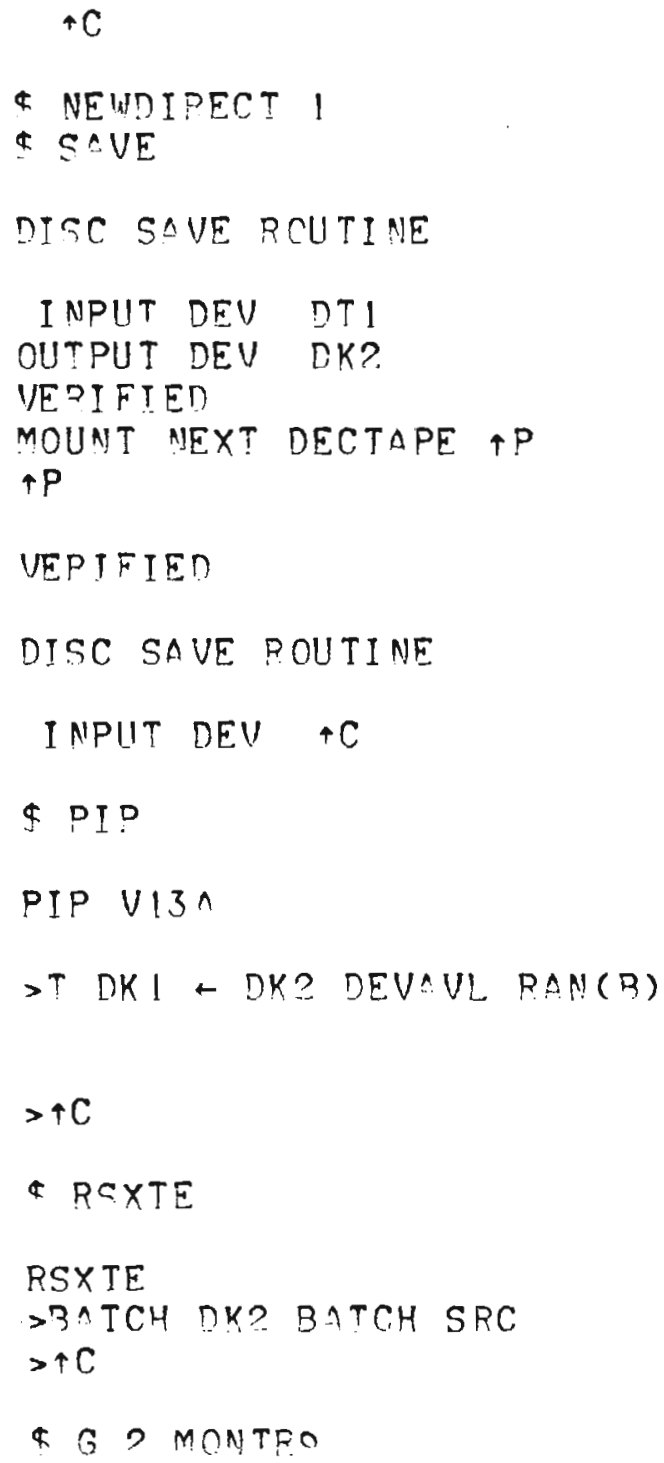

FIGURE A-3. Actual PDP-9 Teletype Trailer used in Loading CIRMIS 
APPENDIX B

$\underline{\text { PDP-11/45 FILE NAMING CONVENTIONS }}$ 
,

. 


\section{APPEIJDIX B}

Surface or map file to be stored at the 11/45 for use by the CIRMIS system or by other programs must use standard $11 / 45$ file naming conventions i.e., DEV: [UIC] FNAME. EXT.

Surface files should also conform to an additional naming procedure for the file name and extension (FNAME. EXT).

This procedure was adopted to eliminate confusion when surface files are needed at a future date where the exact project, surface name and time is required.

Below is a description this procedure:

Standard SETUP:

DEV: [UIC] XXXMYR.YYN

where:

$$
\begin{aligned}
& \text { DEV:--- Device and unit number } \\
& \text { [UIC]-- User identification code if required } \\
& \text { XXX - }- \text { Three character project descriptor } \\
& \text { Examples: HAN - Hanford } \\
& \text { MOX - Moxee } \\
& \text { CCO - clark county } \\
& \text { M - The month surface obtained (1 or 2 digits) } \\
& \text { YR - The year surface obtained (last } 2 \text { digits } \\
& \text { of year. Ex: 74) } \\
& \text { Two character surface descriptor } \\
& \text { a) PT - Potential surface } \\
& \text { b) HC - Hydraulic conductivity } \\
& \text { c) SC - Storage coefficient } \\
& \text { d) DH - Rate of change (DH/DT) } \\
& \text { e) AB - Aquifer bottom } \\
& \text { f) TG - Topography } \\
& \text { g) TM - Transmissivity }
\end{aligned}
$$


Examples

DP : $[167,215]$ HAN9 73.PT 1

$\mathrm{DPl}:[6,4] \mathrm{CCO} 175 . \mathrm{HCl}$

$\mathrm{MT}: \mathrm{HAN} 168 . \mathrm{SCl}$

\section{Additional Benefits}

This method also provides the user with automatic naming procedures for successive files like those used in the VTT Program.

For example if surfaces were to be calculated on a monthly basis for the Hanford potential surface beginning January 1975 this could be done as follows:

Original Surface

FPOT $=$ DP $:[167,215]$ HAN 175. PT 1

The following code takes this name and generates a new name dependent upon month and year.

C DECODE POTENTIAL NAME

3015 ICHRR $=3$

IF (IMO.GT.9) ICHRR $=4$

DO $31 \quad I=1,25$

IF (FPOT(I).EQ.'.') GO TO 32

31 CONTINUE

32 NCHRS $=$ I-I-ICHRR

$T(1)=$ FPOT $(I)$

$T(2)=F P O T(I+1)$

$\mathrm{T}(3)=$ FPOT $(\mathrm{I}+2)$

$\mathrm{T}(4)=\mathrm{FPOT}(\mathrm{I}+3)$

$T(5)=0$

IDATE $=$ IYR $-1900+100 *$ IMO

IF (IYR.GE. 2000) IDATE $=1 Y R-2000+100 *$ IMO

INO $=25-\mathrm{NCHR}-\mathrm{ICHRR}$

$C$ set up new potential name ENCODE (25, 33, FNAM) (FPOT (I), I=1, NCHRS), IDATE, $1 \quad(T(I), I=1, I N O)$

33 FORMAT $(<\mathrm{NCHRS}>\mathrm{Al}, \mathrm{I}<$ ICHRR $>,<$ INO $>\mathrm{Al})$ OPEN (UNIT $=2$, NAME $=$ FNAM , TYPE= ' OLD' , FORM= ' UNFORMATED' , 1 READONLY) 
It can be seen that in this manner a new surface may be set up according to the original surface characteristics but with different dates by simply setting the month and year variable.

NOTE: In the above coding FPOT, FNAM and T are byte arrays. 


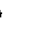


APPENDIX C

CIRMIS MASTER FILE DIRECTORY 



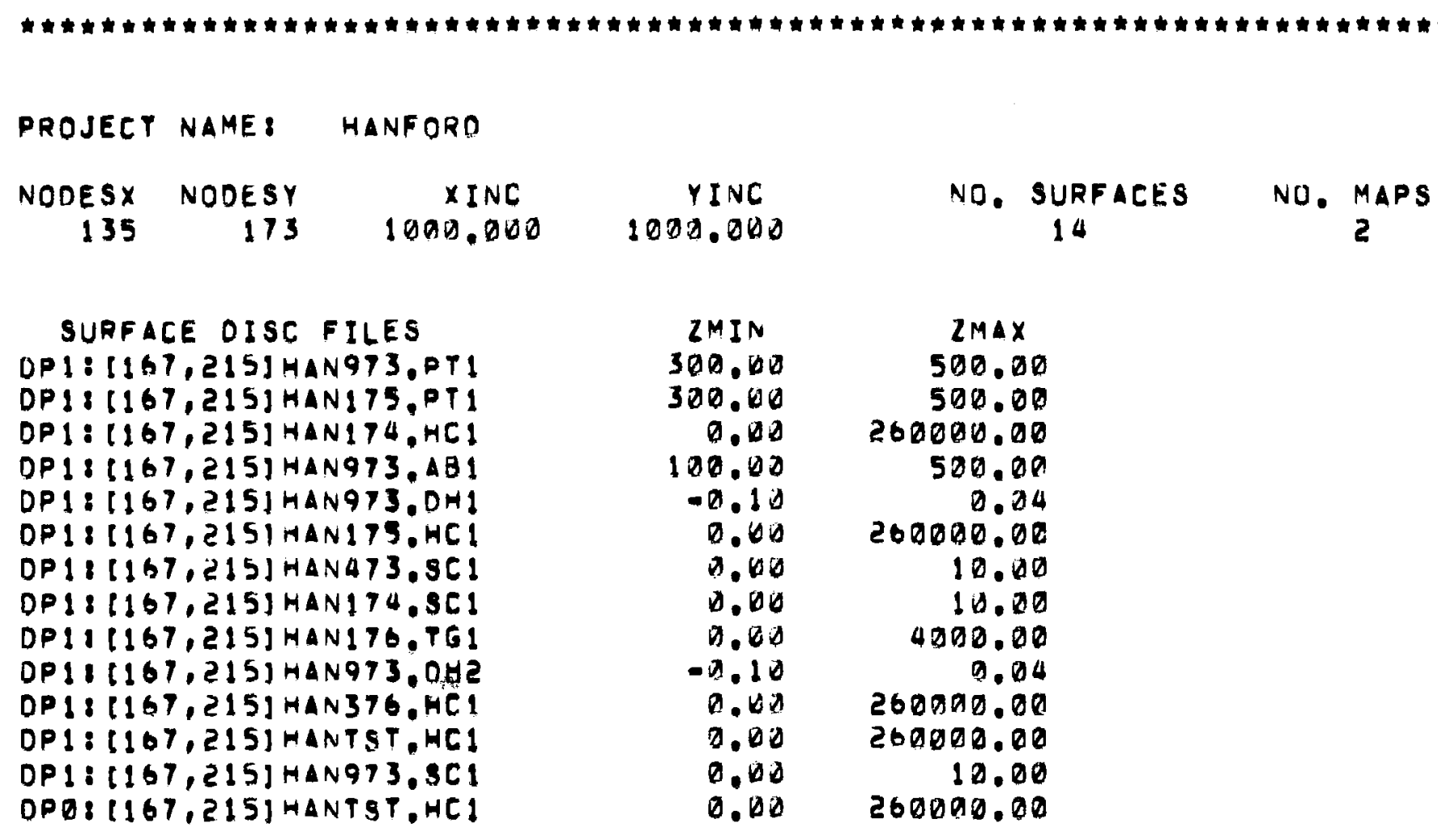

MAP OISC FILES

DP \& $\{1167,215]$ HANFORD, MAP

DP [ [167,2 15$]$ HANF DRD, MAP

PROJEET NAME: TRIDENT

$\begin{array}{rrcccc}\text { NODESX } & \text { NODESY } & \text { XINC } & \text { YINC } & \text { NO. SURFACES } & \text { NO. MAPS } \\ 60 & 35 & 500.000 & 500.000 & 6 & 1\end{array}$

\section{SURF ACE DISC FILES}

OPI: 1167,215$\}$ TROA75,PT1

DP 1: (167,215) TRD475, 40$\}$

DP 1: (167,215) TRD475.AQ2

DP1: (167,215) TRD475, TR

DP 1 : $\{167,215\}$ TRD475,HY1

OP 1: [167, 215] TRO475, S61

$\begin{array}{rr}2 M I N & 2 M A X \\ 100.00 & 800.00 \\ 100.00 & 800.00 \\ 100.00 & 800.00 \\ 100.00 & 50000.00 \\ 0.00 & 260000.00 \\ 0.00 & 10.00\end{array}$




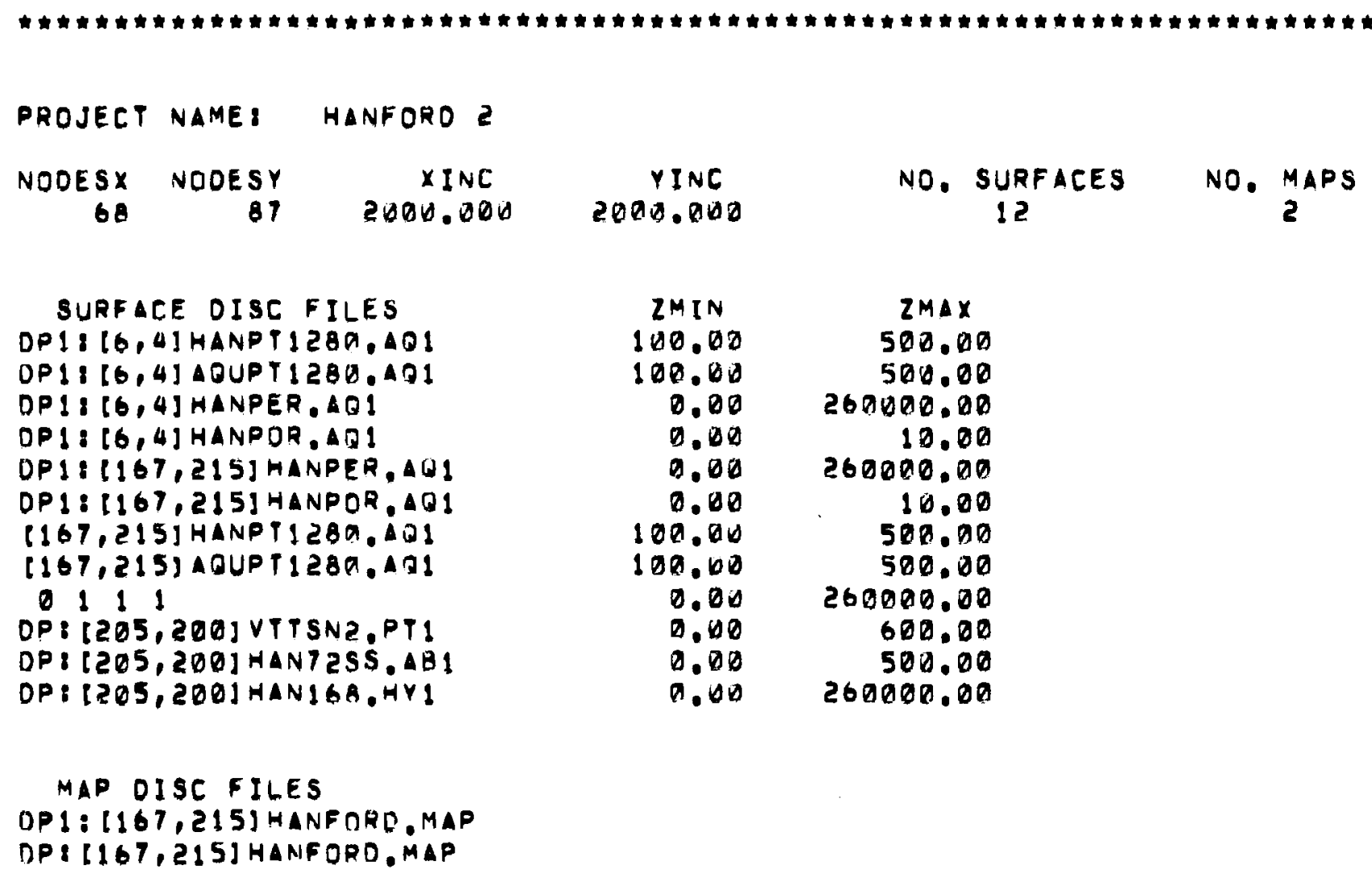

PROJECT NAME: PATHLINE

NODESX NODESY XINC YINC $4141500.000 \quad 500.000$

SURFACE DISC FILES

MTIITSTI25.PTI

OP 1: (167,215) TST125.PT1

OP 1: [167, 215]T\$TI25.HYI

DPI: (167,215]TST125,SG1

DPQ: [17],215] TST125.HC1

DPO: [171, 215]TST125,SC1

MAP OISC FILES

DP 1: [167,215]PATHTST,MAP

OPO:【171,215]PATHTST.MAP

\begin{tabular}{rr}
$2 M I N$ & \multicolumn{1}{c}{$2 M 10 \times$} \\
-100.00 & 100.00 \\
-100.00 & 100.00 \\
0.00 & 200.00 \\
0.00 & 1.00 \\
0.00 & 200.00 \\
0.00 & 1.00
\end{tabular}

6
6 NOE MAPS 


\begin{tabular}{|c|c|c|c|c|c|}
\hline PROJECT & NAME: & TRIGA 300A & & & \\
\hline $\begin{array}{r}\text { NOOESX } \\
25\end{array}$ & $\begin{array}{r}\text { NODESY } \\
33\end{array}$ & $\begin{array}{c}x I N C \\
250.010\end{array}$ & $\begin{array}{c}\text { YINC } \\
250.000\end{array}$ & NO. SURFACES & NO. MAPS \\
\hline $\begin{array}{l}\text { SURFAD } \\
\text { OPI: } 130, \\
\text { DPI: } 330, \\
\text { MTI:N3A) } \\
\text { OPI: } 130 .\end{array}$ & $\begin{array}{l}\text { CE DISC } \\
1 \text { IOOIN3A } \\
1061 N 3 A \\
376 . P T 1 \\
1061 N 3 A\end{array}$ & $\begin{array}{l}\text { FILES } \\
376 . \text { HCI } \\
376 . \text { SCI } \\
376 . \text { PTI }\end{array}$ & $\begin{array}{c}2 M I N \\
0.00 \\
0.00 \\
300.00 \\
300.00\end{array}$ & $\begin{array}{r}2 M 4 X \\
260000.00 \\
11.00 \\
500.00 \\
500.00\end{array}$ & \\
\hline
\end{tabular}

MAP OISC FILES

DP1: [205,200]HAN300. BND

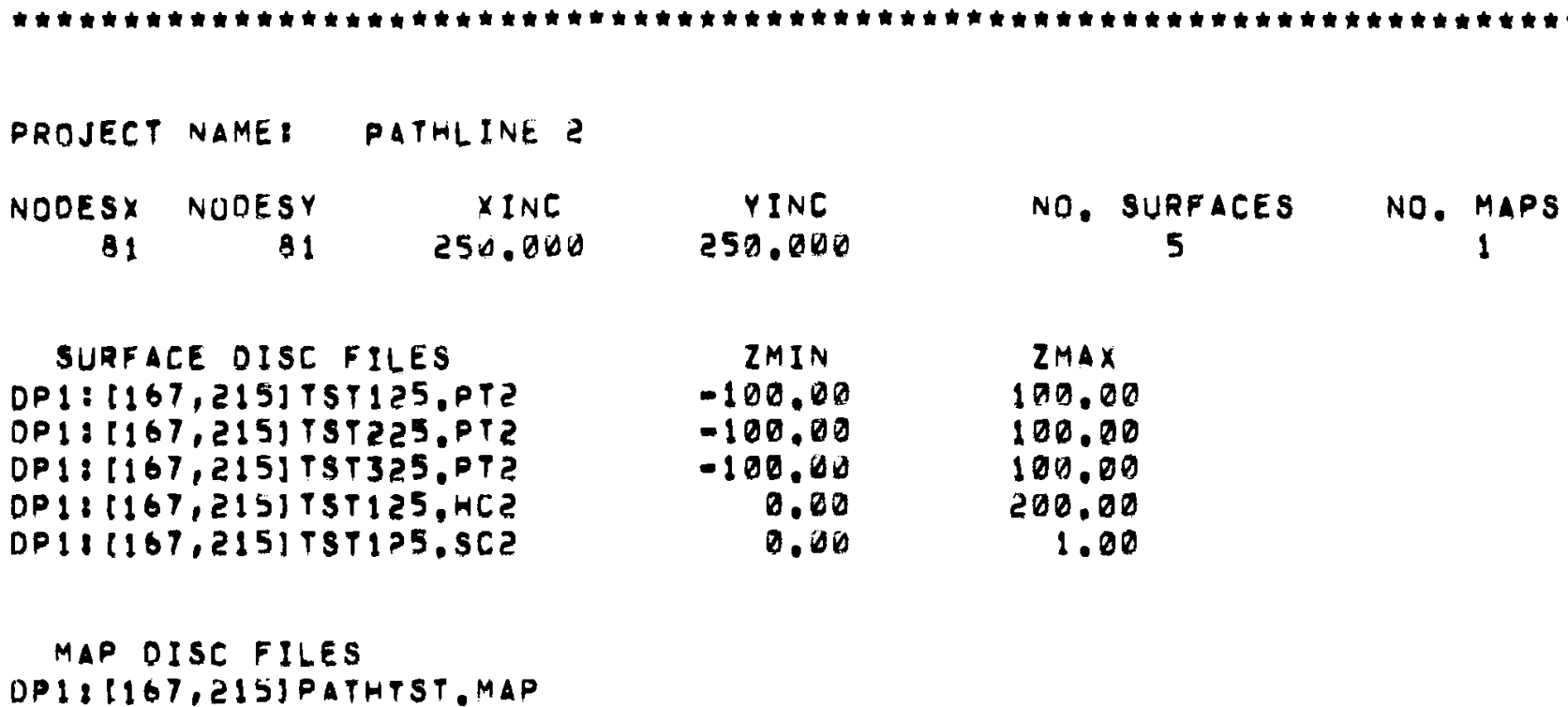

\begin{tabular}{|c|c|c|c|c|c|c|}
\hline PROJEET & NAME: & CLARK COUNT & & & & \\
\hline $\begin{array}{r}\text { NODESX } \\
43\end{array}$ & $\begin{array}{r}\text { NOOESY } \\
52\end{array}$ & $\begin{array}{c}\text { XINC } \\
2640.000\end{array}$ & $\begin{array}{c}\text { YINC } \\
2600.000\end{array}$ & NO. SURFACES & NO. & $l_{1}^{\text {MAPS }}$ \\
\hline 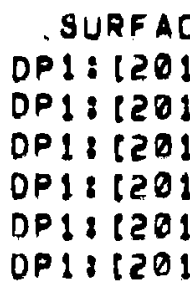 & $\begin{array}{l}C E \text { OISC } \\
1,2201 C C \\
1,2201 C C \\
1,2201 C C \\
1,220 J C C \\
1,2201 C C \\
1,2201 C C\end{array}$ & $\begin{array}{l}\text { FILES } \\
0576 . A T 1 \\
0576 . A T 2 \\
0576 . A B 1 \\
0576 . A B 2 \\
0576.0 T 1 \\
0576.0 T ?\end{array}$ & $\begin{array}{r}2 M I N \\
0.00 \\
-110.00 \\
-110.00 \\
-300.00 \\
0.00 \\
0.00\end{array}$ & $\begin{array}{c}2 M A x \\
2000.00 \\
1100.00 \\
1100.00 \\
1000.00 \\
500.00 \\
600.00\end{array}$ & & \\
\hline
\end{tabular}


MAP OISC FILES

DPI\& (201,220]CLARK,MAP

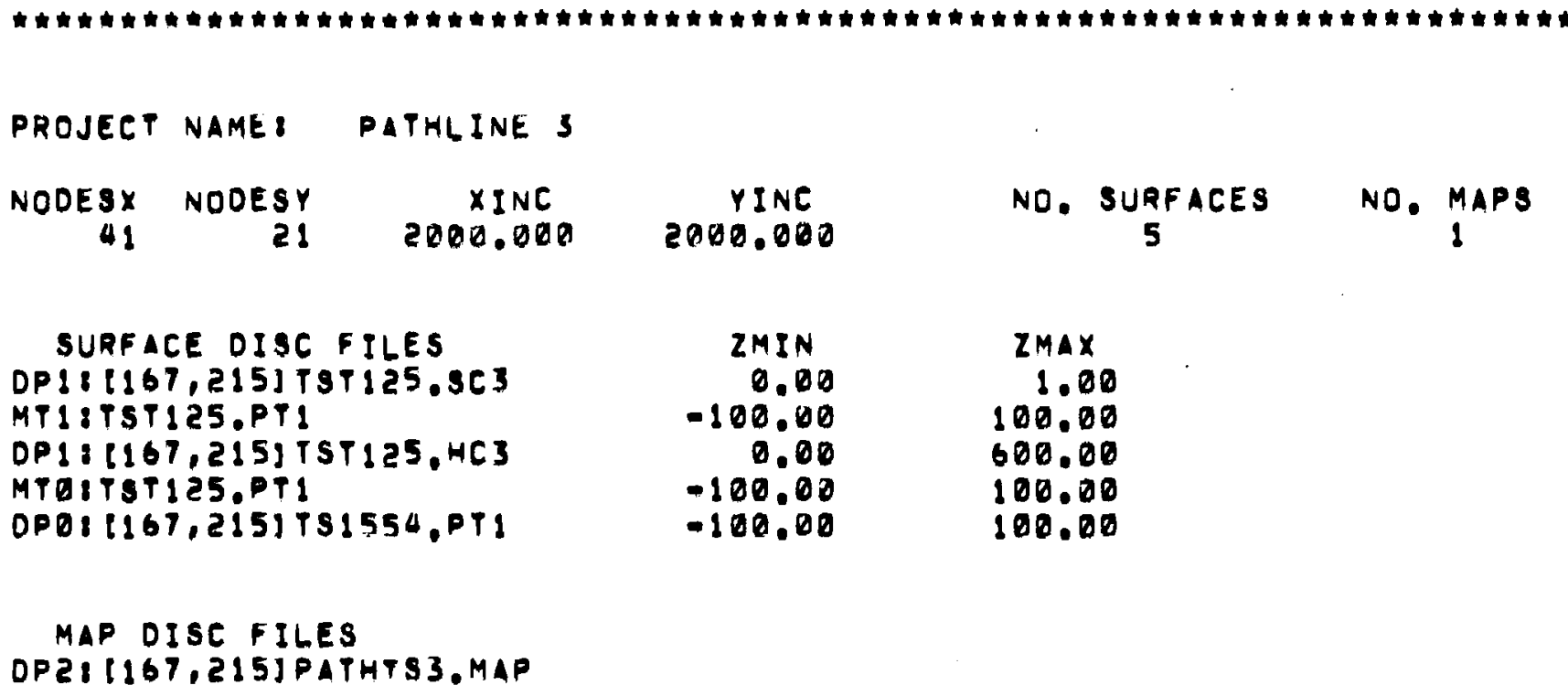

ZMIN

0.00

$-100.00$

0.00

$-100.00$

$-100.00$

ZMAX

1.00

100.00

600.00

100.00

100.00

MAP DISE FILES

DP2I 1167,215]PATHTS3.MAP

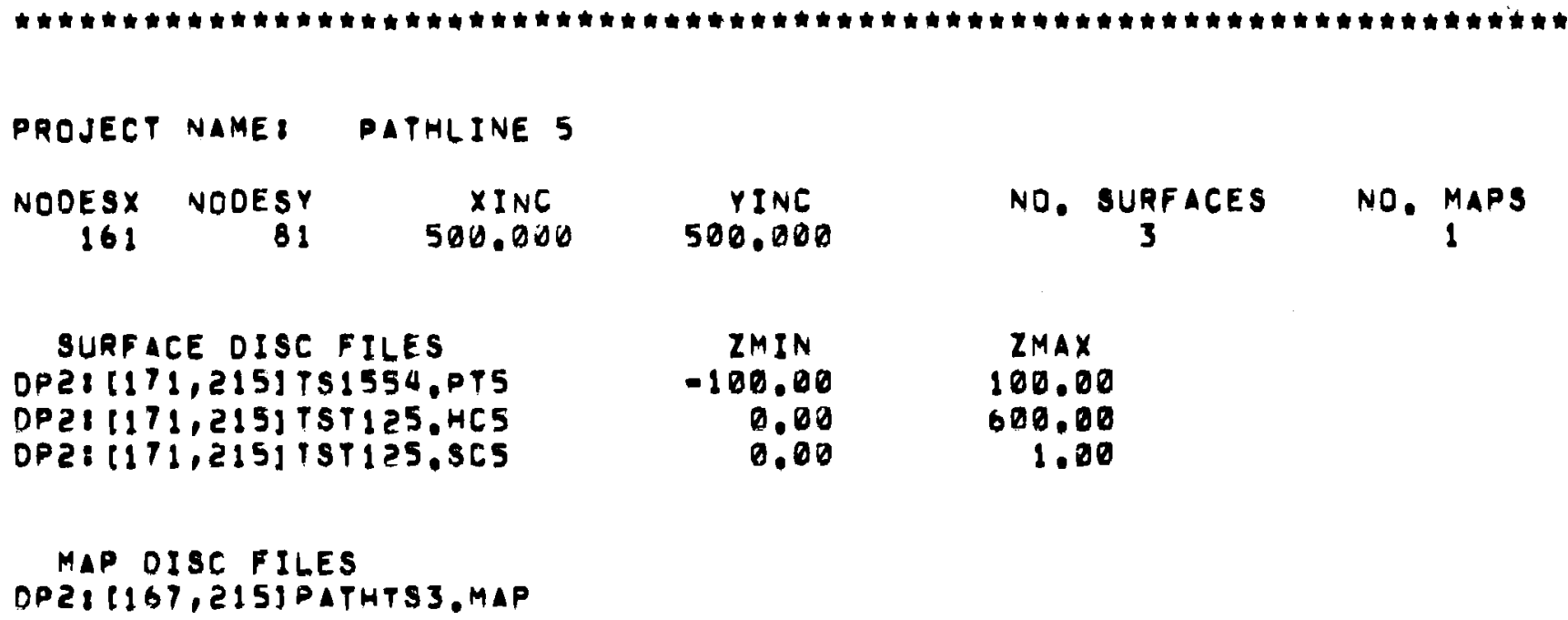

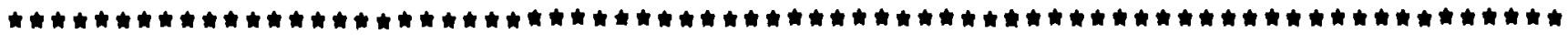

PROJECT NAME: HANFORD JUNE 76

$\begin{array}{rrcccc}\text { NOOESX NODESY } & \text { XINC } & \text { YINC } & \text { NO. SURFACES } & \text { NO. MAPS } \\ 135 & 173 & 1070.000 & 1000.000 & 3\end{array}$

\begin{tabular}{|c|c|c|}
\hline $\begin{array}{l}\text { SURFACE OISC FILES } \\
\text { OPI }\{167,215\} \text { HAN973,PT } \\
\text { OPI }\{167,215\} \text { HAN } 174, H C ! \\
\text { DPI }\{167,2\{5\} \text { HAN } 14, \text { SC }\end{array}$ & $\begin{array}{r}\text { ZMIN } \\
300.00 \\
0.00 \\
0.00\end{array}$ & $\begin{array}{r}2 M 4 X \\
500.00 \\
260000.00 \\
10.00\end{array}$ \\
\hline
\end{tabular}




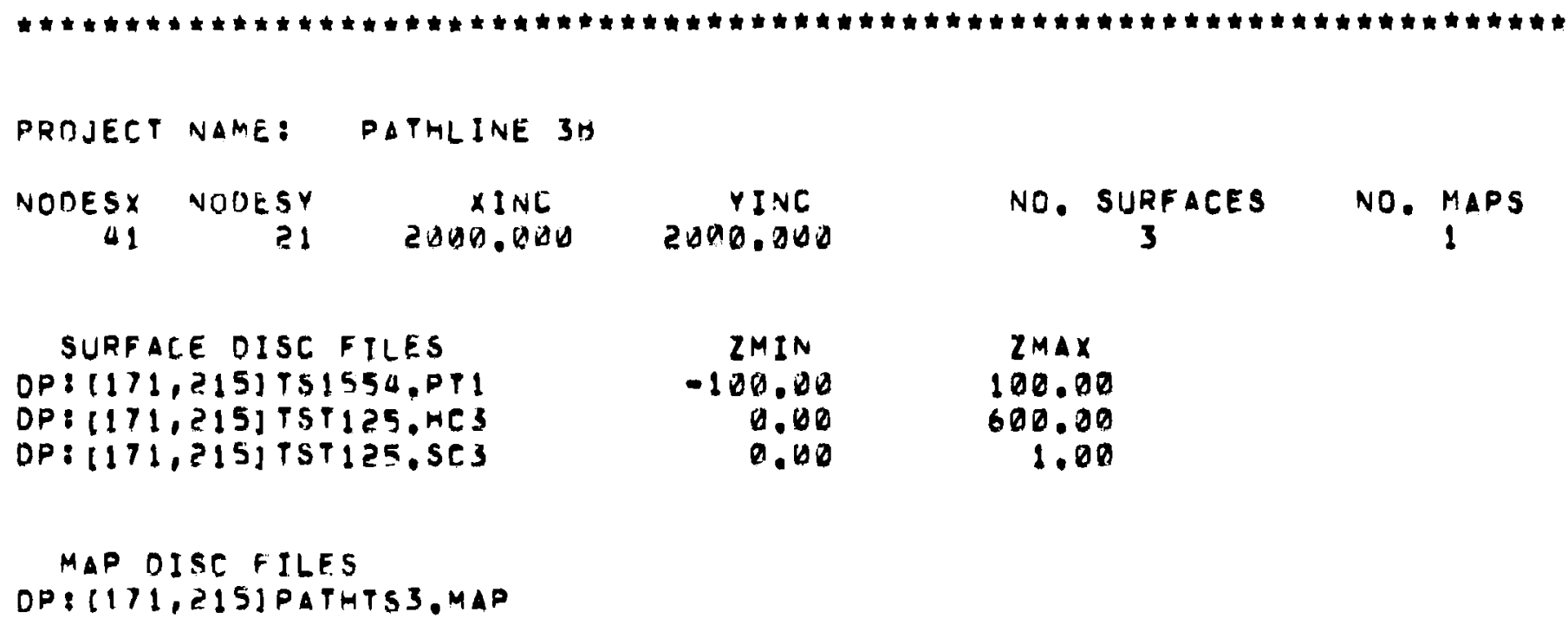

$\begin{array}{rr}2 M I N & 2 M 1 X \\ -100.00 & 100.00 \\ 0.00 & 600.00 \\ 0.00 & 1.00\end{array}$

NO. SURFACES

3

NO. MAPS 1

MAP DISC FILES

DP: 1171,215$] P A T H T S 3$ MAP

\begin{tabular}{|c|c|c|c|c|c|c|}
\hline PROJECT & NAME: & PATHLINE 58 & & & & \\
\hline $\begin{array}{r}\text { NODESX } \\
161\end{array}$ & $\begin{array}{r}\text { NODESY } \\
81\end{array}$ & $\begin{array}{c}X I N C \\
S 00.000\end{array}$ & $\begin{array}{c}Y I N C \\
509.0 D O\end{array}$ & NO. SURFACES & No. & ${ }_{1}^{\text {MAPS }}$ \\
\hline $\begin{array}{l}\text { SURFAC } \\
\text { OP: } 1171, \\
\text { DP: } 1171, \\
\text { OP: } 1171,\end{array}$ & $\begin{array}{l}\text { CE OISC } \\
\text { 2I5ITSI } \\
2151 \mathrm{TST} \\
\text { 215ITST }\end{array}$ & $\begin{array}{l}\text { FILES } \\
554 . P T S \\
125 . \text { HES } \\
125 . \text { SCS }\end{array}$ & $\begin{array}{r}Z M I N \\
-100.00 \\
0.00 \\
0.00\end{array}$ & $\begin{array}{r}2 M 1 \times \\
100.00 \\
600.00 \\
1.00\end{array}$ & & \\
\hline
\end{tabular}


. 


\section{DISTRIBUTION}

No. of

No. of

Copies

Copies

\section{OFFSITE}

A. A. Churm

ERDA Chicago Patent Group

U.S. Energy Research and

Development Administration

Argonne, IL 60439

27 ERDA Technical Information Center

O. P. Gormley

Chief, Waste Facilities Branch ERDA Headquarters

Waste Management and Transportation Division

Germantown, MD 20767

R. W. Ramsey, Jr.

Chief, Development Branch

ERDA Headquarters

Waste Management and Transportation Division

Germantown, MD 20767

R. L. Bullard

Chief, Environmental Specialist Branch

NRC Directorate of Regulation

7920 Norfolk Avenue

Bethesda, MD 20014

W. Gamill

Chief, Site Analysis Branch

NRC Directorate of Regulation

7920 Norfolk Avenue

Bethesda, MD 20014

W. L. Lennemann

Chief, Chemical Process

ERDA Division of Production \& Material Management

Washington, DC 20545
J. W. Pollock

ERDA Division of Production \& Material Management Washington, DC 20545

Dr. A. H. Dahl

Chief, Environmental Science Branch

ERDA

Idaho Falls, ID 83401

G. Debuchananne

U.S. Geological Survey

2100 M. Street

Washington, DC 20037

J. D. Bredehoeft

U.S. Geological Survey

Water Resources Division

Reston, VA 22092

R. D. Magnish

U.S. Geological Survey

Resources Division

one Wash Plaza

Suite 600

1201 Pacific Avenue

Tacoma, WA 98402

Dr. J. S. Gladwell

National Water Commission

800 N. Quincy

Arlington, VA 22209

Dr. M. E. Jensen, Director

USDA-ARS

Snake River Conservation

Research Center

Route 1, Box 186

Kimberly, ID 83341 
No. of

Copies

H. N. Holton, Director USDA Hydrograph Laboratory plant Industry station Soils Building

Beltsville, MD 29705

National Research Council 2101 Constitution Avenue Washington, DC 20418 ATTN: Technical Secretary National Academy of Science Committee on Radioactive Waste Management

K. R. Higginson, Director Idaho Department of Water Administration State House, Annex 2 Boise, ID 83707

J. O. Duguid

Oak Ridge National

Laboratory

Box X

Oak Ridge, TN 37830

E. F. Wallace

State of Washington

Department of Ecology

Olympia, WA 98504

J. Crosby, III

Geologist

Washington state water Research Center

Pullman, WA 99163

R. W. Nelson

Boeing Computer Services

Federal Building

Richland, WA 99352

Sandia Laboratories

Division 5166

Albuquerque, NM 87115
No. of

Copies

P. A. Witherspoon

Department of Civil

Engineering

University of California

Berkeley, CA 94720

J. N. Luthin

University of California at Davis

Department of Water Sciences and Engineering

Davis, CA 95616

P. Kruger

Stanford University

Department of Civil Engineering

Stanford, CA 94305

Professor Ven Te Chow

Hydrosystems Laboratories

University of Illinois

Urbana, IL 61801

G. F. Pinder

Princeton University

Department of Civil and Geological Engineering

Princeton, NJ 08540

Dr. L. G. King

Washington State University

Agricultural Engineering

Department

Pullman, WA 99163

J. Bear

Technion-Israel Institute of Technology

Haifa, ISRAEL

Dr. K. L. Kipp

AERE Harwell

Oxfordshire, ENGLAND 
ONSITE

6 Atlantic Richfield Hanford Company

R. C. Arnett

D. J. Brown

R. A. Deju

P. A. Eddy

R. E. Gephart

W. H. Price

6 ERDA Richland Operations Office

R. B. Goranson

R. L. Ferguson

J. A. Fernandez (2)

J. L. Rhoades

M. W. Tiernon

32 Battelle-Northwest

S. W. Ahlstrom

T. N. Bishop

P. E. Bramson

D. B. Cearlock

C. R. Cole

D. W. Damschen

G. W. Dawson

J. R. Eliason

D. R. Friedrichs (10)

G. A. Lane

H. V. Larson

D. A. Myers (3)

J. R. Raymond (2)

A. E. Reisenauer

A. K. Tyagi

Technical Information (3)

Technical Publications

United Nuclear, Inc.

A. L. Cucchiara 


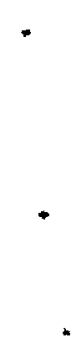

